\title{
Public health implications of the Mediterranean Diet : its interaction with active and passive smoking
}

Citation for published version (APA):

Vardavas, C. I. (2010). Public health implications of the Mediterranean Diet : its interaction with active and passive smoking. [Doctoral Thesis, Maastricht University]. Datawyse / Universitaire Pers Maastricht. https://doi.org/10.26481/dis.20100527cv

Document status and date:

Published: 01/01/2010

DOI:

$10.26481 /$ dis.20100527cv

Document Version:

Publisher's PDF, also known as Version of record

\section{Please check the document version of this publication:}

- A submitted manuscript is the version of the article upon submission and before peer-review. There can be important differences between the submitted version and the official published version of record.

People interested in the research are advised to contact the author for the final version of the publication, or visit the DOI to the publisher's website.

- The final author version and the galley proof are versions of the publication after peer review.

- The final published version features the final layout of the paper including the volume, issue and page numbers.

Link to publication

\footnotetext{
General rights rights.

- You may freely distribute the URL identifying the publication in the public portal. please follow below link for the End User Agreement:

www.umlib.nl/taverne-license

Take down policy

If you believe that this document breaches copyright please contact us at:

repository@maastrichtuniversity.nl

providing details and we will investigate your claim.
}

Copyright and moral rights for the publications made accessible in the public portal are retained by the authors and/or other copyright owners and it is a condition of accessing publications that users recognise and abide by the legal requirements associated with these

- Users may download and print one copy of any publication from the public portal for the purpose of private study or research.

- You may not further distribute the material or use it for any profit-making activity or commercial gain

If the publication is distributed under the terms of Article $25 \mathrm{fa}$ of the Dutch Copyright Act, indicated by the "Taverne" license above, 
Public health implications of the Mediterranean diet; Its interaction with active and passive smoking 


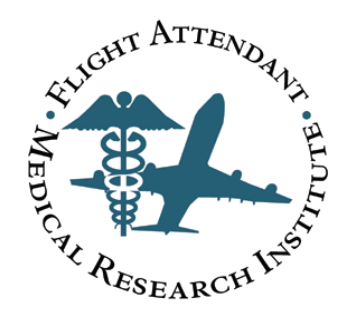

Part of the research described in this thesis was supported by the Flight Attendant Medical Research Institute (FAMRI).

The author is also grateful to the governing office of the prefecture of Heraklion, Crete for support of the MESSARA study.

\section{itutim}

Printing of this thesis was financially supported by NUTRIM, School for Nutrition, Toxicology and Metabolism within Maastricht University, Maastricht, The Netherlands.

Printed by: Datawyse, Universitaire Pers Maastricht

ISBN 9789052789507

C Copyright Cl Vardavas, Maastricht 2010 


\title{
Public health implications of the Mediterranean diet; Its interaction with active and passive smoking
}

\author{
PROEFSCHRIFT \\ Ter verkrijging van de graad van doctor \\ aan de Universiteit Maastricht \\ op gezag van de Rector Magnificus \\ Prof. mr. G.P.M.F. Mols, \\ volgens het besluit van het College van Decanen, \\ In het openbaar te verdedigen \\ op donderdag 27 mei 2010 om 12:00 uur
}

door

Constantine Ilias Vardavas

geboren te Canberra, Australia op 10 mei 1980

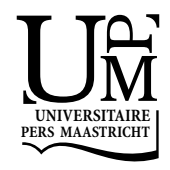


Promotores

Prof. dr. Ir. Wim HM Saris

Emeritus Prof. dr. Anthony G Kafatos (University of Crete, Greece)

\section{Beoordelingscommissie}

Prof. dr. F. J. van Schooten, voorzitter

Prof. dr. Ir. E. Blaak

Prof. dr. Ir R. Mensink

Prof. dr. D. Kromhout (Wageningen University, Wageningen)

Dr. ir. P Zock (Unilever Food and Health Research Institute Vlaardingen) 


\section{TABLE OF CONTENTS}

\section{Chapter 1}

General Introduction

\section{Chapter 2}

Cardiovascular disease risk factors and dietary habits of farmers from Crete 45 years after the first description of the Mediterranean diet: The MESSARA Study

\section{Chapter 3}

Prevalence of obesity and physical inactivity among farmers from Crete (Greece), four decades after the Seven Countries Study: The MESSARA Study

\section{Chapter 4}

Calcium, nutrient and food intake of Greek Orthodox Christian monks during a fasting and non-fasting week

\section{Chapter 5}

Does adherence to the Mediterranean diet have a protective effect against active and passive smoking?

\section{Chapter 6}

Smoking status in relation to serum folate and dietary vitamin intake: the MESSARA Study

\section{Chapter 7}

The role of passive smoking on the prevalence of type II diabetes mellitus among elderly men and women living in Mediterranean islands: the MEDIS study

\section{Chapter 8}

General discussion 

CHAPTER 1

GENERAL INTRODUCTION 


\subsection{The Seven Countries Study and the Mediterranean diet}

The traditional Mediterranean diet of Crete first became world known in the sixties of the last century through the Seven Countries Study (SCS), an epidemiological study with 16 cohorts in 7 countries (from Greece, Finland, Japan, former Yugoslavia, Italy, The Netherlands and the United States) which aimed to investigate into the dietary and lifestyle factors related to the development of cardiovascular disease [1]. As corroborated during the subsequent 10, 25 and 40 year follow up of the SCS, the rural population of Crete was found to have one of the lowest coronary heart disease (CHD) and cancer mortality rates in comparison to all other cohorts [2, 3]. A result clearly attributed to their dietary and lifestyle habits [1]. The traditional diet of Crete is based on a number of specific dietary characteristics which mainly include: a) a high fat intake (estimated at $40 \%$ of the total daily energy intake) comprised mainly of monounsaturated fatty acids (29\% of the daily calorie intake), derived from its high consumption of virgin olive oil, b) a low consumption of red meat, c) a moderate consumption of fish and dairy products, supplemented daily with d) substantial quantities of wild greens, fruits, whole wheat bread, legumes and nuts. Thus the diet is high in antioxidants and polyphenols, low in cholesterol, low in saturated but high in monounsaturated fat as demonstrated by researchers such as Ferro-Luzzi, James \& Kafatos, [4]. Furthermore it has been stated by Simopoulos et al., [5] that another important role in the traditional diet of Crete is played by its ideal omega-6 /omega-3 fatty acid ratio of 2-1:1, in opposition to that of western cultures which have a $\omega-6 / \omega-3$ ratio of approximately 15 for northern Europe and 17 for the current U.S [6].

\subsection{Obesity, the Mediterranean diet and its impact on public health in Crete}

As stated above, in the past the Greek population, and specifically that of Crete, was known to have very low rates of cardiovascular disease (CVD) and cancer compared to the other five SCS countries in Europe, to the US and to Japan [1]. Dietary habits, the level of physical activity and subsequently obesity indexes showed remarkable differences. Farmers in the 1960's had elevated levels of daily moderate to high physical exercise, due to the little mechanical assistance used in farming at that time [7]. Based on job related physical activity, over $60 \%$ of the Cretan men in the Seven Countries Study habitually engaged in hard physical work for which their mean energy expenditure was estimated at more than $3000 \mathrm{kcal}$ per day. Only $7 \%$ of the Crete population in the 1960's was classified as having sedentary levels of physical activity [8]. The result of such a lifestyle was a low Body Mass Index (BMI), a factor lowering the population's risk for cancer and cardiovascular disease. Long time follow ups of both the Cretan and the Corfu cohorts of the SCS have elaborated the fact that adherence to a Mediterranean diet and lifestyle is accompanied by a significant reduction in mortality, a lifestyle globally recognised as an ideal avenue for promoting health and preventing disease [3]. 
Affecting insulin sensitivity, lipid metabolism and promoting systemic inflammation, obesity predisposes to a number of non communicable diseases such as hypertension, dyslipidemia and type II diabetes $[9,10]$. The association between body weight and both total and cardiovascular disease mortality is also well documented in population based follow up studies, as cohorts have clearly demonstrated the relationship between increased obesity indexes and both acute and chronic cardiovascular disease $[11,12]$.

\subsection{Fasting rituals, an important part of the Mediterranean diet}

One of the main components of the Mediterranean diet, which in recent years has found great attention are the fasting rituals of the Greek Orthodox Church. This special characteristic of the traditional Mediterranean diet of Crete and still practiced by many, has attracted much attention due to its suggested beneficial effect on dietary habits and health $[13,14,15,16]$. According to the Greek Orthodox Church recommendations on dietary intake, fasting is performed during three major periods throughout the year (preceding Christmas, Easter Lent and the Assumption), in addition to most Wednesdays and Fridays. During these periods, which totals approximately 180-200 days annually, the consumption of foods of animal origin, dairy products and olive oil is restricted, fish intake is allowed only during the period preceding Christmas (and on non fasting days), while intake of shellfish and molluscs are always allowed [15]. Consequently, adherence to this fasting ritual results in the consumption of a somehow, periodical, vegetarian diet [17], which uniquely characterizes the reported Mediterranean diet of Crete, Greece and Cyprus $[18,19]$. This periodic vegetarian diet of legumes, nuts, fruits, olives, bread, snails and molluscs plays an important role in the population's health [15], by reducing serum lipid values over the fasting periods and possibly effecting obesity status $[16,20]$.

Epidemiological and clinical evidence has convincingly shown that dietary habits are the central mediator of circulating lipoproteins [21-22]. The differences in dietary fat intake are clearly apparent when comparing the Mediterranean diet, with a more westernised diet. Although the fat percentage is similar in quantity, it differs greatly in quality as the Mediterranean diet is rich in monounsaturated fatty acids, such as oleic acid, but very low in saturated fat. Such a diet has the ability to reduce the levels of circulating LDL and VLDL cholesterol, while increasing the beneficial HDL cholesterol [23]. Indeed follow up studies, such as the Lyon Secondary Prevention Heart Study on patients with cardiovascular disease, indicated that adherence to a Mediterranean style diet was more beneficial as prevention measure compare to the American Heart Association's recommended diet [22, 23]. Additionally, olive oil which is high in monounsaturated fatty acids has been proven in numerous studies $[13,24]$ to play an important role in the Mediterranean diet and signifi- 
cantly contribute to an increase in the circulating levels of HDL cholesterol levels. [25]

\subsection{Dietary intakes, micronutrients and smoking. Confounding factors or response?}

Currently one of the emerging issues in environmental toxicology is the evidence that suggests that antioxidant micronutrients and related bioactive compounds, common in fruit and vegetables, may ameliorate the toxicity of environmental chemicals and impact disease development [26]. It has been hypothesised that adherence to the Mediterranean diet might function is such a way [27].

As first noticed almost half a century ago during the Seven Countries Study (SCS) and as corroborated during the subsequent 10, 25 and 40 year follow up, the rural populations of Japan and Crete were found to have the lowest coronary heart disease (CHD) mortality rates in comparison to 14 other cohorts from other European countries, and the US [1-3]. Furthermore, CHD and lung cancer mortality were found to be higher in Northern European and Northern American cohorts when compared to the Southern European and Japanese cohorts of the same study [28]. This above fact was attributed to dietary and lifestyle factors (through which the Mediterranean diet first became renowned), while additional research indicated that absolute lung cancer mortality was inverse associated with the average dietary intake of saturated fat, which was the lowest in both the Mediterranean and the Japanese diet [29]. Specifically, these researchers had hypothesised that saturated fat, may play a role in the cross-cultural variation in lung-cancer mortality, either independently or by effect modification, despite the fact that smoking habits were similar across countries and regions

Epidemiological studies have indicated that diets rich in fruit and vegetables protect against lung cancer [30]. The Mediterranean diet provides such an ideal diet, which would protect against lung cancer. High in fruits, vegetables, nuts, legumes and olive oil, the Mediterranean diet is a prominent source of antioxidants (i.e. vitamin $\mathrm{C}$, vitamin $\mathrm{E}$, beta carotene, glutathione, phytoestrogens, folate and selenium) and monounsaturated fat, while low in saturated fat and cholesterol content, thus combining all the factors that could act as an "effect modifier" on the role cigarette smoking has on ones health [31]. Taking the above into account, further research is warranted to investigate this hypothesis, which could have a significant impact on public health.

Cigarette smoke contains free radicals and other oxidants in abundance. It has been estimated that each puff of a cigarette exposes the smoker to $10^{15}$ oxidative free radicals, a severe source of oxidative stress [32]. Additionally, reactive oxygen species production is further mediated through inflammatory processes induced by the toxins inhaled and absorbed during active and passive smoking [33]. These oxidative free radicals, (such as superoxide, hydroxide radical, nitric oxide and reac- 
tive oxygen) lead to oxidative injury on membrane lipids and proteins and DNA via various molecular pathways, leading to increased DNA damage and oxidative stress $[34,35]$. These higher levels of both exogenous and intracellular produced free radicals can mediate signal transduction, trigger inflammation, and cellular apoptosis and necrosis [36].

The first line of response to oxidative stress in the human body is that of antioxidant enzymes such as superoxide dismutase, catalase and glutathione peroxidase, which take an advantage of the circulating levels of dietary antioxidants, which are a second line of defence against oxidative stress. These antioxidants are digested and enter the circulation, acting as an oxidative buffer, and therefore could have a protective effect against reactive oxidative damage.

Due to the fact that antioxidants are potential pro-oxidants, possible lower concentrations of antioxidants in smokers in comparison to non-smokers may be a defensive adaptation to the pro-inflammatory environment in smoker's tissues [37]. As viewed in the literature, smokers have lower circulating concentrations of a number of micronutrients, such as ascorbic acid, a-carotene, b-carotene and cryptoxanthin. Although it is possible that differences in dietary intakes could potentially account for these disparities, few studies having controlled for differences in nutrient intake. In study planning and design it is imperative that these differences are accounted for since smokers are generally known to adhere to a less healthy diet, consume fewer food items rich in fiber, antioxidants and phytochemicals and tend to prefer a meat/alcohol dietary pattern in comparison to non-smokers [38-42]. An important public health related issue is whether or not the marked changes in the subjects health are solely due to the harmful effects of cigarette smoke or to a combined effect of both the oxidative properties of cigarette smoke and the habitual dietary profile of smokers (which is in general lower in fruit and vegetable intake and higher in alcohol and meat product consumption in comparison to that of non-smokers) [43]. Moreover, it is likely that the cumulative effect of both the elevated oxidative stress and lower dietary intake of antioxidants is partially responsible for the negative impact of smoking on human health. Vitamins $B_{6}$ and $B_{12}$, which are in abundance in diets high in red meat and have been shown to be involved in the regulation of homocysteine, with the elevation of homocysteine shown to be an independent risk factor for coronary heart disease [44]. Chemical components found in tobacco smoke interact with the above and transform them into inactive compounds reducing their active concentration in biological fluids and possibly alter the ability of the cell to store and metabolise folate [45]. The existing literature is vague regarding the relationship between smoking and serum cobalamin levels (vitamin $B_{12}$ ). Two studies investigating into smoking during pregnancy and vitamin status suggest that there may be a dose related relationship between smoking and the metabolism of vitamins $B_{6}$ and $B_{12}$ while a third study (among men only) found significantly higher $B_{12}$ levels among smokers [46-51]. 


\subsection{Passive smoking and cardiovascular risk: biological interactions with the development of cardiovascular disease}

A vast number of studies on the unfavourable effects of second hand smoke (SHS) exist within the scientific literature. The majority of which evaluate longitudinal epidemiological data. Although limited, the experimental studies that assess the acute and short-term effects of exposure to SHS are also increasing in number. They include cellular, animal, and human studies that indicate a number of pathophysiological mechanisms through which the deleterious effects of SHS may arise. Cardiovascular disease (CVD) is a major cause of death and disability throughout the developed world. During the past years several factors have been established as risk markers for the development of the disease, including advanced age, male sex, heredity, history of hypertension, diabetes and dyslipidemia, psychological disorders, as well as various lifestyle habits, like smoking, physical inactivity and unhealthy dietary choices [2,52-53]. Beyond active smoking, exposure to second hand smoke (SHS), or passive smoking, is also considered as a risk factor for CVD [54-56]. Meta analyses and reviews have indicated that the pooled relative risk of developing coronary heart disease when exposed chronically to SHS is 1.3, interpreted as a $30 \%$ increase in risk [57-59].

Although surprising, this disproportionate effect has been attributed to a number of different interactions between human physiology of the cardiovascular system and SHS exposure, including inflammation, platelet aggregation, endothelium dysfunction, lipid peroxidisation and alterations in c-reactive protein (CRP), homocystein and fibrinogen levels [59-61]; however, the evidence is still under debate.

One factor through which exposure to SHS can increase the risk of developing CVD is through its effect on circulating lipoproteins. Cigarette smoking increases the oxidative modification of LDL with circulating products of lipid peroxidation and levels of oxidized LDL found to be significantly increased in both active and passive smokers [62]. Epidemiological and laboratory evidence has indicated that smoking decreases plasma high lipoprotein levels (HDL) and alters the ratios between HDL and low density lipoproteins (LDL), HDL and triglycerides (TG) and HDL and total cholesterol levels, both in animal models and humans [63-64]. Such an alteration in the lipidemic profile of the exposed to SHS can evidently lead to the development of cardiovascular disease, a major part of which is mediated by the circulating serum cholesterol and specifically the ratio between HDL cholesterol and other harmful circulating lipid transferring factors, such as serum LDL, or triglycerides [65].

Cigarette smoke can promote atherosclerosis, in part, by its effects on the lipid profile of the passive smoker, which as noted above is more oxidised than that of a non exposed subject. Animal experiments have shown a synergistic effect between SHS and low-density lipoprotein that facilitated the binding of oxidized low-density lipoprotein to the vessel wall during 2-hour SHS exposures [66]. This oxidised LDL cholesterol may lodge into the arterial endothelial wall, thus attracting macro- 
phages, lymphocytes and subsequently paracrinine factors that will lead to platelet accumulation and thus initiate the creation of foam cells, the first step in developing an atherosclerotic plaque [67]. In line with the above, exposure to SHS has been demonstrated to stimulate human fibroblasts to express several chemokines, including MCP-1 (monocyte chemoattractant protein-1), which plays a key role in the formation of atherosclerotic lesions.

A recent set of data provided evidence that SHS may harm the vasculature not only by directly injuring the vascular endothelium but also by interfering with the vascular repair system, which may lead to chronic damage with recurrent exposures [68]. This was shown by examining endothelial regeneration, a process mediated in part by endothelial progenitor cells circulating in peripheral blood [68]. Specifically, 30minutes of moderate SHS exposure have been shown to lead to a mobilization of dysfunctional endothelial progenitor cells in response to acute vascular injury that was evident for more than 24 hours. Mechanistically, these effects have been linked to an impairment of nitric oxide production in endothelial progenitor cells, providing further evidence that even brief SHS exposures present significant and persistent vascular consequences.

CRP is an acute phase protein produced primarily by the liver in response to inflammatory cytokines, such as IL-6 [69], which has been shown in epidemiological studies to be predictive of future cardiovascular disease [70-71]. Ridker et al, proposed that men with elevated levels of CRP were at a greater risk for myocardial infarction compared to men with normal levels, independently of all other factors known to predict clinical coronary outcomes, including lipid levels. Furthermore, it has been hypothesized that elevated CRP levels in themselves may have a direct effect on the development and aggravation of atherosclerosis [69]. Recent epidemiological evidence has indicated an association between exposure to SHS and CRP both in adults and in youth and through both biomarker and self reported assessment of exposure [60-61]. In the ATTICA study, the investigators reported that exposure to SHS was also positively correlated with homocysteine levels (with SHS exposed found to have mean homocysteine levels higher by $0.4 \mu \mathrm{mol} / \mathrm{L}$ ), an indicator also found by Venn et al., when comparing subjects with detectable cotinine levels with subjects with non detectable cotinine levels, in which a mean difference of $0.8 \mu \mathrm{mol} / \mathrm{L}$ was noticed [59-60]. An elevated plasma homocysteine concentration is associated with an increased risk of myocardial infarction, while homocysteineinduced oxidative stress favours lipid peroxidation and induces the production of inflammatory factors, a mechanism through which exposure to SHS could further accelerate atherosclerosis [72]. 


\subsection{The interaction between passive smoking and the Mediterranean diet on the development of diabetes}

Diabetes mellitus is a public health problem, which has reached pandemic proportions. It is estimated that by the year 2030, 366 million people on the globe will suffer from this disease [73]. Diabetes mellitus is a multi-factorial disease, characterized by hyperglycaemia, resulting from a disturbed insulin secretion, insulin action or both. The long-term effects of diabetes mellitus include increased risk on complications such as foot ulcers, retinopathy, nephropathy and neuropathy. Even more problematic is the fact that $70-80 \%$ of people with diabetes die of cardiovascular disease [74]. Exposure to SHS has been scientifically proven to lead to an increase in both chronic and acute cardiovascular outcomes and further predispose to the development of other illnesses such as respiratory disease and cancer [7577]. While reviews and meta-analyses have indicated that active smoking is strongly dose response related to the development of diabetes, very limited evidence exists in the literature on the role of SHS in the development of diabetes mellitus [78-80]. To the best of our knowledge, only a few studies have indicated that exposure to SHS can lead to an increase in the prevalence of diabetes. Specifically, Houston et al., showed that exposure to SHS was related to a $35 \%$ increase in the prevalence of diabetes, while Hayashino et al., reported that self reported workplace passive smoking was related to an $81 \%$ increase in the development of diabetes mellitus [79-80]. Despite their important results these two studies had some drawbacks. One noted drawback of these studies was the limited amount of information on dietary and lifestyle habits, such as physical activity, factors which play an important preventive role in the development of diabetes mellitus [81]. Furthermore, the Mediterranean region, and especially Greece and Cyprus, has several geographical particularities, and one of them is its many islands, which are, usually, in long distance from the metropolitan areas of the mainland. People living in the Aegean and Ionian Sea, as well as Crete have various lifestyle and dietary habits that are quite different from those living in mainland, as well as in other parts of Europe and the US, particularly and increased adherence to the Mediterranean diet [82].

\subsection{The outline of this thesis}

This thesis is based on a number of studies each one designed to address a different aspect of the topic and mostly based on the MESSARA study (performed in the farming valley of Messara in Crete near to where the SCS took place almost 50 years ago). In comparison to 45 years ago when the Mediterranean diet was first scientifically described, the risk factors for the development of cardiovascular disease in rural Crete have significantly changed and these comparisons are described in Chapter 2. In chapter 3 the MESSARA study participants somatometrics and level of physical activity is investigated into as factors of cardiovascular risk and as con- 
founders in the relationship between smoking, dietary habits and cardiovascular disease development. Further to the above, the role of the fasting habits of the traditional Mediterranean diet, on dietary intakes among the population of Crete is evaluated in Chapter 4.

In Chapter 5, an overview is given on the existing literature which could support our hypothesis that there could be an interaction between adherence to the Mediterranean diet and the health implications of active and passive smoking. The effects of smoking as a severe source of oxidative stress and carcinogens could be ameliorated by the plethora of antioxidants and tumoricidal compounds found within the Mediterranean diet, through a nutrition-environment interaction.

Chapter 6 provides information on the MESSARA study participants' dietary intakes, with its results indicating significantly different dietary habits according to the participants smoking status. This fact not only has an implication on lipid and antioxidant intake but also on their circulating serum levels.

Moreover in Chapter 7, we wished to further assess the impact of a more recently established risk factor in relation to chronic (or acute) exposure to passive smoking. While numerous studies have indicated the interaction between exposure to passive smoking and the development of cardiovascular disease there is very little existing scientific evidence of the relationship between chronic exposure to passive smoking and the development of diabetes mellitus, especially after investigating into the confounding effect of adherence to the Mediterranean diet.

Finally, in chapter $\mathbf{8}$, the results and conclusions of the previous chapters are integrated and discussed in a broader perspective and implications for future research are given. 


\section{REFERENCES}

1. Keys A. Coronary heart disease in Seven Countries. American Heart Association Monograph Number 29. New York: American Heart Association. 1970

2. Menotti A, Keys $\mathrm{A}$, Blackburn $\mathrm{H}$, et al. Comparison of multivariate predictive power of major risk factors for coronary heart diseases in seven countries: results from eight nations of the Seven Countries Study, 25 year follow up. J Card risk. 1996; 3:69-75

3. Panagiotakos DB, Pitsavos C, Polychronopoulos E, et al. Total cholesterol and body mass index in relation to 40 year cancer mortality (The Corfu cohort of the Seven Countries Study). Cancer Epidem. Biomarker. Prev. 2005; 14(7):1797-1801

4. Ferro-Luzzi A, James W, Kafatos A. The high fat Greek diet: A recipe for all? Eur J Clin Nutr 2002, 56:796-809

5. Simopoulos A. Overview of evolutionary aspects of $\omega-3$ fatty acids in the diet. In Simopoulos A (Ed). The return of the $\omega$-3 fatty acids into the food supply: I land-based animal food products and their health effects. World Review of Nutrition Diet. 1998; 83. 1-11

6. Sanders T, Oakley F, Miller G, Mitropoulos K, Crook D, Oliver M. Influence of n- 6 versus n-3 Polyunsaturated Fatty Acids in Diets Low in Saturated Fatty Acids on Plasma Lipoproteins and Hemostatic Factors. Arterioscler Thromb Vasc Biol; 1997; 17:3449-3460.

7. Moschandreas J, Kafatos A, Aravanis C, Dontas A, Menotti A, Kromhout D. Long-term predictors of survival for the Seven Countries Study cohort from Crete: from 1960 to 2000. Int J Cardiol; 2005; 100(1):85-91.

8. Kromhout D, Menotti A, Blackburn H (Editors). Prevention of Coronary Heart Disease. Diet, lifestyle and risk factors in the seven countries study. Kluwer Academic Publishers

9. Pi-Sunyer FX. The obesity epidemic: pathophysiology and consequences on obesity. Obes Res. 2002; 10 (Suppl 2):97-104

10. Kraus RM, Winston M, Fletcher BJ, Grundy SM. Obesity: impact on cardiovascular disease. Circulation. 1998; 98:1472-76

11. Romero-Corral A, Montori V, Somers V et al. Association of bodyweight with total mortality and with cardiovascular events in coronary heart disease: a systematic review of cohort studies. Lancet. 2006; 368:666-78

12. Menotti A, Blackburn H, Kromhout D, Nissinen A, Adachi H, Lanti M. Cardiovascular risk factors as determinants of 25-year all-cause mortality in the Seven Countries Study. Eur J Epidem. 2001; 17;337-346.

13. Kafatos, A., Verhagen, H., Moschandreas, J., Apostolaki, I., \& Van Westerop, J.J.M. Mediterranean diet of Crete: foods and nutrient content. J Am Diet Assoc. 2000; 100, 1487-1493.

14. Chliaoutakis, J.E., Drakou, I., Gnardellis, C., Galariotou, S., Carra, H., \& Chliaoutaki, M. Greek Christian Orthodox Ecclesiastical Lifestyle: Could it become a pattern of health-related behavior? Prev Med. 2002; 34, 428-435.

15. Sarri, K.O., Linardakis, M.K., Bervanaki, F.N., Tzanakis, N.E., \& Kafatos, A.G. Greek Orthodox fasting rituals: a hidden characteristic of the Mediterranean diet of Crete. Brit J Nutr, 2004; 92, 277-284.

16. Sarri, K.O., Tzanakis, N.E., Linardakis, M.K., Mamalakis, G.D., \& Kafatos, A.G. Effects of Greek orthodox Christian church fasting on serum lipids and obesity. BMC Public Health. 2003; 3, 16.

17. Sabaté, J. Religion, diet and research. Brit J Nut, 2004; 92, 199-201.

18. Kafatos, A., Kouroumalis, I., Vlachonikolis, I., Theodorou, C., \& Labadarios, D. Coronary-heartdisease risk-factor status of the Cretan urban population in the 1980s. Am J Clin Nutr, 1991; 54, 591-598.

19. Trichopoulou, A., Kouris-Blazos, A., Wahlqvist, M.L., et al. Diet and overall survival in elderly people. BMJ, 1995; 311, 1457-1460.

20. Papadaki A, Vardavas C, Hatzis C, Kafatos A. Nutrient and food intake during a Greek Orthodox Fasting and non fasting week. Public Health Nutr. 2007 20;1-8 
21. Booker CS, Mann JI. Trans fatty acids and cardiovascular health: translation of the evidence base. Nutr Metab Cardiovasc Dis. 2008; 18(6):448-56.

22. Erkkilä A, de Mello VD, Risérus U, Laaksonen DE. Dietary fatty acids and cardiovascular disease: an epidemiological approach. Prog Lipid Res. 2008; 47(3):172-87

23. Kromhout D, Keys A, Aravanis C, et al. Food consumption patterns in the 1960's in seven countries. Am J Clin Nutr. 1989; 49:889-94

24. Serra-Majem L, Ngo de la Cruz J, Ribas L, Salleras L. Mediterranean Diet and Health: Is all the Secret in Olive Oil? Pathophy Haem Thromb. 2003; 33(5-6): 461-5

25. Vardavas C.I, Linardakis M, Hatzis C, Saris W, Kafatos A. Prevalence of Obesity and Physical Inactivity among Farmers from Crete (Greece), Four Decades after the Seven Countries Study. Nutr Metab Cardiovasc Dis 2009; 19: 156-162

26. Hennig B, Oesterling E, Toborek M. Environmental toxicity and gene interactions in the development of atherosclerosis. Nutr Metab Cardiovasc Dis. 2007; 17:162-169

27. Vardavas C.I, Papadaki A, Saris W, Kafatos A. Is Adherence To The Mediterranean Diet An Effect Modifier Of The Impact Smoking Has On Health? Public Health. 2009; 123(6):459-460

28. Jacobs D, Adachi H, Mulder I, et al. Cigarette smoking and mortality risk. 25 year follow up of the Seven Countries Study. Arch Intern Med. 1999; 159:733-740

29. Mulder I, Jansen $\mathrm{M}$, Smit $\mathrm{H}$, et al. Role of smoking and diet in the cross cultural variation in lung cancer mortality: The seven countries study. Int J Cancer. 2000; 88:665-61

30. Zieler RG, Mayne ST, Swanson CA. Nutrition and lung cancer. Cancer Causes Control. 1996; 7:157177

31. Simopoulos A. The Mediterranean diets: What is so special about the diet of Greece? The Scientific Evidence. Journal of Nutrition. 2001; 131:3065s-3073s

32. Pryor WA, Stone K. Oxidants in cigarette smoke. Radicals, hydrogen peroxide, peroxynitrate and peroxynitrate. Ann New York Acad Sci. 1993; 686:12-27

33. Van der Vaart H, Postma DS, Timens W, Ten Haccken NHT. Acute effects of cigarette smoke on inflammation and oxidative stress: a review. Thorax. 2004; 59:713-721

34. Kosecik M, Erel O, Sevinc E, Selek S. Increased oxidative stress in children exposed to passive smoking. Int J Cardiol. 2005, 100, 61-64.

35. Tang D, Warburton D, Tannenbaum SR, et al. Molecular and genetic damage from environmental tobacco smoke in young children. Cancer Epidem Biomarker Prev. 1999, 8, 427-431.

36. Oxidative stress: adaptation, damage, repair and death, in Halliwell B, Gutteridge JMC, eds. Free radicals in Biology and Medicine. Oxford: oxford University press, 1999 pp 346-350

37. Thurnham DI, Northrop-Clewes CA. Effects of infection on nutritional and immune status. In Hughes DA, Darlington LG, Bendich A, editors. Diet and human immune function. New Jersey: Humana Press; 2004. p35-63

38. Alberg A. The influence of cigarette smoking on circulating concentrations of antioxidant micronutrients. Toxicology 2002; 180: 121-137

39. Zondervan, K.T., Ocke, M.C., Smit, H.A., Seidell, J.C. Do dietary and supplementary intakes of antioxidants differ with smoking status? Int J Epidemiol 1996; 25: 70-79.

40. Margetts, B.M., Jackson, A.A. The determinants of plasma b-carotene: interaction between smoking and other lifestyle factors. Eur J Clin Nutr 1996; 50: 236-238.

41. Touvier $M$, Niravong $M$, Volatier JL, et al. Dietary patterns associated with vitamin/mineral supplement use and smoking among women of the E3N-EPIC cohort. Eur J Clin Nutr 2009; 63(1):39-47.

42. Padrao P, Lunet N, Santos AC, Barros H. Smoking, alcohol, and dietary choices: evidence from the Portuguese National Health Survey. BMC Public Health. 2007; 7:138.

43. Pitsavos C, Panagiotakos D, Chrysohoou C, Stefanadis C. Epidemiology of cardiovascular risk factors in Greece: aims, design and baseline characteristics of the ATTICA study. BMC Public Health. 2003; 3(1): 32

44. Refsum H, Ueland PM, Nygard O, Vollset SE. Homocysteine and cardiovascular disease. Ann Rev Med. 1998; 49:31-62 
45. Northrop-Clewes CA, Thurnham DI. Monitoring micronutrients in cigarette smokers. Clinica Chima Acta. 2000; 377:14-38

46. Ortega RM, Lopez-Sobaler AM, Gonzalez-Gross MM, et al. Influence of smoking on folate intake and blood folate concentrations in a group of elderly Spanish men. J Am Coll Nutr. 1994; 13:68-72. (a)

47. Piyathilake CJ, Macaluso M, Hine RJ, Richards EW, Krumdieck CL. Local and systemic effects of cigarette smoking on folate and vitamin B-12. Am J Clin Nutr 1994; 60:559-66.

48. Pagan K, Hou J, Goldenberg RL, Cliver SP, Tamura T. Effect of smoking on serum concentrations of total homocysteine and B vitamins in midpregnancy. Clin Chim Acta. 2001; 306:103-9.

49. Relton CL, Pearce MS, Parker L. The influence of erythrocyte folate and serum vitamin B12 status on birth weight. Brit J Nutr. 2005; 93:593-9.

50. Tungtrongchitr R, Pongpaew $\mathrm{P}$, Soonthornruengyot $\mathrm{M}$, et al. Relationship of tobacco smoking with serum vitamin B12, folic acid and haematological indices in healthy adults. Pub Health Nutr. 2003; 6:675-81

51. Kim S, Kim J, Shin $\mathrm{H}$ and Keen $\mathrm{C}$. Influence of smoking on markers of oxidative stress and serum mineral concentrations in teenage girls in Korea, Nutrition. 2003; 19:240-243

52. Pitsavos C, Panagiotakos DB, Menotti A, Chrysohoou C, Skoumas J, Stefanadis C, Dontas A, Toutouzas $P$. Forty-year follow-up of coronary heart disease mortality and its predictors: the Corfu cohort of the seven countries study. Prev Cardiol. 2003; 6(3):155-60

53. Van den Hoogen PC, Seidell JC, Menotti A, Kromhout D. Blood pressure and long-term coronary heart disease mortality in the Seven Countries study: implications for clinical practice and public health. Eur Heart J. 2000; 21(20):1639-42.

54. O'Toole TE, Conklin DJ, Bhatnagar A. Environmental risk factors for heart disease. Rev Environ Health. 2008; 23(3):167-202.

55. Raupach T, Schäfer K, Konstantinides S, Andreas S. Secondhand smoke as an acute threat for the cardiovascular system: a change in paradigm. Eur Heart J. 2006; 27(4):386-92.

56. Leone A, Balbarini A. Exposure to passive smoking: a test to predict endothelial dysfunction and atherosclerotic lesions. Angiology. 2008; 59(2):220-3.

57. Barnoya J, Glantz S. Cardiovascular effects of secondhand smoke. Nearly as large as smoking. Circulation. 2005; 111: 2684-2698

58. Thun M, Henley J, Appicella L. Epidemiologic studies of fatal and non fatal cardiovascular disease and ETS exposure from spousal smoking. Environ Health perspect 1999; 107(suppl):841-846

59. Venn A, Briton J. Exposure to Secondhand smoke and biomarkers of cardiovascular disease risk in never smoking adults. Circulation. 2007; 115:990-995

60. Wilkinson JD, Lee DJ, Arheart KL. Secondhand smoke exposure and C reactive protein levels in youth. Nicot tob res. 2007; 9(2): 305-307

61. Panagiotakos DB, Pitsavos C, Chrysohoou C, Skoumas J, Masoura C, Toutouzas P, Stefanadis C; ATTICA study. Effect of exposure to secondhand smoke on markers of inflammation: the ATTICA study. Am J Med. 2004; 116(3):145-50

62. Heitzer T, Ylä-Herttuala S, Luoma J, et al. Cigarette smoking potentiates endothelial dysfunction of forearm resistance vessels in patients with hypercholesterolemia. Role of oxidized LDL. Circulation. 1996; 93(7):1346-53.

63. Yuan $\mathrm{H}$, Wong LS, Bhattacharya $\mathrm{M}$, et al. The effects of second-hand smoke on biological processes important in atherogenesis. BMC Cardiovasc Disord. 2007; 7:1.

64. Ambrose JA, Barua RS The pathophysiology of cigarette smoking and cardiovascular disease: an update. J Am Coll Cardiol. 2004; 43(10):1731-7

65. Moffatt RJ, Chelland S, Pecott D, Stamford B. Acute exposure to environmental tobacco smoke reduces $\mathrm{HDL}-\mathrm{C}$ and $\mathrm{HDL}_{2}-\mathrm{C}$. Prev Med. 2004; 38: 637-641

66. Roberts KA, Rezai AA, Pinkerton KE, and Rutledge JC. Effect of environmental tobacco smoke on LDL accumulation in the artery wall. Circulation 94: 2248-2253, 1996. 
67. Chelland Campbell SC, Moffatt RJ, Stamford B. Smoking and smoking cessation-the relationship between cardiovascular disease and lipoprotein metabolism: a review. Atherosclerosis. 2008; 201(2):225-35

68. Heiss C, Amabile N, Lee AC, et al. Brief secondhand smoke exposure depresses endothelial progenitor cells activity and endothelial function: sustained vascular injury and blunted nitric oxide production. J Am Coll Cardiol 2008; 51: 1760-1771,.

69. Libby P. Inflammation in atherosclerosis. Nature 2002; 420: 868-874

70. Ridker PM, Rifai N, Rose L, Buring JE, Cook NR. Comparison of C-reactive protein and low-density lipoprotein cholesterol levels in the prediction of first cardiovascular events. N Engl J Med. 2002; 347(20):1557-65.

71. Ridker PM, Rifai N, Clearfield M, et al. Measurement of C-reactive protein for the targeting of statin therapy in the primary prevention of acute coronary events. N Engl J Med. 2001; 344(26):1959-65.

72. Wald DS, Law M, Morris JK. Homocysteine and cardiovascular disease: evidence on causality from a meta-analysis. BMJ. 2002; 325:1202.

73. Wild S, Roglic G, Green A, Sicree R, King H. Global prevalence of diabetes: estimates for the year 2000 and projections for 2030. Diabetes Care. 2004; 27(5):1047-53.

74. IDF. Diabetes Atlas, second edition: www.eatlas.idf.org. Accessed September 20, 2009

75. Alberg A. Samet J. Epidemiology of Lung Cancer. J Am Col Chest Phy. 2003; 123: 21s-49s

76. Pitsavos C, Panagiotakos DB, Crysohoou C, Skoumas J, Tzioumis K, Stefanadis C, Toutouzas P. Association between exposure to environmental tobacco smoke and the development of acute coronary symptoms: the CARDIO2000 case control study. Tob Control. 2002; 11(3):220-225

77. Vork KL, Broadwin RL, Blaisdell RJ. Developing asthma in childhood from exposure to secondhand tobacco smoke: insights from a meta-regression Environ Health Perspect. 2007; 115(10):1394-400

78. Willi C, Bodenmann P, Ghali W, Faris P, Cornuz J. Active smoking and the risk of type 2 diabetes. JAMA. 2007; 298(22): 2654-2664

79. Houston T, Person S, Pletcher M, Liu K, iribarren C, Kiefe C. Active and passive smoking and development of glucose intolerance among young adults in a prospective cohort: CARDIA study. BMJ. 2006; 332; 1064-1069

80. Hayashino $\mathrm{Y}$, Fukuhara $\mathrm{S}$, Okamura $\mathrm{T}$, et al. A prospective study of passive smoking and risk of diabetes in a cohort of workers: the High-Risk and Population Strategy for Occupational Health Promotion (HIPOP-OHP) study. Diabet Care. 2008; 31(4):732-4.

81. Panagiotakos DB, Polystipioti A, Papairakleous N, Polychronopoulos E. Long term adoption of the Mediterranean diet is associated with a better health status in elderly people; a cross sectional survey in Cyprus. Asia Pac J Clin Nutr 2007; 16(2):331-7

82. Vardavas $\mathrm{Cl}$, Lionis $\mathrm{C}$, Polychronopoulos E, Zeimbekis A, Bountziouka V, Stravopodis S, Metallinos G, Panagiotakos DB. The role of passive smoking on the prevalence of type II diabetes mellitus among elderly men and women living in Mediterranean islands: the MEDIS study. Diab Med 2010; $27(2): 242-243$ 



\section{CHAPTER 2}

\section{CARDIOVASCULAR DISEASE RISK FACTORS AND DIETARY HABITS OF FARMERS FROM CRETE 45 YEARS AFTER THE FIRST DESCRIPTION OF THE MEDITERRANEAN DIET}

\section{THE MESSARA STUDY}

Constantine I. Vardavas, Manolis Linardakis, Christos Hatzis, Wim H.M Saris, Anthony Kafatos

European Journal of Cardiovascular Prevention and Rehabilitation 2010 (In press) 


\begin{abstract}
Background Farmers from Crete as first studied within the framework of the Seven Countries Study, were historically known for holding the title of the "gold standard" of health status globally and had a very low prevalence of both cardiovascular disease (CVD) and cancer. Taking the above into account we evaluated the changes in CVD risk factors among farmers in Crete, Greece and compared our findings to data from the 1960's.
\end{abstract}

Design: Cross sectional

Methods: 502 farmers (18-79 years old) from the Valley of Messara in Crete were randomly selected and examined in 2005. Complete clinical, biochemical, dietetic, anthropometrical and lifestyle CVD risk factors were assessed, matched and compared to published data from the 1960s.

Results: In comparison to 45 years ago, present day male farmers from Crete were found to have a $30 \%$ higher BMI $\left(29.8 \mathrm{~kg} / \mathrm{m}^{2}\right.$ vs. $\left.22.9 \mathrm{~kg} / \mathrm{m}^{2}, \mathrm{p}<0.001\right)$ and a $16 \%$ higher total cholesterol level $(239.6 \mathrm{mg} / \mathrm{dl}$ vs. $206.9 \mathrm{mg} / \mathrm{dl}, \mathrm{p}<0.001)$ as also a not so favourable daily dietary intake (increase in meat and saturated fat and decrease in fruit, $p<0.001$ respectively), while a significant reduction in systolic blood pressure and energy intake was noticed. In regards to changes in subcutaneous adipose tissue fatty acid composition, a decrease in monounsaturated $(p<0.001)$ and an increase in saturated fatty acids $(p<0.001)$ was also found elucidating the temporal change in dietary habits.

Conclusions: The population's lack of adherence to the Mediterranean diet, have lead to the fact that currently farmers from Crete are likely to be at a higher risk for developing CVD in comparison to previous generations. 


\section{INTRODUCTION}

Cardiovascular disease (CVD) is one of the leading causes of global mortality. In most European countries cardiovascular disease contributes to about $40 \%$ to all cause mortality, with large differences existing between populations [1]. Taking into account trends over time, the proportion of deaths due to cardiovascular disease among OECD countries (Organisation for Economic Co-operation and Development), has decreased over the past 20 years [2]. Moreover, as reported by the Task Force of the European Society of Cardiology, specific countries, such as Finland have witnessed a larger drop than other Northern or Western European countries, while Central and Eastern European countries have had significant increases, thus leading to the currently observed West-East gradient in coronary heart disease patterns. Greece too, has also witnessed a continuous increase in CVD mortality over the past few decades [3].

The health status of farmers from Crete became globally known in the 1960's during the Seven Countries Study (SCS). Initiated in 1960, the purpose of that epidemiological study was to explore into the prevalence and the lifestyle and clinical determinants of the development of coronary heart disease. Within this study, the mortality rates of sixteen populations from seven countries (from Greece, Finland, Japan, former Yugoslavia, Italy, the Netherlands and the United States) revealed that the population of Crete had the lowest rates of cardiovascular disease (observed / expected deaths from CVD $=0.06$ ) and cancer among all 16 cohorts, including other Mediterranean populations [4]. Such a low prevalence of coronary heart disease was attributed to their lifestyle and in particular to the dietary habits of the farmers of Crete, which lead to the first description of the "Mediterranean diet". Since then, an overwhelming amount of evidence both experimental and epidemiological have revealed the beneficial effects of a diet high in monounsaturated fatty acids while low in saturated fatty acids, in relation to the development CHD. Prospective intervention studies supported these results, proving that adopting the traditional diet of Crete provided both primary and secondary protection against coronary heart disease similar to that of the American Heart Association's recommended diet $[5,6]$.

Benefiting from their lifestyle, farmers in Crete were found to have a favourable blood lipid profile, low body weight and an elevated level of physical activity, characteristics that granted them the historical title of the "gold standard" of human health status, due to their low prevalence of disease and long life expectancy. Over the past few decades though, the lifestyle and dietary habits of the Greek population have changed, and a more "western European" lifestyle has been commonly adopted $[7,8]$. To corroborate these facts, recent analyses on the 40-year follow up of the SCS cohort indicated a decline in CVD in the US, Finnish, Dutch and Japanese cohorts, a moderate increase in the Italian population and an exponential increase 
in CVD mortality among the population of Serbia and Greece. Despite this noted increase in mortality, the survivors from the cohort of Crete were still found to maintain the lowest CVD mortality rate in comparison to the survivors of the other cohorts [9].

Keeping the above into account, the aim of this study was to compare cardiovascular disease risk factors, dietary intakes and subcutaneous adipose tissue profiles between farmers from Crete, participants of the SCS and the Christakis study that were performed in 1960-1962 with farmers of the same age, gender and geographical area in 2005 as part of the MESSARA study [1, 10-11].

\section{METHODS}

\section{The MESSARA study}

The MESSARA study was carried out between February to June 2005. The purpose of the study was to estimate the prevalence of cancer, cardiovascular and chronic disease and their risk factors among the farming population in the valley of Messara in Southern Crete. The Messara valley is Crete's largest farming region with the major percentage of Crete's farming produce cultivated there either in open fields or in greenhouses.

Farmers ( $n=662$ ) from the valley of Messara in southern Crete, Greece were randomly selected by using the six municipality's voting lists using a random stratified sampling methodological approach, with the number of participants in each of the 24 villages selected according to the villages total farming population. A participant was regarded as a farmer if his main occupation was farming and/or sheep breeding, and was concurrently insured by the farmer's social insurance fund. Out of the 662 people randomly selected, 599 accepted to participate (90,5\%) out of which 505 were finally examined with $44 \%(n=223)$ of the participants' male and $56 \%$ $(n=282)$ of female gender respectively (age 18-79). One hundred and twenty eight men in the MESSARA study were between 40 and 59 years old and were comparable to the age of the cohorts of the SCS and the Christakis Study.

All examinations were conducted by a trained research team at each village, after participants were informed about the study and written consent was given. Approval to conduct the survey was granted by the Ethical Committee of the University of Crete while the prefecture of Heraklion's governing authority granted funding. Comparability with the historical data of 1960-1962

The data with which we compare our current findings with are two studies that were performed in 1960 and 1962 respectively. The first, performed in 1960 was the Seven Countries Study (SCS), in which a cohort of mainly farmers from Crete $(n=686)$ was examined and provided dietary, lifestyle and clinical information, which was compared with 14 other cohorts of different countries (and one from the Greek island of Corfu). The participants of the Cretan cohort of the SCS were 
from farming and/or sheep breeding areas of the prefecture of Heraklion, in neighbouring villages only a few kilometres from the valley of Messara in which our study took place [4]. Complete dietary data was collected in 1960 with the use of seven day dietary questionnaires and was available for 31 men [11]. Furthermore data on the subcutaneous gluteal adipose tissue fatty acids was available from 78 survivors, during the 40-year follow up that was performed in 2000 [12].

The second study with which we compare our data is the "Christakis study", which took place in 1962 and investigated into similar factors as the SCS, throughout the island of Crete including the prefecture of Heraklion and the valley of Messara. During this study a total of 11 villages and the city of Heraklion were surveyed. These 12 communities were grouped into four rural districts of Sfakia, Viannos, Amari and Messara, while a complete list of all men aged 45 years and over was obtained and subjects from the villages randomly selected and examined. Initially, 280 subjects were examined, while dietary data was collected with the use of a 24 hour recall questionnaire. Subcutaneous gluteal adipose tissue was collected from 200 participants, 38 of which were from the Messara valley, with the remaining subjects from neighbouring counties. Further information on the procedures is available elsewhere [10].

\section{Cardiovascular risk factors assessed}

In the current study, current smoking status, Systolic Blood Pressure (SBP), Diastolic Blood Pressure (DBP), Body Mass Index (BMI), Total Cholesterol (TC) and dietary habits were used as factors that influence the development of cardiovascular disease. Furthermore the qualitative composition of subcutaneous adipose tissue samples was used as an indicator of long term dietary habits.

Participants were classified as having elevated blood pressure if they reported taking anti-hypertensive medication or had a SBP $\geq 130 \mathrm{mmHg}$ or DBP $\geq 85 \mathrm{mmHg}$. In order to measure blood pressure, subjects were seated in a chair with their back supported and their arms bared and supported at heart level. Measurement was performed with the subject not having ingested coffee or smoked for 30 minutes and after at least five minutes of rest. The appropriate cuff size was used to ensure an accurate measurement. Measurements were taken using a mercury sphygmomanometer applied on the right arm of the participants. Two readings separated by two minutes were averaged. If they differed by more than $5 \mathrm{mmHg}$, one additional reading was obtained and then averaged. Early morning, venous blood samples were drawn for biochemical screening tests, following a 12-hour overnight fast. Dyslipidaemia was defined as TC $\geq 220 \mathrm{mg} / \mathrm{dl}$. A subject was classified as a current smoker if he/she reported smoking at least one cigarette a day. The methodological approach used to define anthropometric indexes, was based on the WHO criteria and can be found elsewhere $[13,14]$. 


\section{Dietary assessment}

Dietary and daily energy intake was assessed using three-day dietary report questionnaire that was handed to the participants prior to the examination day of the study and returned the next $(n=251)$. Written and oral explanations were also provided. Where the three-day dietary questionnaires were not returned, a trained dietician completed a 24-hour dietary recall questionnaire on the day of examination ( $n=249$ ) using food model photographs and household measures. To re-ensure internal validity between the three-day dietary report questionnaires and the 24-hr dietary recall questionnaires, statistical comparisons were performed investigating the dietary intakes of those who had completed three-day report questionnaires and the 24hour recall questionnaires. No significant differences were found except for vitamin A intake. Dietary records and fasting habits were available from 500 participants. Nutrient contents were analyzed according to the food database developed at the Department of Social Medicine of the University of Crete in 1998 and updated in 2000 [15]. An extensive description of the database can be found elsewhere as also further information on the population's daily dietary and energy intake [13, 16-17].

Among the long term survivors of the Seven Countries Study, estimates of dietary intake for the non-housebound subjects were obtained by means of a quantitative food frequency questionnaire consisting of 121 common Greek foods \& drinks. To assess usual dietary intake, a 24-hour dietary recall questionnaire was completed. Using the checklist, each meal and all between-meal snacks were discussed. Portion sizes were assessed according to standard household measures with the aid of a commercial set of life-sized food portions. Composite food quantities were given in terms of their components if possible. Subjects were also asked whether they were on a special diet and if they took dietary supplements. Each interview lasted about an hour. When a subject had difficulty providing information, another family member gave assistance.

\section{Fatty acid analysis and sampling methodology}

Buttock subcutaneous tissue samples were collected by aspiration, using the method described by Beynen and Katan [18]. Samples were taken from the left upper outer quadrant of the gluteal area. Prior to aspiration, aspiration sites were sprayed with a local anaesthetic (ethyl chloride). Adipose tissue samples were stored in -80C until analysis. Fatty acid analysis was carried out as previously described [12].

\section{Statistical analysis}

All P-values are based on two-sided tests and a significance level lower than 0.05 was defined. Continuous variables are presented as mean \pm standard deviation, while qualitative variables were depicted with the use of frequencies. Student $t$ and 
chi-squared $\left(\chi^{2}\right)$ tests were used for detecting differences between study groups in regards to their clinical, physical and biochemical characteristics. Finally, $t$ tests were used to evaluate the differences in the characteristics of males in the present study, aged 40-59 years, and those of the SCS in 1960 again in 2000 and of the Christakis study in 1962. The statistical analysis was performed with the statistical package SPSS 17.0. (Statistical Package for Social Sciences, SPSS, Inc, Illinois, USA)

\section{RESULTS}

\section{Comparisons in the epidemiology of cardiovascular risk factors of Cretan farmers 45 years ago}

As compared with the initial data of CVD among Cretan farmers of the SCS in Table 1, the risk factors of CVD among the male farming population of Crete have significantly changed over the past 45 years. The TC blood levels has increased by 32.7 $\mathrm{mg} / \mathrm{dl}$ (an increase of $15.8 \%$ ) from $206.9 \pm 41.4 \mathrm{mg} / \mathrm{dl}$ to $239.6 \pm 45.8 \mathrm{mg} / \mathrm{dl}$ and this difference was statistically significant $(p<0.001)$. This increase in TC is also amplified by the increase in energy intake and the quality and quantity of fatty acid intake.

Table 1. Comparison in cardiovascular disease risk factors between male farmers aged 40-59 of the Seven Countries Study (Cretan cohort) and the Messara study.

\begin{tabular}{|c|c|c|c|c|}
\hline & $\begin{array}{l}\text { Seven Countries } \\
\text { Study } 1960\end{array}$ & $\begin{array}{l}\text { Messara Study } \\
2005\end{array}$ & $\begin{array}{l}\% \\
\text { Change }\end{array}$ & $P$-value \\
\hline Age in years & $49 \pm 5.5$ & $49.6 \pm 5.0$ & -- & 0.213 \\
\hline SBP in $\mathrm{mmHg}$ & $137 \pm 20$ & $127.0 \pm 15.7$ & -7.9 & $<0.001$ \\
\hline $\mathrm{SBP}>130$ & $57.5 \%$ & $31.7 \%$ & -25.8 & $<0.001$ \\
\hline DBP in $\mathrm{mmHg}$ & $81.6 \pm 11.3$ & $83.3 \pm 9.9$ & 2.1 & 0.086 \\
\hline $\mathrm{DBP}>90$ & $17.1 \%$ & $20.8 \%$ & 3.7 & 0.364 \\
\hline TC in $\mathrm{mg} / \mathrm{dl}$ & $206.9 \pm 41.4$ & $240.0 \pm 47.0$ & 16.0 & $<0.001$ \\
\hline TC>200 & $51.5 \%$ & $73.6 \%$ & 22.1 & $<0.001$ \\
\hline Current Smoking & $57.3 \%$ & $52.7 \%$ & -4.6 & 0.377 \\
\hline BMI in $\mathrm{kg} / \mathrm{m}^{2}$ & $22.9 \pm 3$ & $29.8 \pm 4.8$ & 30.1 & $<0.001$ \\
\hline Energy intake in kcal/day & 2820 & $2412 \pm 573$ & -14.5 & $<0.001$ \\
\hline PUFA in gr & 13.4 & $14.8 \pm 6.7$ & 10.4 & 0.038 \\
\hline MUFA in gr & 84.1 & $63.7 \pm 22.4$ & -24.3 & $<0.001$ \\
\hline SFA in $g r$ & 28 & $30.7 \pm 12.2$ & 9.6 & 0.024 \\
\hline
\end{tabular}

* One sample student t-test, values are mean \pm standard deviation

Although the energy intake among participants of the 7 countries study was higher than those of the Messara study a significant increase in the daily intake of PUFA and SFA from $13.4 \mathrm{~g}$ to $14.7 \mathrm{~g}$ and from $28 \mathrm{~g}$ to $30.4 \mathrm{~g}$ and these differences were statistically significant ( $p=0.035$ and $p=0.031$ respectively). The daily intake of MUFA has on the other hand decreased over the past 45 years from $84.1 \mathrm{~g}$ to 63.4 
$g(p<0.001)$. The above dietary fat and energy intake have also affected the BMI among farmers in Crete and the mean BMI was found to have increased by almost $7 \mathrm{~kg} / \mathrm{m}^{2}$ over the past 45 years $(p<0.001)$. On the other hand smoking prevalence has remained the same as also their DBP, while SBP was found to have dropped by $10 \mathrm{mmHg}(p<0.001)$. The dietary habits of farmers from Crete also were found to have changed over the past 45 years. Table 2, depicts the different food groups initially used in the SCS and compares the daily intake between male farmers 40-59 then and now as also that of the survivors of the SCS during the 40 year follow up. A significant decrease in the daily consumption of breads and potatoes is recognised $(<0.001)$ with a parallel increase in cereals $(+70 \%, p<0.001)$. The major dietary differences noted is the increase in daily meat consumption, of 35gr in the 1960's to $124 \mathrm{gr}$ in $2005(+254 \%, \mathrm{p}<0.001)$ and the parallel decrease in both fruit alone and combined fruit and vegetable consumption, on the other hand vegetable consumption witnessed an increase.

Table 2. Differences in self reported dietary intake of food groups between the 1960's and 2005 among farmers from Crete, Greece

\begin{tabular}{|c|c|c|c|c|c|c|c|}
\hline \multirow[b]{3}{*}{$\begin{array}{l}\text { Food groups } \\
\text { in grams/day }\end{array}$} & \multirow{3}{*}{$\begin{array}{l}\text { Messara Study } \\
2005, \text { males, } \\
\mathrm{n}^{1}=112, \\
(40-59 \text { yrs old }) \\
\text { Mean } \pm \text { SD }\end{array}$} & \multicolumn{6}{|c|}{ Seven Countries Study } \\
\hline & & \multicolumn{2}{|c|}{$\begin{array}{l}\text { 1960, males, } n^{1}=31, \\
(40-59 \text { yrs old })\end{array}$} & & \multicolumn{2}{|c|}{$\begin{array}{l}2000, \text { males, } n^{2}=118, \\
(80-96 \text { yrs old })\end{array}$} & \multirow[b]{2}{*}{ P-value ${ }^{4}$} \\
\hline & & Mean & $\begin{array}{c}\% \\
\text { change }\end{array}$ & P-value ${ }^{3}$ & Mean $\pm S D$ & $\begin{array}{c}\% \\
\text { change }\end{array}$ & \\
\hline Bread & $149 \pm 91$ & 380 & -61 & $<0.001$ & $103 \pm 83$ & -31 & $<0.001$ \\
\hline Cereals & $51 \pm 67$ & 30 & +70 & $<0.001$ & $115 \pm 88$ & 125 & $<0.001$ \\
\hline Potatoes & $111 \pm 108$ & 190 & -42 & $<0.001$ & $97 \pm 73$ & -13 & 0.254 \\
\hline Legumes & $40 \pm 76$ & 30 & +33 & 0.189 & $74 \pm 79$ & 85 & 0.001 \\
\hline Vegetables & $283 \pm 184$ & 191 & +48 & $<0.001$ & $166 \pm 117$ & -41 & $<0.001$ \\
\hline Fruits & $118 \pm 182$ & 464 & -75 & $<0.001$ & $232 \pm 203$ & 97 & $<0.001$ \\
\hline Vegetables \& Fruits & $401 \pm 284$ & 655 & -39 & $<0.001$ & $397 \pm 258$ & -1 & 0.915 \\
\hline Meat & $124 \pm 107$ & 35 & +254 & $<0.001$ & $52 \pm 45$ & -58 & $<0.001$ \\
\hline Fish & $41 \pm 75$ & 18 & +128 & 0.002 & $27 \pm 26$ & -34 & 0.066 \\
\hline Eggs & $18 \pm 40$ & 25 & -28 & 0.067 & $12 \pm 25$ & -33 & 0.184 \\
\hline Cheese & $35 \pm 52$ & 13 & +169 & $<0.001$ & $21 \pm 19$ & -40 & 0.009 \\
\hline Alcohol (ethanol) & $23 \pm 32$ & 15 & +53 & 0.008 & $18 \pm 25$ & -22 & 0.186 \\
\hline
\end{tabular}

${ }^{1}$ Dietary data was collected from 31 participants of the initial SCS study back in 1960, while 112 males of the MESSARA Study were of the same age group as the SCS participants; ${ }^{2}$ SCS survivors of 2000 followup; ${ }^{3}$ One sample Student t-test (standard deviations were not available for the SCS data.); ${ }^{4}$ Student ttest.

The daily intake of fruit alone in the 1960's SCS cohort was 464gr in comparison to today's $118 \mathrm{gr}(-75 \%, \mathrm{p}<0.001)$ of the MESSARA cohort, while combined consumption of fruit and vegetables dropped 39\% (655 to 401gr, p<0.001). In comparison to 
the 1960's, the survivors during the 40 year follow up of the SCS were found to have a lower fruit and vegetable intake, albeit a slightly higher meat intake.

Differences in the fatty acid profile of the subcutaneous adipose tissue derived from the Christakis Study in 1962, the last survivors of the initial Seven Countries Cohort in 2000 and the participants of the MESSARA study in 2005 are noted in Table 3. The qualitative differences noted were almost all highly statistically significant $(p<0.001)$. An increase in the saturated fats 14:0, 16:0 and 18:0 between the Christakis study participants and the MESSARA study participants was noted with a $p$-value of $p<0.001, p<0.001$ and $p=0.007$ respectively when comparing men of the same age group, from the same area, 43 years later. . For means of simplicity and categorised according to their level of saturation an increase in the percentage of saturated fats as also a significant decrease in the percentage of monounsaturated and polyunsaturated fats is noticeable during this 43 year period $(p<0.001)$.

Table 3. Subcutaneous gluteal adipose tissue fatty acid profile of farmers in Crete in 1962 and 2005 and in 2000 among the 40 year survivors of the initial cohort of the Seven Countries Study.

\begin{tabular}{|c|c|c|c|c|c|c|c|c|}
\hline \multirow{3}{*}{$\begin{array}{l}\text { Fatty acid } \\
\text { (g/100g total fatty } \\
\text { acids) }\end{array}$} & \multirow{3}{*}{$\begin{array}{l}\text { Chain } \\
\text { length of } \\
\text { fatty acid } \\
\text { and No of } \\
\text { double } \\
\text { bonds } \\
\text { present }\end{array}$} & \multirow{3}{*}{\begin{tabular}{l} 
Messara \\
Study, 2005 \\
(aged $>45 y r s)$ \\
Messara, \\
2005, \\
$\left(n^{1}=125\right)$ \\
\multicolumn{1}{c}{ Mean }
\end{tabular}} & \multicolumn{4}{|c|}{$\begin{array}{l}\text { Christakis et al, } 1965 \text { [10] } \\
\text { (aged>45yrs) }\end{array}$} & \multirow{2}{*}{\multicolumn{2}{|c|}{$\begin{array}{l}\text { Seven Countries } \\
\text { Study, } 40 \text { year } \\
\text { follow-up, } \\
\text { aged } \geq 80 y r s \\
\text { Crete, } 2000 \\
\left(n^{1}=78\right)\end{array}$}} \\
\hline & & & \multicolumn{2}{|c|}{$\begin{array}{l}\text { Mean General } \\
\text { Crete 1962, } \\
\left(n^{1}=200\right)\end{array}$} & \multicolumn{2}{|c|}{$\begin{array}{l}\text { Sub study in the } \\
\text { Messara Valley } \\
1962,\left(n^{1}=38\right)\end{array}$} & & \\
\hline & & & Mean & $p$-value ${ }^{2}$ & Mean & $p$-value ${ }^{3}$ & Mean & $p$-value \\
\hline Myrstic & $14: 0$ & 1.30 & 1.2 & $<0.001$ & 1.0 & $<0.001$ & 1.43 & $<0.001$ \\
\hline Myristoleic & $14: 1$ & 0.13 & 0.5 & $<0.001$ & 0.4 & $<0.001$ & 0.17 & $<0.001$ \\
\hline Palmitic & $16: 0$ & 16.9 & 14.7 & $<0.001$ & 14.4 & $<0.001$ & 14.9 & $<0.001$ \\
\hline Palmitoleic & $16: 1$ & 3.5 & 6.4 & $<0.001$ & 6.0 & $<0.001$ & 3.3 & $<0.001$ \\
\hline Stearic & $18: 0$ & 2.6 & 2.4 & 0.007 & 2.5 & 0.342 & 2.5 & 0.342 \\
\hline Oleic & $18: 1$ & 58.9 & 61.9 & $<0.001$ & 60.9 & $<0.001$ & 62.7 & $<0.001$ \\
\hline Linoleic & $18: 2$ & 9.3 & 10.4 & $<0.001$ & 12.6 & $<0.001$ & 7.8 & $<0.001$ \\
\hline \multicolumn{2}{|l|}{ Saturated fatty acids } & 21.4 & 18.8 & $<0.001$ & 20.5 & $<0.001$ & 19.5 & $<0.001$ \\
\hline \multicolumn{2}{|c|}{ Mono-unsaturated fatty acids } & 65.7 & 68.0 & $<0.001$ & 68.0 & $<0.001$ & 69.6 & $<0.001$ \\
\hline \multicolumn{2}{|c|}{ Poly-unsaturated fatty acids } & 11.6 & 12.3 & $<0.001$ & 11.5 & 0.719 & 9.6 & $<0.001$ \\
\hline
\end{tabular}

${ }^{1}$ Numbers differ according to the number of samples that were available and analysed in each of the study; ${ }^{2}$ Crete 1962 vs. Messara 2005, One sample Student t-test; ${ }^{3}$ Messara 1962 vs. Messara 2005, One sample Student t-test; ${ }^{4}$ Seven Countries Study 2000 follow up vs. Messara 2005, One sample Student ttest. 
These results were derived both in comparison to the general population of Crete (same age and gender) in the 1960's as also from participants from the same farming valley of Messara, in comparison to same age and gender participants 43 years later. Additionally to the above a second analysis was performed comparing the subcutaneous gluteal adipose tissue fatty acid profile of the current MESSARA study participants with that of the survivors of the original SCS cohort who were examined in 2000. Despite the age difference, these participants still retained a profile similar to that of participants in the Christakis study in the 1960's but large differences were noted with the participants of the MESSARA study for the majority of analysed fatty acid esters as depicted above in Table $\mathbf{3}$.

\section{DISCUSSION}

This is the first study to revisit the areas of the Cretan cohort of the SCS, and investigate into CVD risk factors of farmers the same age group of the farmers of the SCS, 45 years after its completion. The cardiovascular risk factors of the current farming population of Crete have altered and although historically being known to hold the title of the "gold standard" of health status globally their cardiovascular risk factors have significantly changed over the past 45 years. Significant differences in the risk factors for the development of CVD in comparison to farmers from Crete in the 1960's were noted in regards to the current populations unfavourable lipid profile, physical inactivity, elevated BMI and non adherence to the Mediterranean diet as verified by both dietary and clinical biomarker data. On the other hand current day farmers were found to have a significantly lower SBP and lower energy intake, and a slightly lower prevalence of smoking (albeit non significant).

High blood pressure, diabetes mellitus, smoking and hypercholesteraimia are well established risk factors for CVD, therefore their correct management and monitoring within primary care is imperative so as to reduce the burden of CVD at both an individual and at a population based level [20-21]. The changes in the prevalence of the risk factors for the development of CVD come to reflect the cultural social and scientific differences between rural Crete of the 1960's and today. The decrease in the mean SBP $(-8 \%)$ and in the percentage of the population with SBP>130 $(-26 \%)$ is likely to be due to the improvement in hypertensive treatment and primary care prevention as part of the global effort to reduce the burden of hypertension [2223]. On the other hand, the $16 \%$ increase in the populations total cholesterol level as also the $30 \%$ increase in mean BMI are a formidable indicator of their excess risk for the development of CVD [24-28]. Prospective follow up cohorts, as the 20, 25 and 40 year follow-ups on the survivors of the initial SCS cohort have demonstrated at a population based level the significance on both cholesterol and BMI on CVD, cancer and general mortality [9, 28-31]. This noted difference in mean cholesterol levels and mean BMI between the initial SCS cohort from Crete and the MESSARA study participants is stressed by the fact that even among the initial participants 
and subsequent 25 year follow up survivors of the SCS, the highest coefficient for mortality found in the multivariate analysis in Greece was for blood cholesterol. On the other hand, SBP and smoking were not statistically related with mortality among the Greek population, which still had one of the lowest coronary heart disease mortality 25 years into the follow up (34.5 CHD death rate per 1000 vs. 221.7 for the Finnish cohort and $\mathbf{1 7 3 . 9}$ for the Dutch) [28]. It is possible that the infrastructural development of rural Crete and the mechanisation of traditional farming are just a few of the changes noticed in rural Crete that might and are likely to have played a part in the increase in the populations elevated BMI. While over $60 \%$ of the participants of the SCS habitually engaged in hard physical work and only $7 \%$ were estimated to live sedentary lifestyles, much different to the low percentage of physical activity noted among current farmers from Crete [15].

Since antiquity the Greek population followed to consume a traditional dietary pattern, known as the Mediterranean diet of Crete. This diet is low in saturated fat and red meat consumption but high in monounsaturated fat (obtained mainly through the elevated intake of olive oil), antioxidants and vitamins (from fresh fruit, wild greens, vegetables, nuts and legumes) [14]. A significant part of the traditional lifestyle of Crete of the 1960's was also the populations high adherence to the traditional fasting days of the Christian Orthodox Church, (a kind of periodic vegetarian diet in which certain types of seafood i.e. cephalopods and molluscs are allowed), which recently have been shown to favourably effect blood pressure and cholesterol levels as well as nutrient intake [16, 32-33]. The mean daily dietary intake of saturated, polyunsaturated and monounsaturated fat has altered over the past 45 years (by $+9 \%,+10 \%$ and $-10 \%$ respectively) among $40-60$ year old's. These results likely indicate a lower adherence to the Mediterranean diet and a decrease most likely in olive oil consumption as verified by the decrease in daily monounsaturated fat intake, a fact that in correlation with the increased protein intake could explain the difference in calorie intake over the past 45 years. Moreover the differences in the dietary habits between 1960 and 2000 among the participants of the SCS could be attributable to both less adherence to the Mediterranean diet as also the dietary habits of the elderly as the remaining survivors of the SCS were in the year 2000, 80-96 year olds. It has been speculated that modern-life prototypes, less time in preparing the meals at home; and the increased cost of olive oil, fish, cereals, fruits and vegetables, instead of other fats and animal products, may have lead southern Mediterranean populations away from this healthy dietary patter, a hypothesis with which we agree to [34].

These above findings although previously noticed among some urban populations in Greece, they have never been found among the rural population, especially that of Crete [35]. The use of adipose tissue as a biomarker of dietary intakes was applied as a method of evaluating long term, chronic dietary intakes. The noted increase in the SFA and the decrease in the MUFA of adipose tissue among farmers 
from Crete over the past 45 years give a clear insight into the abandoning of the traditional Mediterranean diet of Crete and the adoption of a more westernised "modern" diet. Furthermore, the qualitative changes in adipose tissue content between the three studies (MESSARA, SCS and the Christakis Study) are indicative of the increase in cardiovascular risk, as the ratio of adipose tissue fatty acids is a clear marker of CVD and related to mortality [36].

As adherence to the Mediterranean diet has a protective effect on obesity, acute CVD episodes and lowers overall mortality, the gradual trend of the populations move towards a more northern European diet, (replacing saturated with monounsaturated fat), would also have a significant effect on the health status of the population [37-40]. Moreover, as shown among the survivors of the SCS adherence to a Northern European diet, which is high in saturated fat and cholesterol, is an important determinant of CVD and related death [40-41].

This study provides a historical insight into the change in CVD risk factors among the Cretan population. Historically they reaped the benefits of a long life expectancy and the pinnacle of health status globally and whose renowned Mediterranean diet has been adhered to by millions around the globe. The study's epidemiological sampling approach and methodology allow for our findings to be generalised for the farming population of Crete. In line the use of dietary biomarkers (adipose tissue fatty acid composition) for assessing chronic dietary habits allowed us to verify the participants' chronic dietary intakes and interpret the population's dietary changes with relative certainty. There is a possibility that laboratory differences may exist due to newer equipment, even though the methodology has remained the same over the years. Additionally, as the MESSARA study is a cross sectional study, we were unable to provide evidences for causality, although this was not the purpose of the study. Further research is needed to investigate into the behavioural, social and cultural changes that induced the current CVD risk status and the noticed lack of adherence to the classical Mediterranean lifestyle and diet.

\section{Conclusions}

Conclusively, the dietary habits and the CVD risk factors of the farming population of Crete have significantly changed over the past 45 years, indicative of their increasing risk for acute and chronic disease development. Although historically known for their low CVD prevalence currently farmers from Crete are possibly at a higher risk for developing CVD in comparison to their "model" previous generations. 


\section{ACKNOWLEDGEMENTS}

The authors would like to present and to thank the field researchers of the Messara Study, Dr Manolis Papadakis and Dr Nikos Drakonakis from the Health Centre of Haraka, as also Sofia Flouri, Natalia Tsoumani, Magda Vatsina, Maria Paravoliasi and Froso Bervanaki. We are also grateful to the local authorities and the personnel from the rural health centres of Messara for their assistance, the rural population of Messara, Crete and the governing body of the prefecture of Heraklion, Crete for their funding.

Disclosures: None competing interests to declare.

Funding source: Research grant from the governing body of the prefecture of Heraklion 


\section{REFERENCES}

1. Kromhout D. Epidemiology of cardiovascular diseases in Europe. Public Health Nutr. 2001; 4:44157.

2. OECD health indicators, 2005. Health at a glance OECD publishing.

3. Sans S, Kesteloot H, Kromhout D on behalf of the Task Force. The burden of cardiovascular diseases mortality in Europe. Task force of the European Society of Cardiology on Cardiovascular Mortality and Morbidity Statistics in Europe. Eur Heart J. 1997; 18: 1231-48

4. Keys A (editor). Coronary heart disease in seven countries. Circulation. 1970; 41(suppl 1): 1-211.

5. Renaud S., de Lorgeril M., Delaye J, Guidollet J, Jacquard F, Mamelle N, et al. Cretan Mediterranean diet for prevention of coronary heart disease. Am J Clin Nutr 1995; 61 (suppl.): 1360S-1367S

6. De Lorgeril M, Renaud S, Mamelle N, Salen P, Martin J.L, Monjaud I, et al. Mediterranean alphalinolenic acid-rich diet in the secondary prevention of coronary heart disease. Lancet. 1994; 343 : 1454-1459

7. Trichopoulos D, Lagiou P. Mediterranean diet and overall mortality differences in the European Union. Public Health Nutr. 2004; 7(7):949-51.

8. Panagiotakos DB, Pitsavos C, Chrysohoou C, Skoumas J, Tousoulis D, Toutouza M, et al. Impact of lifestyle habits on the prevalence of the metabolic syndrome among Greek adults from the ATTICA study. Am Heart J. 2004; 147(1):106-12

9. Menotti A, Lanti M, Kromhout D, Blackburn H, Nissinen A, Dontas A, et al. Forty-year coronary mortality trends and changes in major risk factors in the first 10 years of follow-up in the seven countries study. Eur J Epidemiol. 2007; 22(11): 747-54.

10. Christakis G, Severinghaus EL, Maldonado Z, Kafatos F, Hashim S. Crete: a study in the metabolic epidemiology of coronary heart disease. Am J Cardiology. 1965; 15(3): 320-332

11. Kromhout D, Keys A, Aravanis C, Buzina R, Fidanza F, Giampaoli S, et al. Food consumption patterns in the 1960's in seven countries. Am J Clin Nutr. 1989; 49:889-94

12. Mamalakis G, Jansen E, Cremers H, Kiriakakis M, Tsibinos G Kafatos A. Depression and adipose and serum cholesteryl ester polyunsaturated fatty acids in the survivors of the seven countries study population of Crete. Eur J Clin Nutr 2006; 60:1016-1023

13. WHO: World Health Organization. Obesity: preventing and managing the global epidemic. WHO/NUT/98.1. Geneva, Switzerland: World Health Organization 1998.

14. Vardavas C.I, Linardakis M, Hatzis C, Saris W.H.M, Kafatos A. Prevalence of obesity and physical inactivity among farmers from Crete (Greece), four decades after the seven countries study. Nutr Metab Cardiovasc Dis. 2009; 19(3):156-62

15. Kafatos AG, Verhagen H, Moschandreas J, Apostolaki I, Van Westerop J. Mediterranean diet of Crete: foods and nutrient content. J Am Diet Assoc. 2000; 100:1487-1493.

16. Sarri K, Linardakis M, Codrington $C$, Kafatos A. Does the periodic vegetarianism of Greek Orthodox Christians benefit blood pressure? Prev Med. 2007; 44(4):341-8.

17. Vardavas $\mathrm{Cl}$, Linardakis $\mathrm{M}$, Hatzis $\mathrm{C}$, Malliaraki N, Saris W, Kafatos A. Smoking status in relation to serum and dietary vitamin and micronutrient concentrations. Tob Induc Dis 2008; 4:8.

18. Beynen A.C. and Katan M.B. Why do polyunsaturated fatty acids lower serum cholesterol? Am J Clin Nutr 1985; 42: 560-563.

19. Metcalfe LD, Schmitz AA, Pekka, JR. Rapid preparation of fatty acid esters from lipids for gas chromatographic analysis, Ann Chem. 1966; 18: 514-515.

20. Zachariadou T, Stoffers HE, Christophi CA, Philalithis A, Lionis C. Implementing the European guidelines for cardiovascular disease prevention in the primary care setting in Cyprus: lessons learned from a health care services study. BMC Health Serv Res. 2008;8(1):148. 
21. Kok L, Engelfriet P, Jacobs-van der Bruggen MA, Hoogenveen RT, Boshuizen HC, Verschuren MW. The cost-effectiveness of implementing a new guideline for cardiovascular risk management in primary care in the Netherlands. Eur J Cardiovasc Prev Rehabil. 2009;16(3):371-6.

22. Danon-Hersch N, Marques-Vidal P, Bovet P, Chiolero A, Paccaud F, Pécoud A, et al. Prevalence, awareness, treatment and control of high blood pressure in a Swiss city general population: the CoLaus study. Eur J Cardiovasc Prev Rehabil. 2009; 16(1):66-72.

23. Levi F, Chatenoud L, Bertuccio P, Lucchini F, Negri E, Vecchia CL. Mortality from cardiovascular and cerebrovascular diseases in Europe and other areas of the world: an update. Eur J Cardiovasc Prev Rehabil. 2009; 16(3):333-350

24. Moschandreas J, Kafatos A, Aravanis C, Dontas A, Menotti A, Kromhout D. Long-term predictors of survival for the Seven Countries Study cohort from Crete: from 1960 to 2000. Int J Cardiol. 2005; 100(1):85-91.

25. Romero-Corral A, Montori V, Somers V, Korinek J, Thomas RJ, Allison TG et al. Association of bodyweight with total mortality and with cardiovascular events in coronary heart disease: a systematic review of cohort studies. Lancet. 2006; 368:666-78

26. Pitsavos C, Panagiotakos DB, Menotti A, Chrysohoou C, Skoumas J, Stefanadis C, et al. Forty-year follow-up of coronary heart disease mortality and its predictors: the Corfu cohort of the seven countries study. Prev Cardiol. 2003;6(3):155-60

27. Menotti A, Lanti M, Nedeljkovic S, Nissinen A, Kafatos A, Kromhout D. The relationship of age, blood pressure, serum cholesterol and smoking habits with the risk of typical and atypical coronary heart disease death in the European cohorts of the Seven Countries Study. Int J Cardiol. 2006; 106(2):157-63.

28. Menotti A, Blackburn H, Kromhout D, Nissinen A, Adachi H, Lanti M. Cardiovascular risk factors as determinants of 25-year all-cause mortality in the seven countries study. Eur J Epidemiol. 2001; 17(4):337-46.

29. Menotti A, Keys A, Blackburn H, Kromhout D, Karvonen M, Nissinen A, et al. Comparison of multivariate predictive power of major risk factors for coronary heart diseases in seven countries: results from eight nations of the Seven Countries Study, 25 year follow up. J Cardiovasc Risk. 1996; 3:69-75

30. Menotti A, Keys A, Aravanis C, Blackburn H, Dontas A, Fidanza F, et al. Seven Countries Study. First 20 year mortality data in 12 cohorts of six countries. Ann Med. 1989; 21:175-179

31. Panagiotakos DB, Pitsavos C, Polychronopoulos E, Chrysohoou C, Menotti A, Dontas A, et al. Total cholesterol and body mass index in relation to 40 year cancer mortality (The corfu cohort of the Seven Countries Study). Cancer Epidemiol Biomarkers Prev. 2005; 14(7):1797-1801

32. Papadaki A, Vardavas C, Hatzis C, Kafatos A. Nutrient and food intake during a Greek Orthodox Fasting and non fasting week. Public Health Nutr. 2007; 20:1-8

33. Sarri KO, Tzanakis NE, Linardakis MK, Mamalakis GD, Kafatos AG. Effects of Greek Orthodox Christian Church fasting on serum lipids and obesity. BMC Public Health. 2003; 3:16.

34. Panagiotakos DB, Matalas AL. Back to the ancient diet: A matter of urgency for southern European countries. Nutr Metab Cardiovasc Dis. 2009; 19:153-155

35. Panagiotakos DB, Tzima N, Pitsavos C, Chrysohoou C, Zampelas A, Toussoulis D, et al. The association between adherence to the Mediterranean diet and fasting indices of glucose homoeostasis: the ATTICA Study. J Am Coll Nutr. 2007; 26(1):32-8.

36. Harris $W$, Poston $W$, Haddock K. Tissue $n-3$ and $n-6$ fatty acids and risk for coronary heart disease events. Atherosclerosis. 2007; 193: 1-10

37. Trichopoulou A, Costacou T, Bamia C, Trichopoulos D. Adherence to a Mediterranean diet and survival in a Greek population. N Engl J Med. 2003; 348(26):2599-608. 
38. Mendez MA, Popkin BM, Jakszyn P, Berenguer A, Tormo MJ, Sanchéz MJ, et al. Adherence to a Mediterranean diet is associated with reduced 3-year incidence of obesity. J Nutr. 2006; 136: 2934-8.

39. Sánchez-Taínta A, Estruch R, Bulló M, Corella D, Gómez-Gracia E, Fiol M, et al. Adherence to a Mediterranean-type diet and reduced prevalence of clustered cardiovascular risk factors in a cohort of 3,204 high-risk patients. Eur J Cardiovasc Prev Rehabil. 2008; 15(5):589-93.

40. Verschuren WM, Jacobs DR, Bloemberg BP, Kromhout D, Menotti A, Aravanis C, et al. Serum total cholesterol and long-term coronary heart disease mortality in different cultures. Twenty-five-year follow-up of the seven countries study. JAMA. 1995; 274(2):131-6.

41. Kromhout D, Menotti A, Bloemberg B, Aravanis C, Blackburn H, Buzina R, et al. Dietary saturated and trans fatty acids and cholesterol and 25-year mortality from coronary heart disease: the Seven Countries Study. Prev Med. 1995; 24(3):308-15. 


\section{CHAPTER 3}

\section{PREVALENCE OF OBESITY AND PHYSICAL INACTIVITY AMONG FARMERS FROM CRETE (GREECE), FOUR DECADES AFTER THE SEVEN COUNTRIES STUDY}

\section{THE MESSARA STUDY}

Constantine I. Vardavas, Manolis Linardakis, Christos Hatzis, Wim H.M Saris, Anthony Kafatos

Nutrition Metabolism and Cardiovascular Disease 2009; 19:156-162 


\section{ABSTRACT}

Background-Aim: As first shown 40 years ago farmers from Crete had one of the healthiest lifestyles compared to other participants of the Seven Countries Study. Taking the above into account we investigated into the prevalence of obesity and its indexes among farmers in Crete in 2005.

Methods- Results: 502 farmers (18-79 years old) from the Valley of Messara in Crete were randomly selected and examined. Body Mass Index (BMI), waist circumference (WC), waist-to-hip ratio (W/Hip Ratio), waist-to-height ratio (W/Height Ratio), conicity index, percentage of body fat and hours of daily light physical activity (LPhA) and moderate-to-vigorous physical activity (MVPhA) were calculated for each subject. $86,1 \%$ of the study population was overweight and/or obese. Specifically $42.9 \%$ had a BMI of $25.1-30 \mathrm{~kg} / \mathrm{m}^{2}$ and were overweight and $43.2 \%$ were obese with a $\mathrm{BMI}>30 \mathrm{~kg} / \mathrm{m}^{2}$. The percentage of body fat was estimated at $27.3 \%$ of total body weight among males and $39.3 \%$ among females, while all obesity indexes were found to differ between gender.

Conclusions: In comparison to middle aged male farmers from Crete in the 1960's, mean weight has increased by $20 \mathrm{~kg}$ ( $83 \mathrm{~kg}$ vs. $63 \mathrm{~kg}$ ), which has lead to an $7 \mathrm{~kg} / \mathrm{m}^{2}$ in mean BMI $\left(22.9 \mathrm{~kg} / \mathrm{m}^{2}\right.$ vs. $\left.29.8 \mathrm{~kg} / \mathrm{m}^{2}\right)$, findings that support the fact that the prevalence of obesity in Greece has risen dramatically over the years, even among farmers from Crete, a population historically known for being the gold standard of health status globally. 


\section{INTRODUCTION}

In the past, the Greek population, specifically that of Crete, was known to have very low rates of cardiovascular disease (CVD) and cancer compared to other five other countries in Europe, to the US and to Japan, as first discovered during the Seven Countries Study (SCS) [1]. The population of Crete, adhered to the traditional farmers way of life, with a diet based on the high consumption of vitamins fibre and antioxidants, through the consumption of olive oil, wild greens, fruits, whole wheat bread and legumes, walnuts, almonds and snails, supplemented with a rare to moderate consumption of red meat, fish and dairy products [2]. Farmers in the 1960 's also had elevated levels of daily moderate to high physical exercise, due to the little mechanical assistance used in farming, until recently [3]. The result of such a lifestyle was naturally a low Body Mass Index (BMI), a factor lowering the population's risk for cancer, chronic and cardiovascular disease. Long time follow ups of both the Cretan and the Corfu cohorts of the SCS have elaborated the fact that adherence to a Mediterranean style diet and lifestyle is accompanied by a significant reduction in mortality, a lifestyle globally recognised as an ideal avenue for promoting health and preventing disease [3-4].

Affecting insulin resistance, lipid metabolism and promoting systemic inflammation, obesity predisposes to a number of non communicable diseases such as hypertension, dyslipidaimia and type II diabetes [5-6]. The association between bodyweight and both total and cardiovascular disease mortality is well documented [7]. Population based follow up studies have clearly demonstrated the relationship between increased obesity indexes and both acute and chronic cardiovascular disease [8-10].

The above facts are alarming when one takes into account the rise in the prevalence of obesity globally. It is estimated that there are approximately 1000 million overweight and 300 million obese adults worldwide [11]. Greece, unfortunately has not avoided the maelstrom, since epidemiological studies have shown that the prevalence of obesity is not only elevated among adults, but also among children and adolescents [12-13]. Taking the above into account, the purpose of this epidemiological study was to estimate the prevalence of overweight, obesity and physical exercise among farmers in the valley of Messara in Crete, Greece and to compare them with previous rates found among farmers from rural Crete and other populations currently within Greece.

\section{RESEARCH METHODS AND PROCEDURES}

The MESSARA study was carried out between February and June 2005. The purpose of the study was to estimate the prevalence of cancer, cardiovascular and chronic disease and their risk factors among the farming population in the valley of Messara in Southern Crete. 


\section{Sampling}

Farmers ( $n=662)$ from the valley of Messara in southern Crete, Greece were randomly selected by using the six municipality's voting lists using a random stratified sampling methodology, with the number of participants in each of the 24 villages selected according to the villages total farming population. A participant was regarded as a farmer if his main occupation was farming and/or sheep breeding, and was concurrently insured by the farmer's social insurance fund. Out of the 662 people randomly selected, 599 accepted to participate $(90,5 \%)$ out of which 505 were finally examined with $44 \%(n=223)$ of the participants' male and $56 \%(n=282)$ of female gender respectively (age 18-79). Regarding the participants level of education males were higher educated than females $(p=0.011) .63 .5 \%$ of males and $72,6 \%$ of females had $<6$ years of education, $30,1 \%$ of males and $25,5 \%$ of females held only a high school degree and university degrees were held by $6,4 \%$ of males and $1.8 \%$ of females respectively.

All examinations were conducted by a trained research team at each village, after participants were informed about the study and written consent was given. Approval to conduct the survey was granted by the Ethical Committee of the University of Crete while the prefecture of Heraklion's governing authority granted funding.

\section{Classification of adiposity and physical activity}

A digital scale (Seca) was used to measure body weight (BW) with an accuracy of \pm $100 \mathrm{~g}$. Subjects were weighed without shoes, in their underwear or light clothing. Standing body height $(\mathrm{BH})$ was measured without shoes to the nearest $0.5 \mathrm{~cm}$ with the use of a commercial stadiometer with the shoulders in a relaxed position and the arms hanging freely. BMI was calculated as BW in kilograms $(\mathrm{kg})$ divided by the square of the $\mathrm{BH}$ in meters $\left(\mathrm{m}^{2}\right)$. Waist circumference (WC) was measured in the middle between $12^{\text {th }}$ rib and iliac crest at the level of umbilicus and the hips circumference $(\mathrm{HC})$ at the fullest point around the buttocks. WC $(\mathrm{cm})$ was divided by $\mathrm{HC}$ $(\mathrm{cm})$ and $\mathrm{BH}(\mathrm{m})$ in order to calculate the waist-to-hip (W/Hip) and waist-to-height (W/Height) ratio respectively. The percentage of body fat was assessed by measuring the thickness of subcutaneous adipose tissue in millimetres using a Lange skin fold calliper. The skin fold thickness was measured twice on the left side of the body at four sites: biceps and triceps (limb), sub scapular and supra iliac (trunk). The sum of the four skin fold thickness measures were considered an indicator of total subcutaneous fat according to the participant's sex and age [14]. BMI was calculated as weight (in kg) divided by height (in meters) squared. According to the WHO classification one was defined as overweight if their BMI was between 25 and $29.9 \mathrm{~kg} / \mathrm{m}^{2}$ and obese if their BMI was $\geq 30 \mathrm{~kg} / \mathrm{m}^{2}$ [15]. WC cut-offs were defined as $>102 \mathrm{~cm}$ for male and $>88 \mathrm{~cm}$ for female participants. The participants conicity index $(\mathrm{Cl})$ was calculated as a means of calculating abdominal adiposity as it is a 
function of abdominal girth, weight and height. The $\mathrm{Cl}$ has been claimed to have several advantages over other obesity indexes due to the fact that it has an adjustment for height and weight and that it does not need hip circumference to assess fat distribution [16]. Greek Orthodox Christian fasting days per year were noted and included into the investigation due to their acknowledged role in the health status of the Greek population [17-18]. Energy intake was calculated with the use of three day record dietary questionnaires $(n=251)$ and 24 hour dietary questionnaires $(n=249)$. Further information on the population's daily dietary and energy intake can be found elsewhere [19].

Light physical activity (LPhA) and moderate to vigorous physical activity (MVPhA) was calculated using a weighted weekday and weekend physical activity questionnaire used in previous studies, as also in Crete [20-22]. This questionnaire divides daily activities into 5 categories with a different yield coefficient for each activity level (sedentary hours have a coefficient of 1.0; very light activity has a coefficient of 1.5; light activity has a coefficient of 2.5; while moderate and heavy activity levels have coefficients of 5.0 and 7.0 respectively). The sum of which is multiplied by the hours performed per day and then divided by the 24 hours in each day to provide the PAL.

\section{Statistical analysis}

For means of analysis and easy comparison with other studies the anthropometric results were classified according to $\mathrm{BMI}$ and age. The age groups used were 18-39, 40-59 and 60-80 and the BMI cut-offs for overweight and obesity were as described above. All P-values are based on two-sided tests and a significance level of $5 \%$. Continuous variables are presented as mean \pm standard deviation, while qualitative variables were depicted with the use of frequencies. Finally, obesity and physical activity indexes were compared with the Student t-test (equal variances were not assumed during the analysis). The chi- squared test $\left(\chi^{2}\right)$ was used to investigate differences in prevalence of overweight and obesity between both genders in each age group. During the investigation regarding the possible factors that influence the obesity indexes of the population a multiple stepwise linear regression analysis was performed. Independent variables in this analysis included the participants' gender, age in years, educational level, smoking status (smokers, ex/non smokers), PAL, energy intake (in kcal) and fasting days per year. The participants' educational status was grouped according to their years of education: elementary/none (0-6 years), high school (6-12 years) and higher education (12+ years). The statistical analysis was performed with the statistical package SPSS 16.0. (Statistical Package for Social Sciences, SPSS, Inc, Illinois, USA) 


\section{RESULTS}

Eighty six percent (86.1\%) of the study population was overweight and/or obese. Specifically $42.9 \%$ had a BMI of $25.1-30$ and were overweight (52\% of male and $33.7 \%$ of female participants) and $43.2 \%$ were obese with a BMI $>30 \mathrm{~kg} / \mathrm{m}^{2}(35.7$ $\%$ of male and $50.7 \%$ of female participants. On the whole female participants were more obese than male and this difference was statistically significant $(p<0.001)$. Waist circumference also differed between both genders $(p<0.001)$ with $40.3 \%$ of males and $85.8 \%$ of females found to have a waist circumference greater than 102 / 88. Table 1 depicts the prevalence of overweight, obesity and waist circumference measurements of the study sample, according to the age groups specified above.

Table 1. Prevalence of overweight and obesity according to Body Mass Index and waist circumference measurements of the study sample.

\begin{tabular}{|c|c|c|c|c|c|}
\hline \multirow[b]{2}{*}{ Age (yrs) } & \multirow[b]{2}{*}{ Anthropometric Measurements } & & Males & Females & \multirow[b]{2}{*}{$P$-value } \\
\hline & & & $\%(N)$ & $\%(N)$ & \\
\hline \multirow[t]{3}{*}{$18-39$} & Body Mass Index $\left(\mathrm{kg} / \mathrm{m}^{2}\right)$ & $25.1-30$ & $61.5(32)$ & $31.9(23)$ & \multirow{2}{*}{0.002} \\
\hline & & $>30$ & $25.0(13)$ & $30.6(22)$ & \\
\hline & Waist circumference $(\mathrm{cm})$ & $>102 / 88$ & $21.2(11)$ & $65.3(47)$ & $<0.001$ \\
\hline \multirow[t]{3}{*}{$40-59$} & Body Mass Index $\left(\mathrm{kg} / \mathrm{m}^{2}\right)$ & $25.1-30$ & $47.1(57)$ & $37.4(55)$ & \multirow{2}{*}{ ns } \\
\hline & & $>\mathbf{3 0}$ & $41.3(50)$ & $53.1(78)$ & \\
\hline & Waist circumference $(\mathrm{cm})$ & $>102 / 88$ & $43.0(52)$ & $90.5(133)$ & $<0.001$ \\
\hline \multirow[t]{3}{*}{$60-80$} & Body Mass Index $\left(\mathrm{kg} / \mathrm{m}^{2}\right)$ & $25.1-30$ & $55.3(26)$ & $27.0(17)$ & \multirow{2}{*}{0.001} \\
\hline & & $>30$ & $31.9(15)$ & $68.3(43)$ & \\
\hline & Waist circumference $(\mathrm{cm})$ & $>102 / 88$ & $53.2(25)$ & $98.4(62)$ & $<0.001$ \\
\hline \multirow[t]{3}{*}{ Total } & Body Mass Index $\left(\mathrm{kg} / \mathrm{m}^{2}\right)$ & 25.1-30 & $52.0(115)$ & 33.7 (95) & \multirow{2}{*}{$<0.001$} \\
\hline & & $>\mathbf{3 0}$ & 35.7 (79) & $50.7(143)$ & \\
\hline & Waist circumference $(\mathrm{cm})$ & $>102 / 88$ & $40.3(89)$ & $85.8(242)$ & $<0.001$ \\
\hline
\end{tabular}

\# Chi-square test

ns: statistically not significant difference

As shown in Table 2 the mean BMI of the total population was $29.3 \mathrm{~kg} / \mathrm{m}^{2}$ in males and $30.6 \mathrm{~kg} / \mathrm{m}^{2}$ among females, whilst the percentage of body fat calculated using skin fold thickness was estimated at $27.3 \%$ of total body weight among males and $39.3 \%$ of total body weight among females. Both BMI and waist circumference were statistically related to gender with a $p$-value of 0.007 and $<0.001$ respectively. Similar findings were also found regarding WC (males $100.4 \mathrm{~cm}$, females $102.7 \mathrm{~cm}$, $p=0.037$ ), W/Hip ratio (males 0.99 , females $0.96, p=0.001$ ) and $W /$ Height ratio (males 0.60, females $0.66, \mathrm{p}<0.001$ ). 
Table 2. Anthropometric measurements of the study sample classified according to age group.

\begin{tabular}{|c|c|c|c|c|c|c|}
\hline \multirow[b]{2}{*}{ Age (yrs) } & & \multicolumn{2}{|c|}{ Males } & \multicolumn{2}{|c|}{ Females } & \multirow[b]{2}{*}{$P$-value } \\
\hline & & $\mathbf{N}$ & Mean (SD) & $\mathbf{N}$ & Mean (SD) & \\
\hline \multirow[t]{8}{*}{$18-39$} & Body Mass Index $\left(\mathrm{kg} / \mathrm{m}^{2}\right)$ & 52 & $28.6(4.5)$ & 72 & $27.8(6.2)$ & ns \\
\hline & Waist circumference $(\mathrm{cm})$ & & $95.3(12.8)$ & & $94.4(15.4)$ & ns \\
\hline & Waist-to-hip ratio & & $0.93(0.08)$ & & $0.91(0.08)$ & ns \\
\hline & Waist-to-height ratio & & $0.55(0.07)$ & & $0.59(0.09)$ & 0.008 \\
\hline & \% Body Fat & & $22.6(4.3)$ & & $33.6(5.3)$ & $<0.001$ \\
\hline & Conicity Index & & $1.24(0.08)$ & & $1.30(0.09)$ & $<0.001$ \\
\hline & LPhA (hours/day) & & $3.3(2.3)$ & & $5.0(3.1)$ & 0.001 \\
\hline & MVPhA (hours/day) & & $7.4(4.4)$ & & $4.8(4.0)$ & 0.001 \\
\hline \multirow[t]{8}{*}{$40-59$} & Body Mass Index $\left(\mathrm{kg} / \mathrm{m}^{2}\right)$ & 121 & $29.8(4.7)$ & 147 & 30.9 (4.9) & ns \\
\hline & Waist circumference $(\mathrm{cm})$ & & $101.6(10.5)$ & & $103.4(12.1)$ & ns \\
\hline & Waist-to-hip ratio & & $1.01(0.07)$ & & $0.97(0.08)$ & $<0.001$ \\
\hline & Waist-to-height ratio & & $0.61(0.06)$ & & $0.66(0.08)$ & $<0.001$ \\
\hline & \% Body Fat & & $28.7(5.3)$ & & $40.5(4.5)$ & $<0.001$ \\
\hline & Conicity Index & & $1.32(0.07)$ & & $1.37(0.09)$ & $<0.001$ \\
\hline & LphA (hours/day) & & $3.8(2.8)$ & & $5.0(2.6)$ & $<0.001$ \\
\hline & MVPhA (hours/day) & & $6.4(4.0)$ & & $5.1(3.6)$ & 0.006 \\
\hline \multirow[t]{8}{*}{$60-80$} & Body Mass Index (kg/m²) & 47 & $28.9(3.4)$ & 63 & $32.8(5.2)$ & $<0.001$ \\
\hline & Waist circumference $(\mathrm{cm})$ & & $102.5(11.0)$ & & $110.8(11.2)$ & $<0.001$ \\
\hline & Waist-to-hip ratio & & $1.02(0.09)$ & & $1.02(0.11)$ & Ns \\
\hline & Waist-to-height ratio & & $0.62(0.06)$ & & $0.73(0.07)$ & $<0.001$ \\
\hline & \% Body Fat & & $29.0(4.6)$ & & 43.0 (3.9) & $<0.001$ \\
\hline & Conicity Index & & $1.36(0.08)$ & & $1.44(0.08)$ & $<0.001$ \\
\hline & LphA (hours/day) & & $4.2(2.5)$ & & $5.3(2.3)$ & 0.013 \\
\hline & MVPhA (hours/day) & & $5.2(3.3)$ & & $3.0(3.3)$ & 0.002 \\
\hline \multirow[t]{8}{*}{ Total } & Body Mass Index (kg/m²) & 221 & $29.3(4.4)$ & 282 & $30.6(5.6)$ & 0.007 \\
\hline & Waist circumference $(\mathrm{cm})$ & & $100.4(11.5)$ & & $102.7(14.0)$ & 0.037 \\
\hline & Waist-to-hip ratio & & $0.99(0.08)$ & & $0.96(0.10)$ & 0.001 \\
\hline & Waist-to-height ratio & & $0.60(0.07)$ & & $0.66(0.10)$ & $<0.001$ \\
\hline & \% Body Fat & & $27.3(5.6)$ & & $39.3(5.7)$ & $<0.001$ \\
\hline & Conicity Index & & $1.31(0.08)$ & & $1.37(0.10)$ & $<0.001$ \\
\hline & LphA (hours/day) & & $3.8(2.6)$ & & $5.1(2.6)$ & $<0.001$ \\
\hline & MVPhA (hours/day) & & $6.4(4.0)$ & & $4.5(3.7)$ & $<0.001$ \\
\hline
\end{tabular}

\# Student t test (equal variances not assumed) ns: statistically not significant difference

Furthermore, a stepwise linear regression analysis of the descriptive and lifestyle variables that affected the participants' obesity indexes was performed and is presented in Table 3. The participants BMI was found to be affected by their age and gender ( $p<0.001$ and $p=0.009$ respectively) and their WC by their age and daily energy intake. The educational status of the population was found to be correlated both to their WC/height ratio and to their $\mathrm{Cl}$ with a $p$-value of $p=0.008$ and $p=0.022$ 
respectively. Additionally the participants $\mathrm{Cl}$ was found to be affected according to gender $(p<0.001)$, daily energy intake $(p=0,019)$ and fasting days that the participant adheres to per year $(p=0.010)$.

Table 3. Regression analysis of the variables found to affect obesity indexes among Cretan farmers, participants in the Messara study.

\begin{tabular}{|c|c|c|c|c|c|}
\hline \multicolumn{3}{|c|}{ Dependent variable. Independent variable. Beta } & \multirow{2}{*}{$\frac{t}{5.76}$} & \multirow{2}{*}{$\begin{array}{l}\mathbf{R}^{2} \text { adjusted } \\
0.063\end{array}$} & \multirow{2}{*}{$\frac{p \text { p-value }}{<0.001}$} \\
\hline BMI & age & 0.253 & & & \\
\hline & gender & 0.116 & 2.63 & 0.075 & 0.009 \\
\hline \multirow[t]{2}{*}{ WC } & age & 0.362 & 8.42 & 0.145 & $<0.001$ \\
\hline & energy intake & -0.100 & -2.32 & 0.153 & 0.021 \\
\hline \multirow[t]{3}{*}{ WC/height } & age & 0.410 & 9.73 & 0.219 & $<0.001$ \\
\hline & gender & 0.326 & 8.69 & 0.333 & $<0.001$ \\
\hline & education & 0.112 & 2.64 & 0.342 & 0.008 \\
\hline \multirow[t]{5}{*}{ Conicity Index } & age & 0.473 & 10.73 & 0.260 & $<0.001$ \\
\hline & gender & 0.265 & 6.01 & 0.337 & $<0.001$ \\
\hline & education & 0.097 & 2.29 & 0.343 & 0.022 \\
\hline & fasting days & -0.110 & -2.57 & 0.349 & 0.010 \\
\hline & energy intake & -0.101 & -2.36 & 0.355 & 0.019 \\
\hline
\end{tabular}

Stepwise Linear Regression analysis (on 480 male and female farmers aged 18-75) : The independent variables used were Gender, Age (in years), Education, Smoking status (Smokers, Ex-smokers,, Nonsmokers), PAL, Energy intake (in kcal) and fasting days (in days per year)

\section{DISCUSSION}

This descriptive epidemiological study is important in the context of the history of cardiovascular epidemiology, since to our knowledge this is the first time in $\mathbf{4 0}$ years that the prevalence of overweight and obesity among a randomly selected sample of farmers in Crete, Greece has been recorded. This study notes the highest prevalence of obesity and overweight in Greece to date, and in a population that has historically been a gold standard of health.

It is of significant interest to compare our results with the results of the Seven Countries Study, which took place in Crete in the 1960s with a cohort of men from several villages, 75\% of which were farmers born between 1900 to 1919 and followed up over 40 years [1]. The mean age of the participants then was 49 years (range 40-59) and their mean BMI was $22.9 \mathrm{~kg} / \mathrm{m}^{2}$. For the same age group in our study population the mean BMI was $29.8 \mathrm{~kg} / \mathrm{m}^{2}$, almost $7 \mathrm{~kg} / \mathrm{m}^{2}$ higher than the $\mathrm{BMI}$ of farmers in Crete forty years ago. The average body weight of farmers was $63 \mathrm{~kg}$ in the 60 's during the baseline measurements of the seven countries study, 
while male participants in Messara currently have an average weight of $83 \mathrm{~kg}$, thus noting an alarming 32\% increase, a fact that can't be explained by the noted decrease in energy intake (2820kcal in the 1960's to 2412Kcal in the Messara study) $[19,23]$. The lifestyle habits of the population in rural Crete also have changed over the past forty years. Based on job related physical activity, over $60 \%$ of the men in the Seven Countries Study habitually engaged in hard physical work for which their mean energy expenditure was estimated at more than 3000 kcal per day, while only $7 \%$ of the population in the 1960s; were classified as having sedentary levels of physical activity [24], Notably, the level of physical activity among the Messara Study participants is lower, a factor further increasing the populations mortality risk [25].

A sex-specific association with overweight and obesity was also detected among participants in the MESSARA study. Females had a higher BMI, WC, W/Hip ratio, $W /$ Height ratio and percentage of body fat when compared to male participants. Such a difference in obesity indexes could possibly be attributed to the smaller amount of physical activity performed by females due to the women's traditional role in such villages (their main role still is looking after the children and household and only mildly participating in farming activities). Women of all ages were found to have a more sedentary lifestyle and noted lower levels of MVPhA and higher levels of LPhA thus affecting their daily energy expenditure and subsequently also their obesity indexes and most likely their risk for both CVD and cancer [26]. These levels of physical inactivity are comparable to those found among urban women in Greece, of which 68\% report a sedentary or low physical activity status [27].

According to the International Obesity Task Force, the prevalence of overweight and obesity in Greek men and women is the highest among European countries with $78.6 \%$ of men and $74.7 \%$ of women classified as obese and overweight, lower than the percentage derived from the results of the MESSARA study [28]. In comparison, the prevalence of overweight/obese in male participants of the ATTICA study, (which is representative of the general population in the prefecture of Attica -including Athens- and has been adopted by Surf II-WHO as the national indicators for CVD risk, including obesity) has been estimated at $73 \%$ (significantly lower than the $87.7 \%$ of our findings ( $z$-test $p<0.05$ ), while among overweight/obese female participants the difference in prevalence was even greater ( $84.4 \%$ in the MESSARA study vs. $46 \%$ of the ATTICA study, z-test, $p<0.05$ ) [12]. In the ATTICA study's rural population the prevalence of obesity was estimated at $10 \%$, a percentage that the authors had attributed to differences in occupational status. We estimated the prevalence of obesity at $43.2 \%$ among farmers, very similar to the percentage of overweight adults in the mainly urban, general population of the ATTICA study. Comparing levels of BMI, the population of the ATTICA study also had lower index levels, with a mean BMI of $27.4 \mathrm{~kg} / \mathrm{m}^{2}$ in men and $25.3 \mathrm{~kg} / \mathrm{m}^{2}$ in women compared to our $29.3 \mathrm{~kg} / \mathrm{m}^{2}$ (z-test, $p<0.0001$ ) and $30.6 \mathrm{~kg} / \mathrm{m}^{2}$ (z-test, $p<0.0001$ ) respectively. 
Our results are closer to the EPIC study findings, which among other fields also researched into overweight and obesity in 50 -64 year olds in Greece, although their study participants are not exactly representative of the general population of that age group [29]. According to the EPIC study, 81\% of Greek men and $83 \%$ of Greek women of that age group were overweight and obese. Comparing the MESSARA study findings to those of the Greek EPIC cohort the prevalence of overweight/obesity among men was lower in the latter ( $87,7 \%$ vs. $80,5 \%$, z-test $p<0.05)$ while non significant in regards to overweight/obese women ( $84.4 \%$ vs. $82.1 \%$, ztest $p=\mathrm{NS}$ )

Regarding the $\mathrm{W} / \mathrm{Hip}$ ratio we found similar results among men of that age group (1.01 vs. 0.97) but large differences among females (1.00 vs. 0.83). Regarding WC, $97 \%$ of females and $44 \%$ of males in the MESSARA study had a WC larger than specified as the normal cut-off compared to $55 \%$ and $39 \%$ of the EPIC study cohort respectively. The large difference in the prevalence in overweight and obesity between the EPIC, ATTICA and MESSARA study could be attributed to different lifestyles between the general and the farming population, even though one could hypothesize that farmers would have a better lifestyle and BMI.

Educational as also socioeconomic status has been demonstrated to have an effect on obesity indexes, physical activity levels and dietary habits in both national and internationally based studies [30-31]. The noted low educational level of the Messara study participants, is expected as this is an occupational cohort of farmers. It is highly likely that the farming population of Southern Crete is not educated enough on matters regarding physical activity, nutrition, obesity and its health indications in general and also in comparison to the general population low to their low educational status and would greatly benefit from an educational or lifestyle population based intervention. This fact is strengthened by the fact that the participants $\mathrm{W} /$ height ratio and $\mathrm{Cl}$ was found to be statistically affected by their educational level as seen in the regression analysis of the variables found to affect obesity indexes. The paradox in our analysis, that the populations $\mathrm{WC}$ and $\mathrm{Cl}$ are negatively associated with daily energy intake is most likely due to the fact that that the participants with a higher $\mathrm{WC}$ and $\mathrm{Cl}$ were of greater age and had a subsequently lower energy intake, as also to the fact that the distribution of the populations BMI was severely skewed to the right.

Due to the study's cross-sectional design we were not able to draw any firm conclusions regarding causality between the dependent and independent variables in our study. Although this is not a general population based study and therefore the results are not generalisable of the whole population of Crete, the occupational randomly stratified study design allows us to conclude on the generalisability of our results among the farming population of Crete, which has been under investigation by a number of researchers over the past half century $[1,3,4,8,24]$. 
The MESSARA study's findings prove that overweight and obesity has dramatically risen in Crete over the past forty years, and currently even surpasses the prevalence estimated in urban Athens. Farmers from Crete, once renowned as the gold standard of health status globally in the 1960's are now mostly overweight and obese. Such high levels of obesity indexes, enhanced by the low educational status of the farmers, stress the need for the creation and adoption of an educational health and nutrition policy in Greece, especially in Crete, since the population is currently been stricken by an obesity epidemic with serious adverse effects on its health.

Acknowledgements: The authors would like to present and to thank Sofia Flouri, Natalia Tsoumani, Magda Vatsina and Maria Paravoliasi, for their help in collecting the data. We are also grateful to the local authorities and the personnel from the rural health centres of Messara for their assistance and the governing body of the prefecture of Heraklion for their funding. Additionally we would like to thank the personnel from the Charaka health centre, especially $\operatorname{Dr} \mathrm{N}$ Drakwnakis and $\operatorname{Dr} \mathrm{M}$ Papadakis for their support in data collection. 


\section{REFERENCES}

1. Keys A, Blackburn H, Menotti A, et al. Coronary heart disease in seven countries. Circulation; 1970; 41(suppl 1): 1-211.

2. Kafatos AG, Verhagen H, Moschandreas J, Apostolaki I, Van Westerop J. Mediterranean diet of Crete: foods and nutrient content. J Am Diet Assoc. 2000; 100:1487-1493

3. Moschandreas J, Kafatos A, Aravanis C, Dontas A, Menotti A, Kromhout D. Long-term predictors of survival for the Seven Countries Study cohort from Crete: from 1960 to 2000. Int J Cardiol 2005; 100(1):85-91.

4. Panagiotakos DB, Pitsavos C, Polychronopoulos E, et al. Total cholesterol and body mass index in relation to 40-year cancer mortality (the Corfu cohort of the seven countries study). Cancer Epidemiol Biomarkers Prev. 2005; 14(7):1797-801.

5. Pi-Sunyer FX. The obesity epidemic: pathophysiology and consequences on obesity. Obes Res. 2002; 10 (Suppl 2):97-104

6. Kraus RM, Winston M, Fletcher BJ, Grundy SM. Obesity: impact on cardiovascular disease. Circulation. 1998; 98:1472-76

7. Romero-Corral A, Montori V, Somers V et al. Association of bodyweight with total mortality and with cardiovascular events in coronary heart disease: a systematic review of cohort studies. Lancet. 2006; 368:666-78

8. Menotti A, Blackburn H, Kromhout D, Nissinen A, Adachi H, Lanti M. Cardiovascular risk factors as determinants of 25-year all-cause mortality in the Seven Countries Study. Eur J Epidem. 2001; 17;337-346.

9. Panagiotakos DB, Pitsavos C, Chrysohoou C, Skoumas I, Stefanadis C. Five year incidence of cardiovascular disease and its predictors in Greece: the Attica Study. Vasc Med. 2008; 13(2):113-21

10. Panagiotakos DB, Pitsavos C, Chrysohoou C, Stefanadis C, Toutouza P. Risk stratification of coronary heart disease through established and emerging lifestyle factors in a Mediterranean population; Cardio2000 epidemiological study. J Cardiovasc Risk. 2001; 8:329-335.

11. World Health Organization. Global strategy on diet, physical activity and health. Chronic disease information sheets. Obesity and overweight. http://www.who.int/dietphysicalactivity/publications/facts viewed 3/8/06

12. Pitsavos C, Panagiotakos DB, Chrysohoou C, Stefanadis C. Epidemiology of overweight and obesity in a Greek adult population: the ATTICA Study. Obes Res 2004; 12(12):1914-20.

13. Magkos F, Manios Y, Christakis G, Kafatos A. Age-dependent changes in body size of Greek boys from 1982 to 2002. Obesity 2006; 14(2):289-94.

14. Darnin J \& Womersley J. Body fat assessed from total body density and its estimation from skinfold thickness measurements. Br J Nutr 1974; 32:77

15. World Health organisation. Obesity: preventing and managing the global epidemic: report of a World Health organisation Cosultation. Presented at the World Health Organisation. Geneva, Switzerland, June 3-5, 1997.

16. Valdez R, Seidell JC, Ahn YI, Weiss KM. A new index of abdominal adiposity as an indicator of risk for cardiovascular disease. A cross populational study. Int J Obes. 1993; 17:77-82

17. Sarri KO, Linardakis MK, Bervanaki FN, Tzanakis NE, Kafatos AG. Greek Orthodox fasting rituals: a hidden characteristic of the Mediterranean diet of Crete. Br J Nutr. 2004; 92(2):277-84.

18. Sarri KO, Tzanakis NE, Linardakis MK, Mamalakis GD, Kafatos AG. Effects of Greek Orthodox Christian Church fasting on serum lipids and obesity. BMC Public Health. 2003; 3:16.

19. Vardavas C.I, Linardakis M, Hatzis C, Malliaraki N, Saris W, Kafatos A. Smoking Status in Relation to Serum and Dietary Vitamin and Micronutrient Concentrations. Tob Induc Dis, 2008; 4:8

20. Sarri K, Linardakis M, Codrington C, Kafatos A. Does the periodic vegetarianism of Greek Orthodox Christians benefit blood pressure? Prev Med 2007; 44(4):341-8.

21. World Health Organization (1985) Energy and Protein Requirements. Report of a Joint FAO/ WHO/ UNU Expert Consultation Technical Report Series no. 724 Geneva WHO 
22. Lof $M$, Hannestad $U$ and Forsum E. Comparison of commonly used procedures, including the doubly- labelled water technique, in the estimation of total energy expenditure of women with special reference to the significance of body fatness. Br J Nutr 2003; 90:961- 968

23. Kromhout D, Keys A, Aravanis C, et al. Food consumption patterns in the 1960's in seven countries. Am J Clin Nutr 1989; 49:889-94

24. Kromhout D, Menotti A, Blackburn H (Editors). Prevention of Coronary Heart Disease. Diet, lifestyle and risk factors in the seven countries study. Kluwer Academic Publishers

25. Wei M, Kampert JB, Barlow CE, Nichaman MZ, Paffenbarger Jr RS, Blair SN. Relationship between low cardiorespiratory fitness and mortality in normal-weight, overweight and obese men. JAMA. 1999; 282:1547-53

26. Kruk J, Aboul-Enein HY. Physical activity in the prevention of cancer. Asian Pac J Cancer Prev. 2006; 7(1):11-21

27. Pitsavos C, Panagiotakos D, Crysohoou C, Stefanadis C. Epidemiology of cardiovascular disease risk factors in Greece: aims, design and baseline characteristics of the Attica Study. BMC Public Health. 2003; 3;32

28. International Obesity Task Force. IOTF database. March 2005. European Obesity prevalence fact sheet. http://www.iotf.org/media/europrev.htm viewed 1/8/06

29. Haftenberger M, Lahmann PH, Panico S, et al. Overweight, obesity and fat distribution in 50 to 64year-old participants in the European Prospective Investigation into Cancer and Nutrition (EPIC). Public Health Nutr 2002; 5:1147-62.

30. Tzotzas $T$, Konstantinidis $T$, Bougoulia M, Krassas GE.Factors associated with body mass index in adults from Northern Greece. Hormones (Athens). 2004; 3(2):111-9.

31. Boynton A, Neuhouser ML, Sorensen B, McTiernan A, Ulrich CM. Predictors of diet quality among overweight and obese postmenopausal women. J Am Diet Assoc 2008; 108(1):125-30. 



\section{CHAPTER 4}

\section{CALCIUM, NUTRIENT AND FOOD INTAKE OF GREEK ORTHODOX CHRISTIAN MONKS DURING A FASTING AND NON-FASTING WEEK}

Angeliki Papadaki, Constantine I. Vardavas, Christos Hatzis, Anthony Kafatos

Public Health Nutrition 2008; 11(10):1022-9. 


\section{ABSTRACT}

Objective: To assess the calcium, nutrient and food intake of Greek Orthodox Christian monks during a vegetarian-type fasting week, compared to their normal diet.

Design: Dietary data collection (using 7-day weighed food records), anthropometric and blood pressure measurements, as well as serum glucose and lipid analyses were performed during Palm Sunday week (fasting) and the week following Pentecost Sunday (non-fasting). Mean daily nutrient and food (g/day) intakes were calculated from the food records.

Setting: The study took place in two monasteries in the Municipality of Heraklion, Crete.

Subjects: The study involved ten healthy monks aged 25-65 years, with BMI>30, who had been performing fasts for the last 24.4 (SD 10.4) years and living in monasteries in Crete during April-June 2005.

Results: Nutrient and food intake profiles were more favourable during the fasting week, when participants had lower intakes of total and saturated fat and trans fatty acids, and higher intakes of dietary fibre, iron, folate, legumes and fish/seafood. Calcium intake was lower when participants fasted, whereas dairy product, meat and egg consumption increased significantly in the non-fasting week. Systolic blood pressure was significantly higher, whereas blood lipid levels were more favourable during the fasting week.

Conclusions: The periodic vegetarianism recommended by the Greek Orthodox Church contributes to the favourable profiles of several biomarkers of health among this sample of monks. The fasting rituals described are an important component of the traditional diet of Crete and should be emphasised in nutrition education programmes promoting this Mediterranean eating pattern. 


\section{INTRODUCTION}

The traditional Mediterranean diet of Crete is a dietary pattern that is promoted for its health benefits [1]. The Seven Countries study was the first study to raise interest in this diet's health-promoting qualities, due to the low overall mortality rates, low rates of chronic disease and increased longevity demonstrated by people living in Crete [2-5]. The excellent health of the population of Crete was mainly attributed to their diet, which was rich in plant foods and (mainly unrefined) cereals. In addition, the moderate intake of dairy products and the low consumption of animal foods gave a low intake of saturated fat, whereas the use of olive oil as the main source of fat in the diet provided an abundant intake of health-promoting antioxidants and plant sterols [6]. The lifestyle of the population of Crete was also characterised by moderate to vigorous daily physical activity ${ }^{2}$. Despite their rich dietary heritage, the dietary habits of the population of Crete have been deteriorating over the last four decades and have started to resemble a more 'Western' eating pattern, characterised by increased consumption of animal products and reduced intake of cereals, fruits, legumes and vegetables [5].

One of the main characteristics of the Mediterranean diet of Crete and Greece, which was ignored by the original investigators of the Seven Countries Study [7], was the periodic fasting practiced by members of the Greek Orthodox Church. In recent years, much interest has focused on this special practice that is retained and is characteristic of the Mediterranean diet of Crete and its suggested beneficial effect on dietary habits and health [8-11]. According to the Greek Orthodox Church dietary recommendations, fasting occurs at three major periods during the year: Christmas (50 days); Easter Lent (40 days); and the Assumption (15 days), in addition to almost every Wednesday and Friday. During these periods, which total approximately 180-200 days annually, the consumption of foods of animal origin, dairy products and olive oil is restricted, fish intake is allowed only during Christmas and intake of seafood and snails is always allowed [9]. Snails, in particular, are often consumed in Greece (and especially Crete), mainly in casseroles with tomatoes and wheat or vegetables but also fried in olive oil and vinegar. They are consumed mainly during spring/summer months, irrespective of fasting. However, they are a good source of protein, calcium and alpha-linolenic acid during fasting, whereas they are low in total and saturated fat [12]. Consequently, adherence to this fasting ritual results in the periodic consumption of a vegetarian diet [13], which characterises the reported Mediterranean diet of Crete and Greece $[5,14]$.

The role of calcium in the regulation of cellular processes determining health and well-being is well recognised [15]. Adequate calcium intake is critical to the acquisition of ideal peak bone mass and the maintenance of bone mineral density in adults [16-18]. Milk and dairy products are the main food sources of calcium, in addition to providing this mineral in a readily absorbable form by the body, 
whereas bioavailability of calcium from plant foods is questionable $[15,19,20]$. A growing body of evidence, however, supports the beneficial effects of fruits and vegetables on bone health [21]. Inulin, for example, a substance abundant in certain plants, such as artichokes, has been reported to increase calcium absorption,' whereas calcium absorption from low-oxalate vegetables, such as kale and broccoli, appears to be excellent $[22,23]$. In the traditional diet of Crete, dairy products are the principal source of dietary calcium, in addition to legumes, vegetables, nuts and small fish. Since the fasting rituals of the Greek Orthodox Church involve the periodic restriction of dairy products, their impact on dietary calcium intake is as yet unclear.

The aim of the present study was to add to the earlier literature examining the impact of the Greek Orthodox Christian Church's dietary recommendations on the food intake and nutrient composition of diets of adherents to this Church's fasting rituals, and to assess the adequacy of such a diet in calcium. To our knowledge, this is the first specific study evaluating the intake of this important mineral in the Mediterranean diet and, in particular, its intake during a dietary fasting period associated with a religious practice. Although calcium intake during fasting is expected to be relatively low due to the restriction of dairy products in the diet, we hypothesised that overall, dietary habits and nutrient and non-nutrient intakes would be more favourable during a fasting compared to a non-fasting period.

\section{METHODS}

\section{Participants}

A total of eleven Greek Orthodox Christian monks from the area of Heraklion, Crete participated in the present study. These men were faithful fasters, who adhered to all the Orthodox Christian Church fasting recommendations [9]. To recruit such participants, two monasteries in the Municipality of Heraklion were contacted and all monks were orally informed about the study. Eligibility criteria included males aged $25-65$ years and in good health, as determined by medical history and physical examination. Participants were ineligible if they had a history of cardiovascular, liver or renal disease; cancer; gastrointestinal disorders; diabetes; lactose malabsorption or intolerance. In addition, we did not include participants taking medication known to negatively influence calcium bioavailability (e.g. anticonvulsants, glucocorticoids), or smokers. During the study, participants were required to consume their usual diets. The monasteries did not have a central feeding system and every participant was free to prepare and consume meals of their choice. Those who met the study criteria, were willing and agreed to participate signed an informed consent form. Participation was voluntary and anonymity was ensured. The study was conducted from April 2005 to June 2005 and approval was obtained from the Medical School Ethics Committee of the University of Crete. 


\section{Study design}

Two sets of examinations were scheduled to cover one Greek Orthodox Church fasting week (Palm Sunday week) and one non-fasting week (week following Pentecost Sunday). All measurements were performed on Mondays, one day following the end of each examination period, between 08.00 and 10.00 hours and included the collection of fasting blood and 24-hour urine samples (biochemical analysis), anthropometric and blood pressure measurements, dietary intake and collection of duplicate food portions for chemical analyses, and bone mineral density measurements. This paper reports data from dietary, anthropometric and blood pressure measurements, as well as blood glucose and lipid analyses. Results not reported here will be reported in a forthcoming publication.

\section{Anthropometric measurements}

All anthropometric measurements were performed by the same researcher. Body weight was measured at both assessment weeks (fasting and non-fasting), with a portable digital scale (Seca, Hamburg, Germany, Model 770) with an accuracy of $\pm 100 \mathrm{~g}$, with participants in light clothing and without shoes. Standing height was measured once with a stadiometer (Seca, Hamburg, Germany, Model 225) measuring to the nearest $0.1 \mathrm{~cm}$ in participants without shoes, with shoulders relaxed, with arms hanging freely and with heels adducted. Body Mass Index (BMI) was calculated as weight $(\mathrm{kg})$ divided by height squared $\left(\mathrm{m}^{2}\right)$.

\section{Blood pressure measurements}

Arterial blood pressure measurements were performed during both assessment weeks, with a mercury sphygmomanometer (Focal FC-110, Tokyo, Japan), with participants resting for 10 minutes before measurements. The width of the cuff was placed at the highest possible part of the right arm, covering $50-75 \%$ of the area. The measurement was taken three times, with a 2-3 min interval between each reading. The mercury was allowed to fall $2 \mathrm{~mm} / \mathrm{s}$. Final readings of systolic and diastolic blood pressure were taken as the mean values of the second and third measurements.

\section{Blood samples}

Blood samples were drawn in the morning after a 12-hour overnight fast one day following the end of each examination period. Blood samples were drawn in EDTA sample tubes (K2E, BD Vacutainer 368861, Plymouth, UK) without stasis by venepuncture (antecubital fossa) and the serum was separated by centrifugation at $1100 \times \mathrm{g}$ for $10 \mathrm{~min}$ at $4^{\circ} \mathrm{C}$ (HERMLE Z400K, rpm 4000, Wehingen, Germany) and frozen at $-80^{\circ} \mathrm{C}$ until assayed. Serum total cholesterol, triglycerides and blood glucose (CIBA Corning kits, Gilford Systems, Oberlin, $\mathrm{OH}$ ) were determined on the day of collection. High-density-lipoprotein (HDL) cholesterol was determined after apol- 
ipoprotein B (apo B)-containing lipoproteins were precipitated by the dextran sulfate-manganese method [24]. Low-density-lipoprotein (LDL) cholesterol was estimated using the Friedwald formula [25].

All clinical chemistry measurements were performed in a Gilford - 400 autoanalyzer (Corning Laboratory Sciences Co. Oberlin, $\mathrm{OH}$ ). Besides the internal quality control, the laboratory of the Department of Social Medicine participates in the Wellcome Diagnostic Laboratory external quality-control program. The total serum cholesterol concentrations of our laboratory were within the prescribed 2 SD of the mean Wellcome values during the period of the study.

\section{Dietary data}

All participants were provided with food scales and record forms, in order to record their food and liquid intake for seven consecutive days. Participants were required to weigh all foods and beverages consumed over the fasting and non-fasting weeks of measurements and to provide cooking methods and recipes for any composite meals. The food scales (Salter, Model 2006, Kent, England) had a maximum weight capacity of $1 \mathrm{~kg}$ and precision of $\pm 1 \mathrm{~g}$. Detailed written and oral instructions for completion of the 7-day weighed food records were provided and participants were encouraged to contact the researchers if they had any questions regarding this procedure. A date for commencement of diary completion was set and completed diaries were returned during a meeting with the researchers, following the last diary entry date.

Dietary records were checked for completeness on-site to clarify any queries (e.g. unknown food items or food servings). To avoid coding errors, data were computer entered by the same researcher, using a comprehensive Greek national food composition database that is currently under construction and includes some chemically analyzed Greek-origin foods. In the case when a consumed food item was not included in the database, participants were either asked to provide specific recipes or food brand names, or values from an item of similar nutrient content were used. The food database Greek Diet, used to calculate dietary intakes, was initially created in 1990 by the Preventive Medicine and Nutrition Clinic of the University of Crete and was upgraded in 1998 using the USDA Nutrient Database for Standard Reference (release 11, 1996, USDA Agricultural Research Service, Washington DC, USA). A description of the database has been published in detail elsewhere $[11,26]$. The food items and recipes were categorized into sixteen food groups: bread; cereals; potatoes; milk and yogurt; cheese; eggs; meat, poultry and meat products; fish and seafood; legumes (including peas); snails; fruits, nuts and seeds; vegetables; alcoholic drinks; fats and oils; sugar and sugar products; and pastries. Mean daily food (g/day), nutrient and micronutrient intakes were calculated from the food records. 


\section{Statistical analysis}

All analyses were performed using the Statistical Package for the Social Sciences (SPSS for Windows, release 11.5, 2002, SPSS, Chicago, Illinois) and significance was defined as $P<.05$ (two-sided). Mean (with standard deviations) energy, macro- and micronutrient, as well as food intakes were calculated from the 7-day weighed food records. Comparisons of anthropometric and blood pressure measurements, fasting serum glucose and lipids, as well as dietary intakes during the two assessment weeks (fasting and non-fasting) were performed with the use of the Wilcoxon Signed Ranks Test and paired-samples $t$ test for non-normal and normally distributed variables, respectively.

\section{RESULTS}

Of the eleven monks who agreed to take part in the study, one was not available during the examinations performed in the non-fasting week, resulting in complete data (from both fasting and non-fasting weeks) from 10 participants. Participants' age ranged from 25 to 65 years, with a mean age of 37.5 years (SD 12.3) and they had been involved in fasting, according to the tradition, for an average of 24.4 (SD 10.4) years prior to the study.

\section{Comparisons of anthropometric, blood pressure and biochemical measurements}

Table 1 depicts the anthropometric, blood pressure and biochemical analyses results. Body weight and BMI were slightly higher during the non-fasting, as opposed to the fasting week and slightly above ideal, although all monks were apparently healthy.

Table 1. Anthropometric, blood pressure, fasting serum glucose and blood lipid measurements in Greek Orthodox Christian monks during a fasting and a non-fasting week

\begin{tabular}{|c|c|c|c|}
\hline & $\begin{array}{l}\text { Fasting week } \\
(N=10) \\
\text { Mean (SD) }\end{array}$ & $\begin{array}{l}\text { Non-fasting week } \\
(N=10) \\
\text { Mean (SD) }\end{array}$ & P-value \\
\hline Body weight $(\mathrm{kg})$ & $89.3(10.8)$ & $90.9(11.3)$ & $0.059^{+}$ \\
\hline Body Mass Index $\left(\mathrm{kg} / \mathrm{m}^{2}\right)$ & $30.8(4.3)$ & $31.3(4.6)$ & $0.059^{+}$ \\
\hline Systolic blood pressure $(\mathrm{mm} \mathrm{Hg})$ & $124(12.5)$ & $116(13.9)$ & $0.012^{\ddagger}$ \\
\hline Diastolic blood pressure $(\mathrm{mm} \mathrm{Hg})$ & $78.1(6.6)$ & $77.3(7.1)$ & $0.654^{\ddagger}$ \\
\hline Serum glucose $(\mathrm{mg} / \mathrm{dl})$ & $91.1(7.9)$ & $94.2(11.2)$ & $0.253^{\ddagger}$ \\
\hline Serum total cholesterol $(\mathrm{mg} / \mathrm{dl})$ & $161(29.6)$ & $196(43.1)$ & $0.005^{\dagger}$ \\
\hline Serum LDL-cholesterol $(\mathrm{mg} / \mathrm{dl})$ & $91.9(27.0)$ & $134(38.4)$ & $0.005^{\dagger}$ \\
\hline Serum HDL-cholesterol $(\mathrm{mg} / \mathrm{dl})$ & $39.2(8.1)$ & $41.2(9.2)$ & $0.193^{\ddagger}$ \\
\hline Total: HDL-cholesterol & $4.3(1.0)$ & $4.9(1.2)$ & $0.005^{+}$ \\
\hline Serum triglycerides $(\mathrm{mg} / \mathrm{dl})$ & $149(73.8)$ & $99.1(43.6)$ & $0.017^{+}$ \\
\hline
\end{tabular}


Interestingly, systolic and diastolic blood pressure measurements were lower during the non-fasting week, but only systolic blood pressure reached statistical significance. In contrast, total and LDL-cholesterol levels were significantly increased at the end of the non-fasting week, probably reflecting the higher intake of animal foods (see Table 4), whereas the increase (albeit not significant) in HDL-cholesterol levels for the same week probably reflected the increased total cholesterol levels and perhaps the absence of olive oil during the fasting week in the diets of many of the participants studied. The ratio of total:HDL-cholesterol, a better predictor of coronary heart disease risk status than total cholesterol levels [27], was also significantly lower during the fasting week, suggesting the potential contribution of the Greek Orthodox fasting rituals in favourable blood lipid profiles.

\section{Comparisons of nutrient intakes}

Comparisons of energy, macro- and micronutrient intakes for the two assessment weeks are presented in Table 2. Several favourable patterns emerged during the fasting week, when intakes of total and saturated fat, trans fatty acids and dietary cholesterol were lower compared with the non-fasting week, and intakes of dietary fibre and folate were higher. Despite meat and meat products being one of the most important sources of iron in the diet, intake of this mineral were significantly higher when participants fasted. This might have resulted from the participants' increased intake of legumes, shellfish, snails and nuts, all good sources of iron in the diet, during the fasting week. In contrast, dietary intake of calcium was significantly lower during the fasting, compared with the non-fasting week, most probably reflecting the absence of dairy products in participants' diets during that period. Intake of protein was also significantly higher when participants followed their nonfasting diets, possibly due to the non-prohibited consumption of animal proteinrich foods (e.g. meat, dairy products) at non-fasting periods.

Significant favourable differences were also observed when macronutrient intake was expressed as a percentage of daily energy intake (Table 3). Thus, participants had lower intakes of total and saturated fat, as well as trans fatty acids, lower intakes of protein and higher intakes of total carbohydrates when they fasted

\section{Comparisons of food consumption}

Table 4 presents the comparison of daily consumption of selected foods during the two assessment weeks. As expected, consumption of dairy products, eggs, as well as meat and meat products were significantly higher when participants did not fast. In contrast, the consumption of legumes and fish and seafood was significantly higher during the non-fasting week. An interesting finding is that although changes in total fruit and vegetable consumption did not reach statistical significance, daily intake of this food group was reduced by more than one serving (104 g) during the non-fasting week, which can be considered of clinical significance according to current recommendations regarding fruit and vegetable consumption [28-19]. 
Table 2. Estimation of daily energy and nutrient intake in Greek Orthodox Christian monks during a fasting and a non-fasting week, based on 7-day weighed food records

\begin{tabular}{|c|c|c|c|c|c|}
\hline \multirow[b]{2}{*}{ Energy or nutrient } & \multicolumn{2}{|c|}{ Fasting week $(N=10)$} & \multicolumn{2}{|c|}{$\begin{array}{l}\text { Non-fasting week } \\
(N=10)\end{array}$} & \multirow[b]{2}{*}{ P-value } \\
\hline & Mean & $S D^{*}$ & Mean & $S D^{*}$ & \\
\hline Energy (kcal) & 2030 & 554 & 2240 & 464 & $0.286^{\dagger}$ \\
\hline Protein (g) & 60.8 & 19 & 76.8 & 17 & $0.028^{\ddagger}$ \\
\hline Total fat (g) & 86.6 & 25.1 & 120 & 19.7 & $0.013^{\ddagger}$ \\
\hline Saturated fatty acids (g) & 13.9 & 4.16 & 33.5 & 7.86 & $0.005^{\ddagger}$ \\
\hline Monounsaturated fatty acids (g) & 50.4 & 16.5 & 57.2 & 10.6 & $0.200^{\dagger}$ \\
\hline Total cis monounsaturated fatty acids (g) & 43.9 & 17.6 & 55.7 & 10.7 & $0.059^{\ddagger}$ \\
\hline Polyunsaturated fatty acids (g) & 14.2 & 6.21 & 13.8 & 5.31 & $0.878^{\ddagger}$ \\
\hline Total cis polyunsaturated fatty acids (g) & 11 & 5.62 & 12.7 & 5.09 & $0.386^{\ddagger}$ \\
\hline Total cis unsaturated fatty acids (g) & 54.2 & 20.7 & 68.4 & 14.2 & $0.139^{\ddagger}$ \\
\hline Trans fatty acids (g) & 0.361 & 0.454 & 1.55 & 0.544 & $0.005^{\ddagger}$ \\
\hline$\omega-6$ fatty acids (g) & 9.59 & 5.81 & 12.3 & 4.74 & $0.241^{\ddagger}$ \\
\hline$\omega-3$ fatty acids (g) & 0.752 & 0.336 & 0.901 & 0.393 & $0.283^{\ddagger}$ \\
\hline $\mathrm{C} 12: 0+\mathrm{C} 14: 0+\mathrm{C} 16: 0(\mathrm{~g})$ & 8.53 & 3.07 & 22.2 & 5.47 & $<0.001^{\dagger}$ \\
\hline Total carbohydrates (g) & 252 & 97 & 208 & 82.7 & $0.169^{\ddagger}$ \\
\hline Total sugars (g) & 53.9 & 17.7 & 59.9 & 32 & $0.421^{\dagger}$ \\
\hline Dietary fibre (g) & 27.7 & 8.08 & 13.8 & 2.83 & $<0.001^{\dagger}$ \\
\hline Alcohol (g) & 6.33 & 11.2 & 6.12 & 7.59 & $0.407^{\ddagger}$ \\
\hline Cholesterol (mg) & 135 & 65.1 & 310 & 80.4 & $0.005^{\ddagger}$ \\
\hline Phytosterols (mg) & 154 & 62.3 & 152 & 38.1 & $0.916^{\dagger}$ \\
\hline Calcium (mg) & 429 & 96.4 & 702 & 350 & $0.022^{\ddagger}$ \\
\hline Iron (mg) & 17.7 & 6.35 & 11.8 & 2.48 & $0.008^{\dagger}$ \\
\hline Potassium (mg) & 3120 & 744 & 2890 & 692 & $0.285^{\ddagger}$ \\
\hline Sodium (mg) & 1640 & 729 & 1790 & 709 & $0.646^{\ddagger}$ \\
\hline Magnesium (mg) & 366 & 152 & 237 & 53.6 & $0.009^{\ddagger}$ \\
\hline Phosphorus (mg) & 1080 & 442 & 1130 & 292 & $0.721^{\ddagger}$ \\
\hline Zinc (mg) & 7.58 & 3.47 & 8.59 & 2.17 & $0.386^{\ddagger}$ \\
\hline Folate (mg) & 326 & 122 & 160 & 30.3 & $0.005^{\ddagger}$ \\
\hline Vitamin A (IU) & 7270 & 5500 & 5500 & 4910 & $0.508^{\ddagger}$ \\
\hline Vitamin A (RE) & 769 & 561 & 755 & 456 & $0.721^{\ddagger}$ \\
\hline Vitamin E (mg) & 11.3 & 4.16 & 9.36 & 2.19 & $0.160^{\dagger}$ \\
\hline Vitamin C (mg) & 113 & 39.2 & 103 & 40.1 & $0.285^{\ddagger}$ \\
\hline Thiamin (mg) & 1.49 & 0.631 & 2.08 & 1.61 & $0.386^{\ddagger}$ \\
\hline Riboflavin (mg) & 1.08 & 0.426 & 2.33 & 1.42 & $0.022^{\ddagger}$ \\
\hline Niacin (mg) & 17.3 & 5.98 & 19 & 6.21 & $0.508^{\ddagger}$ \\
\hline Pantothenic acid (mg) & 3.04 & 0.853 & 4.19 & 0.991 & $0.028^{\ddagger}$ \\
\hline Vitamin B-6 (mg) & 1.45 & 0.417 & 1.84 & 0.512 & $0.074^{\ddagger}$ \\
\hline Vitamin B-12 ( $\mu \mathrm{g})$ & 3.66 & 2.13 & 4.42 & 3.11 & $0.721^{\ddagger}$ \\
\hline
\end{tabular}

SD = standard deviation

${ }^{\dagger}$ Levels of significance were assessed with the use of the Paired-Samples $t$ test

${ }^{\ddagger}$ Levels of significance were assessed with the use of the Wilcoxon Signed Ranks test 
Table 3. Estimation of daily macronutrient intake expressed as percentage of daily energy intake during a fasting and a non-fasting week, based on 7-day weighed food records

\begin{tabular}{|c|c|c|c|c|c|}
\hline \multirow[b]{2}{*}{ Macronutrient } & \multicolumn{2}{|c|}{$\begin{array}{l}\text { Fasting week } \\
(N=10)\end{array}$} & \multicolumn{2}{|c|}{$\begin{array}{l}\text { Non-fasting week } \\
(N=10)\end{array}$} & \multirow[b]{2}{*}{ P-value ${ }^{\dagger}$} \\
\hline & Mean & $\mathrm{SD}^{*}$ & Mean & SD $^{*}$ & \\
\hline Protein & 12.9 & 2.4 & 14.8 & 0.80 & 0.030 \\
\hline Total fat & 38.9 & 8.1 & 48.9 & 8.1 & 0.009 \\
\hline Saturated fatty acids & 6.2 & 0.80 & 13.4 & 1.3 & 0.005 \\
\hline Monounsaturated fatty acids & 23.1 & 7.1 & 23.9 & 6.6 & 0.610 \\
\hline Polyunsaturated fatty acids & 6.1 & 1.1 & 5.6 & 1.9 & 0.074 \\
\hline Trans fatty acids & 0.10 & 0.20 & 0.60 & 0.20 & 0.005 \\
\hline$\omega-6$ fatty acids & 4.0 & 1.3 & 4.9 & 1.8 & 0.284 \\
\hline$\omega-3$ fatty acids & 0.40 & 0.20 & 0.40 & 0.20 & 0.754 \\
\hline Total carbohydrates & 48.7 & 8.5 & 36.1 & 9.2 & 0.005 \\
\hline
\end{tabular}

SD = standard deviation

${ }^{+}$Levels of significance were assessed with the use of the Wilcoxon Signed Ranks test

Table 4. Estimation of daily intake of selected foods $(\mathrm{g} / \mathrm{d})$ during a fasting and a non-fasting week, based on 7-day weighed food records

\begin{tabular}{|c|c|c|c|c|c|}
\hline \multirow[b]{2}{*}{ Food group } & \multicolumn{2}{|c|}{ Fasting week $(N=10)$} & \multicolumn{3}{|c|}{ Non-fasting week $(N=10)$} \\
\hline & Mean & SD $^{*}$ & Mean & $\mathrm{SD}^{*}$ & P-value \\
\hline Bread & 140 & 108 & 79.1 & 67.7 & $0.074^{\dagger}$ \\
\hline Cereals & 127 & 76.1 & 113 & 61 & $0.445^{\dagger}$ \\
\hline Potatoes & 66.8 & 54.3 & 102 & 45.5 & $0.169^{+}$ \\
\hline Milk and yoghurt & 0.00 & 0.00 & 39.5 & 77.3 & $0.027^{+}$ \\
\hline Cheese & 0.00 & 0.00 & 52.7 & 29.8 & $0.008^{\dagger}$ \\
\hline Eggs & 0.00 & 0.00 & 25.5 & 17.7 & $0.012^{+}$ \\
\hline Meat & 0.00 & 0.00 & 146 & 70.4 & $0.008^{+}$ \\
\hline Fish and seafood & 87.1 & 35.6 & 25 & 31.6 & $0.009^{+}$ \\
\hline Legumes & 63.5 & 34.5 & 13.3 & 12.2 & $0.005^{\dagger}$ \\
\hline Snails & 23.8 & 40.4 & 5.86 & 18.5 & $0.123^{+}$ \\
\hline Fruits and nuts & 144 & 83.0 & 114 & 95.5 & $0.446^{\ddagger}$ \\
\hline Vegetables & 237 & 101 & 163 & 75.9 & $0.074^{+}$ \\
\hline Alcoholic drinks & 54.0 & 83.5 & 62.4 & 72.5 & $0.314^{\dagger}$ \\
\hline Fats and oils & 62.4 & 28.7 & 64.9 & 12.3 & $0.746^{\ddagger}$ \\
\hline Sugar/ sugar products & 14.8 & 6.75 & 16.4 & 14.9 & $0.799^{+}$ \\
\hline Pastries & 63.3 & 66.9 & 74.1 & 65.4 & $0.646^{\dagger}$ \\
\hline
\end{tabular}

SD = standard deviation

${ }^{+}$Levels of significance were assessed with the use of the Wilcoxon Signed Ranks test

${ }^{\ddagger}$ Levels of significance were assessed with the use of the Paired-Samples t test 


\section{DISCUSSION}

Overall, the findings of the present study indicate a more favourable dietary profile during a fasting week for monks who are devout Greek Orthodox adherents, when a periodic vegetarian-type of diet is followed as compared to these monks' normal diets. In addition, this healthy eating pattern was reflected in favourable blood lipid levels, suggesting the potential benefits of the Greek Orthodox Church fasting rituals regarding chronic disease prevention.

This study contributes to obtaining an overall picture of the fasting diet recommended by the Greek Orthodox Church and the food habits that may be responsible for providing nutritional benefits. Our results agree with an earlier study investigating the eating habits of people living in monasteries and free-living individuals who perform fasts, in comparison with matched controls who never perform fasts [9]. Fasters were generally reported to have lower intakes of dietary cholesterol, total and saturated fat, protein and calcium and higher intakes of dietary fibre, folate, iron and carbohydrates, during fasting, as compared to non-fasting periods. In this earlier study, fish/seafood consumption also appeared to be higher whereas, in contrast to the present study, legume intake was lower when participants fasted. Meat consumption during non-fasting periods was similar to the intake reported during the non-fasting week in the present study [9]. A model of the Greek Orthodox fasting rituals was also established in another study, which assessed the nutrient composition of this eating pattern by chemically analyzing the weekly food and nutrient intake of a strict adherent to the Church's recommendations [11]. Similar to our findings, this study demonstrated higher intakes of dietary fibre and antioxidant vitamins and lower intakes of saturated fat and dietary cholesterol compared to adults and adolescents of the same region.

This is, to our knowledge, the first study to specifically evaluate the intake of calcium in the Mediterranean diet and, in particular, its intake during a dietary fasting period associated with a religious practice. Our expectation that calcium intakes would be lower during the fasting, compared to the non-fasting, week, was confirmed. This is in accordance with earlier literature and most probably reflects the restriction of dairy products during Greek Orthodox fasting periods [9,11]. A finding of concern is that mean calcium intake was low during both assessment weeks. Although there are wide variations in the estimates of daily calcium requirements and recommended levels made by different expert authorities, depending, among other factors, on age, food patterns and physical activity levels, this agrees with evidence that calcium intakes are below the recommended levels for many population groups $[16,17,20]$. In the past, calculation of calcium intake has been reported to be underestimated due to under-reporting of food intakes. In addition, dietary 
supplements, drinking water and calcium-fortified foods might well contribute to total calcium intake [17]. However, under-reporting of food intake, which might have led to low reported calcium intakes, is unlikely to have occurred in the present study, due to the dietary assessment method used (weighed food record). Furthermore, participants in the present study did not take dietary supplements and did not report consuming any fortified foods, so the contribution of these two factors in their calcium intake is probably zero. Nevertheless, short-term dietary calcium insufficiencies have not been reported to be detrimental to health [30]. In addition, calcium bioavailability is an important factor that should always be studied along with calcium content of foods [20].

The study by Sarri et al. reported that habitual fasters displayed decreased blood lipid levels and body weight during fasting periods compared to non-fasting periods, in conjunction with our results [8]. In the present study, body weight and BMI did not reach statistical significance, however, probably due to the small sample size. Decreased HDL-cholesterol levels have previously been associated with lowfat and vegetarian diets [31], which might explain the lower levels of this lipid marker during the fasting week in this population. In addition, systolic blood pressure appeared significantly higher at the end of the fasting week. This increased level of systolic blood pressure was observed despite the restriction of animal foods and the estimated lower mean intake of sodium and higher mean intake of potassium during the fasting period (Tables 4 and 2). Perhaps this was a result of lower calcium intakes during that week, since dietary calcium has been beneficially implicated in the regulation of blood pressure [15]. Another possible explanation could be that for the taste of meals to be improved during the fasting week, salt added to foods during cooking or at the table increased. Added salt intake was not, however, assessed in this study. Diastolic blood pressure was not changed between the two assessment weeks, which agree with the earlier study reporting results on these measurements [8].

A further indication of the healthy dietary habits associated with the Greek Orthodox Church's fasting rituals is the increased mean daily fruit and vegetable intake observed during the fasting week. We contend that seasonal variation would not affect the intake of this food group, since recording of dietary data took place during spring and summer months, when seasonal, fresh fruits and vegetables are abundant in Greece. It seems more probable that the allowed consumption of animal products during the non-fasting week led to the substitution of some of the, usually consumed during fasting, fruits and vegetables with animal-origin foods. The lack of statistical significance concerning the intake of fruits and vegetables in the two assessment weeks, in contrast to the study by Sarri et al., might have been the result of the small sample size [9]. 
The healthier lifestyle of strict Orthodox Christian fasters has also been reported by Sarri et al. and was confirmed in the present study, where none of the participants smoked and their alcohol intake averaged approximately one serving of alcoholic drinks per day. In addition, fasting is proposed to 'allow the body to rest and recuperate', since energy intake and the consumption of energy-dense foods is decreased during fasting periods [7,9]. Although it did not reach statistical significance, mean daily energy intake in the present study was lower by almost $200 \mathrm{kcal}$ during the fasting, compared to the non-fasting week. This healthier lifestyle might add to the favourable lipid profile of this population.

Although the results from this study are adding to earlier research on Greek Orthodox Church fasting recommendations, our findings cannot be generalized to all Orthodox Christians, since the sample size was small, mainly due to the limited number of monks living in Crete and the increased number of measurements involved. In addition, some selection bias might have occurred since participants volunteered to take part in the study. Self-selection of participants, however, has been shown to result in the provision of more accurate responses in food consumption surveys compared with non-volunteers [32]. Nevertheless, these findings give a good indication of the health benefits of the fasting rituals of the traditional Mediterranean diet of Crete, as indicated by the favourable blood lipid profile of this population and the generally healthier eating habits during fasting. A study we are currently undertaking, involving a bigger sample of nuns and a sex- and agematched control group of free-living individuals will ideally shed more light into the potential benefits of Greek Orthodox Christian fasting recommendations. In recent years, a number of researchers have used the traditional Mediterranean diet of Crete recommendations as the nutritional basis of secondary $[33,34]$ and primary [35] nutrition interventions and shown that this eating pattern can be successfully adopted by patients who are motivated to change their diet, as well as healthy volunteers. Apart from good dietary acceptability, these earlier studies have reported favourable effects on several biomarkers associated with health. The present study confirms that this traditional eating pattern, which incorporates a kind of periodic vegetarianism, as recommended by the Greek Orthodox Church fasting rituals, could offer cardio-protective benefits, as reflected in the favourable blood lipid profiles observed in this sample of habitual fasters. Although long-term effects of these fasting recommendations are yet to be investigated by a cohort study and such a diet should be carefully planned and balanced to avoid the insufficient intake of micronutrients such as calcium, its potential importance should be emphasised in nutrition education programmes promoting this Mediterranean eating pattern. 


\section{REFERENCES}

1. Nestle M. Mediterranean diets: historical and research overview. American Journal of Clinical Nutrition 1995; 61: 1313S-1320S.

2. Keys A. Coronary heart disease in seven countries. Circulation 1970; 41: 1-211.

3. Kromhout D, Keys A, Aravanis C, Buzina R, Fidanza F, Giampaoli S, Jansen A, Menotti A, Nedeljkovic S, Pekkarinen M, Simic BS, Toshima H. Food consumption patterns in the 1960 s in seven countries. American Journal of Clinical Nutrition 1989; 49: 889-894.

4. Helsing E. Traditional diets and disease patterns of the Mediterranean, circa 1960. American Journal of Clinical Nutrition 1995; 61: 1329S-1337S.

5. Kafatos A, Kouroumalis I, Vlachonikolis I, Theodorou C, Labadarios D. Coronary-heart-disease riskfactor status of the Cretan urban population in the 1980s. American Journal of Clinical Nutrition 1991; 54: 591-598.

6. Hakim I. Mediterranean diets and cancer prevention. Archives of Internal Medicine 1998; 158 : 1169-1170.

7. Cannon G. Out of the Christmas box. Public Health Nutrition 2004; 7: 987-990.

8. Sarri KO, Tzanakis NE, Linardakis MK, Mamalakis GD, Kafatos AG. Effects of Greek orthodox christian church fasting on serum lipids and obesity. BMC Public Health 2003; 3: 16.

9. Sarri KO, Linardakis MK, Bervanaki FN, Tzanakis NE, Kafatos AG. Greek Orthodox fasting rituals: a hidden characteristic of the Mediterranean diet of Crete. British Journal of Nutrition 2004; 92: 277284.

10. Chliaoutakis JE, Drakou I, Gnardellis C, Galariotou S, Carra H, Chliaoutaki M. Greek Christian Orthodox Ecclesiastical Lifestyle: Could it become a pattern of health-related behavior? Preventive Medicine 2002; 34: 428-435.

11. Kafatos A, Verhagen $\mathrm{H}$, Moschandreas J, Apostolaki I, Van Westerop JJM. Mediterranean diet of Crete: foods and nutrient content. Journal of the American Dietetic Association 2000; 100: 14871493.

12. Galli C, Marangoni F. N-3 fatty acids in the Mediterranean diet. Prostaglandins Leukotriene Essential Fatty Acids 2006; 75: 129-133.

13. Sabaté J. Religion, diet and research. British Journal of Nutrition 2004; 92: 199-201.

14. Trichopoulou A, Kouris-Blazos A, Wahlqvist ML, Gnardellis C, Lagiou P, Polychronopoulos E, Vassilakou T, Lipworth L, Trichopoulos D. Diet and overall survival in elderly people. British Medical Journal 1995; 311: 1457-1460.

15. Miller GD, Jarvis JK, McBean LD. The importance of meeting calcium needs with foods. Journal of the American College of Nutrition 2001; 20: 168S-185S.

16. Fishbein L. Multiple sources of dietary calcium- some aspects of its essentiality. Regular Toxicology Pharmacology 2004; 39: 67-80.

17. Cashman KD. Calcium intake, calcium bioavailability and bone health. British Journal of Nutrition 2002; 87: S169-S177.

18. Matkovic V. Calcium and peak bone mass. Journal of Internal Medicine 1992; 231: 151-160.

19. Miller DD. Calcium in the diet: food sources, recommended intakes and nutritional bioavailability. Advanced Food and Nutrition Research 1989; 33: 103-156.

20. Weaver CM, Proulx WR, Heaney R. Choices for achieving adequate dietary calcium with a vegetarian diet. American Journal of Clinical Nutrition 1999; 70: 543S-548S.

21. New SA. Do vegetarians have a normal bone mass? Osteoporosis International 2004; 15: 679-688.

22. Kaur N, Gupta AK. Applications of inulin and oligofructose in health and nutrition. Journal of Bioscience 2002; 27: 703-714.

23. Heaney RP, Weaver CM. Calcium absorption from kale. American Journal of Clinical Nutrition 1990; 51: 656-657.

24. Warnick R, Benderson J, Albers JJ. Dextran sulphate-Mg2+ precipitation procedure for quantitation of high-density-lipoprotein cholesterol. Clinical Chemistry 1982; 28: 1379-1384. 
25. Friedwald WT, Levy RI, Fredrickson DS. Estimation of the concentration of low density lipoprotein cholesterol in plasma without the use of the preparative ultracentrifuge. Clinical Chemistry 1972; 18: 499-502.

26. Moschandreas J, Kafatos A. Food and nutrient intakes of Greek (Cretan) adults. Recent data for food-based dietary guidelines in Greece. British Journal of Nutrition 1999; 81: S71-S76.

27. Kinosian B, Glick H, Garland G. Cholesterol and coronary heart disease: predicting risks by levels and ratios. Annals of Internal Medicine 1994; 121: 641-647.

28. Williams C. Healthy eating: clarifying advice about fruit and vegetables. British Medical Journal 1995; 310: 1453-1455.

29. World Health Organisation. Diet, Nutrition and the Prevention of Chronic Diseases. Geneva: Joint FAO/WHO, 2002.

30. O'Brien KO, Abrams SA, Liang LK, Ellis KJ, Gagel RF. Increased efficiency of calcium absorption during short periods of inadequate calcium intake in girls. American Journal of Clinical Nutrition 1996; 64: 579-583.

31. Masarei JR. Vegetarian diets, lipids and cardiovascular risk. Australian New Zealand Journal of Medicine 1984; 14: 400-404.

32. Cade J, Thompson R, Burley V, Warm D. Development, validation and utilisation of food-frequency questionnaires-a review. Public Health Nutrition 2002; 5: 567-587.

33. Renaud S, de Lorgeril M, Delaye J, Guidollet J, Jacquard F, Mamelle N, Martin JL, Monjaud I, Salen P, Toubol P. Cretan Mediterranean diet for prevention of coronary heart disease. American Journal of Clinical Nutrition 1995; 61: 1360S-1367S.

34. de Lorgeril M, Salen P, Martin JL, Monjaud I, Boucher P, Mamelle N. Mediterranean dietary pattern in a randomized trial: Prolonged survival and possible reduced cancer rate. Archives of Internal Medicine 1998; 158: 1181-1187.

35. Papadaki A, Scott JA. The Mediterranean Eating in Scotland Experience project: evaluation of an Internet-based intervention promoting the Mediterranean diet. British Journal of Nutrition 2005; 94: 290-298. 



\section{CHAPTER 5}

\section{DOES ADHERENCE TO THE MEDITERRANEAN DIET HAVE A PROTECTIVE EFFECT AGAINST ACTIVE AND PASSIVE SMOKING?}

A review

Constantine Vardavas, Andreas Flouris, Aristides Tsatsakis, Anthony Kafatos, Wim H.M. Saris

Public Health (Submitted) 


\begin{abstract}
Active and passive smoking constitute a significant threat to global health and a major cause of disease and death. A potent mixture of chemicals, carcinogens and toxins, its chemical consistency is a major source of oxidative stress and a cause of lipid peroxidation, vascular and airway inflammation and carcinogenesis, which are only a few of the plethora of biological processes attributable to its exposure. On the other hand the Mediterranean diet has been shown in both epidemiological and laboratory studies to have a protective effect against biochemical and molecular processes that lead to cancer, cardiovascular disease and a change in overall mortality. Based on the consumption of olive oil, wild greens, fruits, whole wheat bread and legumes and supplemented with a rare to moderate consumption of red meat, fish and dairy products the Mediterranean diet fortifies those who adhere to it with a high daily intake of vitamins, fibre and antioxidants, which could at as an effect modifier of the roles smoking has on ones health. Amongst such outcomes, epidemiological studies have indicated that lung cancer mortality is positively associated with the average dietary intake of saturated fat and reversely associated with certain antioxidants, indicating such a possible interaction between dietary intakes and a significant outcome of active and passive smoking.

Based on the existing scientific evidence, we investigated into the means through which adherence to the Mediterranean diet could modify the outcome of certain diseases attributable to active and passive smoking, with a focus on cardiovascular disease, cancer, chronic obstructive pulmonary disease and asthma.
\end{abstract}




\section{INTRODUCTION}

\section{1.a Detrimental effects of active and passive smoking}

Smoking is one of the largest causes of preventable death and anticipated to kill 1 billion people prematurely this century [1], while second hand smoke is another serious threat to public health, subsequent to tobacco use, and is a potent mixture of carcinogens, volatile toxins and chemicals [2-3]. It has been estimated that at least 1 billion adults are smokers worldwide and that at least 700 million children breathe air polluted by tobacco smoke at home [4]. Exposure to secondhand smoke (SHS) is related to the ever increasing frequency of diseases both among children and adults, such as respiratory illness, asthma, otitis media, sudden infant death syndrome and vascular dysfunction, and predisposition towards cardiovascular disease and cancer [5-8]. Moreover, although cardiovascular and chronic lung disease are generally the result of long-term processes, recent evidence shows that even brief SHS exposures appear to initiate mechanisms that contribute to their development [9-10].

Cigarette smoke contains free radicals and other oxidants in abundance. It has been estimated that each puff of a cigarette exposes the smoker to $10^{15}$ oxidative free radicals, a severe source of oxidative stress [11]. Additionally, reactive oxygen species production is further mediated through inflammatory processes induced by the toxins inhaled and absorbed during active and passive smoking [12]. The first line of response is that of antioxidant enzymes such as superoxide dismutase, catalase and glutathione peroxidase, which take an advantage of the circulating levels of dietary antioxidants, a second line of defence against oxidative stress. These antioxidants are digested and enter the circulation, acting as a buffer against oxidative stress, and therefore could have a protective effect against antioxidant depletion.

An important public health related issue is whether or not the marked changes in the subjects health are solely due to the harmful effects of cigarette smoke or to a combined effect of both the oxidative properties of cigarette smoke and the habitual dietary profile of smokers, which is in general lower in fruit and vegetable intake and higher in alcohol and meat product consumption in comparison to that non-smokers [13-15]. Moreover, it is likely that the cumulative effect of both the elevated oxidative stress and lower dietary intake of antioxidants is partially responsible for the negative impact of smoking on human health.

\section{1.b The Mediterranean diet and the smoking paradox}

The Mediterranean diet became world renowned in the early 1960's through the Seven Countries Study (SCS), an epidemiological study with 16 cohorts in 7 countries (Greece, Finland, Japan, former Yugoslavia, Italy, Holland and the United 
States), which aimed to investigate into the dietary and lifestyle factors related to the development of cardiovascular disease [16]. As corroborated during the subsequent 10, 25 and 40 year follow up of the SCS, the rural population of Crete was found to have one of the lowest coronary heart disease (CHD) and cancer mortality rates in comparison to all other cohorts [17-18], a result attributed to their dietary and lifestyle habits. The traditional diet of Crete, which is what the typical "Mediterranean diet" usually refers to, is based on the high intake of vitamins, fibre and antioxidants, through the consumption of olive oil, wild greens, fruits, whole wheat bread and legumes, walnuts, almonds and snails, supplemented with a rare to moderate consumption of red meat, fish and dairy products [19]. In addition to the above, monounsaturated fat (through the extensive consumption of olive oil) accounted for $29 \%$ of the daily calorie intake, while saturated fat intake was limited to $8 \%$ of total energy intake [20].

Furthermore, after following up the 12,763 men of the SCS for 25 years, lung cancer mortality was found to be higher in Northern European and Northern American cohorts in comparison with the Southern European and Japanese cohorts [21], while absolute lung cancer mortality was positively associated with average dietary intake of saturated fat, which was lowest in both the Mediterranean and the Japanese diet, both known for their high antioxidant and low saturated fat profile [2223]. Specifically, these researchers had hypothesised that saturated fat, may play a role in the cross-cultural variation in lung-cancer mortality, either independently or by effect modification, despite the fact that smoking habits were similar across countries and regions.

\section{1.c Aims and scope}

Currently, one of the emerging issues in environmental toxicology is the evidence which suggest that antioxidant micronutrients and related bioactive compounds common in fruit and vegetables, may ameliorate the toxicity of environmental chemicals and impact disease development, [24] and it has been hypothesised that adherence to the Mediterranean diet might function is such a way [23].

Taking the above scientific facts and epidemiological findings into account, we aimed at investigating into the existing evidence that could indicate whether adherence to the Mediterranean diet may have a role as an effect modifier, of active and passive smoking, on human health.

\section{Active/passive smoking, cardiovascular disease and the Mediterranean diet.}

\section{2.a Active and passive smoking and the risk of cardiovascular disease}

Active cigarette smoking and exposure to SHS are strongly associated with vascular dysfunction and atherosclerosis and impact all phases of atherosclerosis from endothelial dysfunction to acute clinical events [25-26]. Cigarette smoke can promote 
atherosclerosis, in part, by its effects on the lipid profile of the active and passive smoker. Smoking decreases plasma high lipoprotein levels (HDL) and alters the ratios between HDL and low density lipoproteins (LDL), HDL and triglycerides (TG) and HDL and total cholesterol levels, both in animal models and humans [25,27]. It is interesting to note that lipid peroxidation among young smokers is noted, even after controlling for dietary intake, as an reliable indicator of the level of smoking. Cigarette smoking also increases the oxidative modification of LDL with circulating products of lipid peroxidation and levels of oxidized LDL found to be significantly increased in both active and passive smokers [27-29]. This oxidised LDL may enter into the arterial endothelial wall, leading to attract macrophages, lymphocytes and subsequently paracrinine factors that cause platelet accumulation and initiation of foam cells. This is the first step in developing an atherosclerotic plaque [30]. Additionally, it has been hypothesised that cigarette smoke alters catecholamine release and thus fatty acid release, which in turn increases LDL and very low density lipid concentrations (VLDL), and also contributes to lowering circulating HDL levels [31].

\section{2.b Interaction between adherence to the Mediterranean diet and the cardiovascular factors influenced by active and passive smoking}

In contrast to the above it has been shown in randomized controlled trials that adherence to the Mediterranean diet had a beneficial effect on circulating oxidised LDL levels, a factor that could possibly counter balance the increase in oxidised LDL molecules induced by exposure to tobacco smoke [32]. Epidemiological and clinical evidence has convincingly shown that dietary habits are the central mediator of circulating lipids [33-34]. The differences in dietary fat intake are clearly apparent when comparing the Mediterranean diet, with a more westernised diet. Although the fat percentage is similar in quantity in both, it differs dramatically in quality as the Mediterranean diet is rich in monounsaturated fatty acids, such as oleic acid, but very low in saturated fat. Such diet has the ability to reduce the levels of circulating LDL and VLDL lipids, while increasing the beneficial HDL lipids [35]. Indeed follow up studies, such as the Lyon Secondary Prevention Heart Study on patients with cardiovascular disease, indicated that adherence to a Mediterranean style diet was more beneficial as prevention measure compare to the American Heart Association's recommended diet and other pharmaceutical or surgical interventions [34-35]. Additionally, olive oil is high in monounsaturated fatty acids and as proven in numerous studies [19-20,38] plays an important role in the Mediterranean diets and significantly contributes to an increase in the circulating levels of HDL.

It has been stated that another important role in the traditional Mediterranean diet of Crete is played by its ideal omega- 6 /omega-3 fatty acid ratio of 2-1:1. [39], in opposition to that of western cultures which have an $\omega-6 / \omega-3$ ratio of approximately 15 for northern Europe and 17 for the current U.S [40]. These dietary $\omega-3$ 
fatty acids are associated with a lower prevalence of hypertension and lower systolic blood pressure, hyperlipidemia and inflammation [41-42] These beneficial effects may be mediated through several distinct mechanisms, including alterations in cell membrane composition and function, gene expression, or eicosanoid production and studies reveal that they play a role in nerve conduction velocity due to the incorporation of $\omega-6$ fatty acids in membrane phospholipids [42]. On the contrary, smoking and SHS exposure has a significant impact on the levels and interaction between $\omega 3$ and $\omega 6$ polyunsaturated fatty acids and can alter their metabolism [43]. As the dietary intake of alpha-linolenic acid (an omega -3 fatty acid) is inversely related to plasma concentrations of inflammation markers (reflecting lower levels of inflammation and endothelial activation) it is possible to partially explain the role of this fatty acid in preventing cardiovascular disease due to smoking [44]. Moreover, the Mediterranean diet of Crete is abundant in wild greens, which are a rich source of both essential $\omega 3$ fatty acids and antioxidants [45-46] and eaten in abundance, especially during the days of fasting. This periodical vegetarian diet observed during the approximately 180 days of fasting of the Greek Orthodox Church leads to an even more favourable lipid profile as fasters are generally reported to have lower intakes of dietary cholesterol, total and saturated fat, protein and calcium and higher intakes of dietary fibre, folate, iron and carbohydrates, during fasting, as compared to non-fasting periods [47]. This high fruit and vegetable intake also leads to an increase in vitamin and antioxidant intake with additional protective properties. Human health benefits from these high levels of antioxidant vitamins such as vitamin C, beta-Carotene as well as lutein that inhibit the oxidative process of LDL cholesterol into its atherogenic forms and therefore preserve endothelial function and prevent the development of atherosclerosis and coronary heart disease [48-50].

\section{Active/passive smoking, the Mediterranean diet and cancer}

\section{3a Active and passive smoking and the risk of cancer}

The causal relationship between exposure to active and passive smoking and cancer is well acknowledged [3]. It is also common knowledge that there is no lower threshold for tobacco carcinogenesis between the two types of smoking, either regarding lung cancer or tumors in other tissues that are indirectly exposed. Carcinogens absorbed in the lung are distributed throughout the body and have been proven to create or aggravate tumor genesis [51-52]. Such tobacco specific carcinogens and their urinary metabolites, such as 4- (methylnitrosamino)-1-(3pyridyl)-1-butanone, (NNAL) has been found to be consistently elevated in both active and passive smokers and also indicate to the causal link between exposure and lung cancer [3]. In addition to the toxins and carcinogens incorporated in tobacco smoke, the gas phase as previously mentioned, exposes the smoker to more 
than $10^{15}$ free radicals per puff [11]. These oxidative free radicals, (such as superoxide, hydroxide radical, nitric oxide and reactive oxygen) lead to oxidative injury on membrane lipids and proteins and DNA via various molecular pathways, leading to increased DNA damage and oxidative stress [7-8]. These higher levels of both exogenous and intracellular produced free radicals can mediate signal transduction, trigger inflammation, and cellular apoptosis and necrosis [53].

\section{3.b The interaction between adherence to the Mediterranean diet and the carcinotoxicity of active and passive smoking}

A plethora of research and reviews exist on the role of the Mediterranean diet against cancer and its effect on overall mortality. One of the most recent such meta-analyses is that of Sofi et al, 2008 who investigated a total of 12 cohorts and approximately 1,5 million subjects [54]. According to their results, adherence to the Mediterranean diet was associated with a significant reduction in overall mortality and the incidence of mortality from cancer. Similar findings have been reported earlier by De Lorgeril et al, based on a randomised control trial [55].

Both toxicological and epidemiological evidence supports the fact that dietary intake of fatty acids may alter the prevalence of cancer among populations that adhere to the Mediterranean diet $[18,39,56]$. Dietary $\omega-6$ fatty acids also have been shown to possess effective tumoricidal properties, when taken according to their recommended daily intake, against prostate and breast cancers $[57,58]$ as well as pancreas tumors [59]. Additionally, essential $\omega-3$ fatty acids have been found in mice to slow the growth of various types of cancers, including lung, colon, mammary, and prostate [60]. Epidemiological data has indicated that a Mediterranean style diet has been found to have a protective effect against the development of colorectal adenomas with the strongest protective effect found among current smokers [61]. Red meat and processed meat intake, which is also significantly reduced in populations that adhere to the Mediterranean diet, has also been found to be independently associated with an increased risk of lung cancer, and strongly correlated with the development of adenocarcinomas and squamous cell carcinomas both among smokers and non smokers [62]. On the contrary, a different interaction between smokers and non smokers has been noticed in regards to the role of certain flavonoid compounds, such as epicatechin, catechin, quercetin, and kaempferol, which have been found to be associated inversely with lung cancer among tobacco smokers, but not among non-smokers, a fact that could indicate their possibly protective role against tobacco smoke [63].

As with the cardiovascular protective effects of the Mediterranean diet, its protective role against cancer can be also attributed to its high content in olive oil, possibly the most characteristic descriptor of the Mediterranean diet [19, 35, 38-39]. Oleic acid, the central monounsaturated fatty acid found in olive oil has been hypothesised to regulate key cancer related oncogenes by repressing their transla- 
tion. Specifically oleic acid has been found to suppress a well characterised oncogene (neu or erb-2) that plays a key role in the aetiology, progression and chemosensitivity of various types of human cancer including breast, ovarian and stomach carcinomas [64-65]. The above anti-tumor properties proposed have been related not only to its content in oleic acid, but also to its protective effect from oxidative DNA damage due to its richness in antioxidant components which are scavengers of reactive species [66-68]. While olive oil is a rich source of oleic acid and polyphenolic compounds, it is the fruit content of the Mediterranean diet which provides it with its high daily intake of alpha-carotene, beta-carotene, and beta-cryptoxanthin [69]. Epidemiological studies have indicated a statistically significant inverse relationship between these antioxidant carotenoids and lung cancer even after adjusting for smoking, indicating the role of fruit and vegetable intake of the Mediterranean diet could have on the incidence of lung cancer among populations that adhere to it [70-71]. Consistent with inhibition of the lung cancer cell growth, betacryptoxanthin (found in abundance in citrus fruits) has been found to inhibit the growth of A549 cells, a non-small-cell lung cancer cell line in a dose-dependent manner and induce the mRNA levels of retinoic acid receptor beta (RARbeta) in BEAS-2B cells which suggest an anti-proliferative mechanism [72]. This elevated dietary intake of fruits, vegetables and wild edible greens, also provides higher amounts of carotenoid, L-ascorbic acid, phylloquinone, gamma-tocopherol, alphatocopherol and total polyphenols [39, 46]. Alpha-tocopherol and gammatocopherol are two of the major chemical forms of vitamin E. Like other antioxidants, vitamin $\mathrm{E}$ can scavenge free radicals and may, as a result, prevent oxidative tissue damage by trapping organic free radicals. By including large quantities of fresh greens into their diet populations that adhere to the Mediterranean diet guarantee a substantial daily intake of these valuable antioxidants, many of which have been shown above to be associated with a lower risk of cancer [46].

\section{Active/passive smoking, the Mediterranean diet and respiratory disease}

\section{Asthma}

Oxidative stress has been widely recognized as an important component of airway inflammation in asthma. Exposed to the oxidative particles of tobacco smoke and/or other oxidative-toxic components, a large amount of reactive oxygen species can be created which in turn deplete glutathione buffers and lead to a destabilized situation in epithelial cells. Glutathione is an abundant airway antioxidant which reduces organic hydroperoxides and protects the airway from lipid peroxidation [73-74]. Such an oxidative substance is peroxynitrate, which has been shown to cause oxidative stress in epithelial cells and which has been indicated to play a role in the molecular and cellular response to air pollution [75]. Indeed children with severe asthma have increased biomarkers of antioxidant stress in the epithe- 
lial lining fluid of their airways, which are associated with a shift in the glutathione redox potential towards the more oxidized state. Interventions to increase epithelial lining fluid glutathione concentrations have been suggested as a therapeutic intervention [76].

The Mediterranean diet is characterised by a large intake in fresh fruit, vegetables, wild greens and olive oil, in which antioxidants, such as glutathione, can be found in substantial quantities and could indicate a protective effect $[39,46]$. It is this exact dynamic equilibrium between oxidative and anti-oxidative substances that is where the interaction between antioxidant depletion and supplementation and the nutritional/environmental exposure interaction takes place [77-78]. Despite the above scientific indications, there is limited evidence of the effect separate antioxidant supplementation on glutathione levels and the outcome of asthma, when providing additional selenium, magnesium and vitamin $\mathrm{C}$ in the context of randomised control trials [77]. It is possible that the separate antioxidants have a less significant role on their own then when they are provided within the context of the Mediterranean diet, most possibly due to the synergistic interactions with other dietary compounds such as lipids. Indeed, the optimal balance between dietary ALA and linoleic acid, such as the one in the traditional diet of Crete has recently shown to reduce the risk for asthma [79]. Adherence to the Mediterranean diet, but not antioxidant supplementation, has a protective effect against asthma and other illnesses that have been strongly correlated to active and passive smoking $[5,80]$. Epidemiological evidence has indicated that children who adhere to the Mediterranean diet are less likely to develop asthma, wheezing and sneezing and allergies [81-82]. In addition to modifying children's reactions to SHS, high adherence to traditional Mediterranean diet also has been found to increase the likelihood of asthma to be under control in adults, indicating an additional public health implication of adherence to a Mediterranean style diet [83].

\section{Chronic Obstructive Pulmonary Disease}

Chronic Obstructive Pulmonary Disease (COPD) is associated with a high incidence of morbidity and mortality, and both active and passive smoking can cause COPD exacerbation and progression [84]. As with asthma, COPD also can be influenced through an imbalance in antioxidants especially among smokers, whose circulating neutrophils (in both the blood and the alveoli) produce more oxidative molecules and lead to bronchial hyper-responsiveness, suggesting a pathogenetic pathway between oxidative stress and airway abnormalities in COPD [85-88]. Numerous studies have investigated the relationship between antioxidants, pulmonary function and COPD disease [88]. Data from the NHANES III, indicated that serum antioxidants vitamin $\mathrm{C}$, vitamin $\mathrm{E}$, selenium and beta carotene are associated with lung function, while the Dutch MORGEN study revealed that a higher intake of vitamin $\mathrm{C}$ and beta carotene was also correlated with a higher FEV1, a significant prognostic 
indicator of COPD [89-90]. Epidemiological studies, such as the one by Walda et al., have also confirmed the relationship between dietary intakes and 20-year chronic obstructive pulmonary disease mortality in middle aged men [91]. In this prospective cohort study of 2917 men, the authors observed an inverse trend of 20 year COPD mortality with an increase in dietary intake of fruit and vitamin $E$, an intake of which would be substantial in populations that adhere to the Mediterranean diet. Moreover, it has been hypothesised that it is the antioxidant and antiinflammatory properties of the dietary polyphenols, and flavonoids that might explain these above beneficiary effects of adherence to such a diet [92-94].

\section{Conclusions and public health implications}

While the evidence on the role of antioxidants and dietary intakes on cancer, cardiovascular, respiratory and other chronic diseases is extensive, our knowledge of the role of antioxidant or micronutrient supplementation on these outcomes is incomplete and contradictive as the evidence is insufficient to conclude that micronutrient supplementation has a definite protective effect [95-99]. To date, the existing scientific literature has indicated that the dietary intake of beneficial antioxidants, lipids and other micronutrients, through adherence to the Mediterranean diet, can have a protective effect on cancer, cardiovascular and respiratory diseases and it is possible that this diet can act as an positive effect modifier of the role active and passive smoking on health.

Although the best ways to avoid the negative health ramifications of active and passive smoking are to stop smoking, avoid exposure to SHS and promote cessation and the adoption of smoke free environments, adherence to the Mediterranean diet could provide an additional supportive effect to the above and thus have significant implications on clinical outcomes and public health.

\section{ACKNOWLEDGEMENTS}

This review was partly supported by a Flight Attendant Medical Research Institute (FAMRI) grant provided to author C.I.V, for research into second hand smoke exposure.

Conflict of interest: None to declare 


\section{REFERENCES}

1. Mackay J, Eriksen, Shafey O. The tobacco atlas, 2nd Edition. Atlanta: American Cancer Society, 2006.

2. WHO Report on tobacco smoke and child health: consultation report. WHO: Geneva, Switzerland, 1999.

3. International Agency for Research on Cancer IARC. Monographs Programmme on the Evaluation of Carcinogenic Risks to Human, 2002; Volume 83; http://www.iarc.fr (accessed: December 3, 2008).

4. WHO (1999) Consultation report. World Health Organization Division of Noncommunicable Disease, Tobacco Free Initiative. International Consultation on Environmental Tobacco Smoke (ETS) and Child Health. WHO: Geneva, Switzerland, 1999. http://www.who.int/tobacco/ research/en/ets_report (accessed: December 3, 2008).

5. Chilmonczyk B, Salmun L, Metathlin K, et al. Association between exposure to environmental tobacco smoke and exacerbation of asthma in children. N Engl J Med. 1993, 329, 1659-1665.

6. Schoendorf K, Kiely J. Relationship of sudden infant death syndrome to maternal smoking during and after pregnancy. Pediatrics 1992, 90, 905-908.

7. Kosecik M, Erel O, Sevinc E, Selek S. Increased oxidative stress in children exposed to passive smoking. Int J Cardiol. 2005, 100, 61-64.

8. Tang D, Warburton D, Tannenbaum SR, et al. Molecular and genetic damage from environmental tobacco smoke in young children. Cancer Epidem Biomarker Prev. 1999, 8, 427-431.

9. Metsios $G S$, Flouris $A D$, Jamurtas $A Z$, et al. A brief exposure to moderate passive smoke increases metabolism and thyroid hormone secretion. J Clin Endocrinol Metab 2007;92:208-211.

10. Flouris AD, Metsios GS, Carrillo AE, et al. Acute and Short-Term Effects of Secondhand Smoke on Lung Function and Cytokine Production. Am J Respir Crit Care Med 2009; In Press.

11. Pryor WA, Stone K. Oxidants in cigarette smoke. Radicals, hydrogen peroxide, peroxynitrate and peroxynitrate. Ann New York Acad Sci. 1993; 686:12-27

12. Van der Vaart H, Postma DS, Timens W, Ten Haccken NHT. Acute effects of cigarette smoke on inflammation and oxidative stress: a review. Thorax. 2004; 59:713-721

13. Vardavas C.I, Linardakis M, Hatzis C, Malliaraki N, Saris W, Kafatos A. Smoking Status in Relation to Serum and Dietary Vitamin and Micronutrient Concentrations. Tob Induc Dis 2008, 4:8

14. Rust $P$, Lehner $P$, Elmadfa I. Relationship between dietary intake, antioxidant status and smoking habits in female Austrian smokers. Eur J Nutr. 2001; 40: 78-83

15. Dietrich M, Block G, Norkus EP, et al. Smoking and exposure to environmental tobacco smoke decrease some plasma antioxidants and increase gamma-tocopherol in vivo after adjustment for dietary antioxidant intakes. Am J Clin Nutr. 2003;77(1):160-6.

16. Keys A, Blackburn H, Menotti A, et al. Coronary heart disease in seven countries. Circulation; 1970; 41(suppl 1): 1-211.

17. Menotti A, Keys A, Blackburn $\mathrm{H}$, et al. Comparison of multivariate predictive power of major risk factors for coronary heart diseases in seven countries: results from eight nations of the Seven Countries Study, 25 year follow up. Journal of Cardiovascular risk. 1996; 3:69-75

18. Panagiotakos DB, Pitsavos C, Polychronopoulos E, et al. Total cholesterol and body mass index in relation to 40 year cancer mortality (The Corfu cohort of the Seven Countries Study). Cancer Epidem Biomarker Prev. 2005; 14(7):1797-1801

19. Kafatos AG, Verhagen $\mathrm{H}$, Moschandreas J, Apostolaki I, Van Westerop J. Mediterranean diet of Crete: foods and nutrient content. J Am Diet Assoc. 2000; 100:1487-1493

20. Ferro-Luzzi A, James W, Kafatos A. The high fat Greek diet: A recipe for all? Eur J Clin Nutr. 2002; 56:796-809

21. Jacobs D, Adachi H, Mulder I, et al. Cigarette smoking and mortality risk. 25 year follow up of the Seven Countries Study. Arch Inter Med. 1999; 159:733-740

22. Mulder I, Jansen $M$, Smit $H$, et al. Role of smoking and diet in the cross cultural variation in lung cancer mortality: The seven countries study. Int J Cancer. 2000; 88:665-61 
23. Vardavas C.I, Papadaki A, Saris WH, Kafatos A. Is adherence to the Mediterranean diet an effect modifier of the impact smoking has on health? Pub Health. 2009; 123(6):459-60

24. Hennig B, Oesterling E, Toborek M. Environmental toxicity and gene interactions in the development of atherosclerosis. Nutr Metab Cardiovasc Dis. 2007; 17:162-169

25. Yuan $\mathrm{H}$, Wong LS, Bhattacharya $\mathrm{M}$, et al. The effects of second-hand smoke on biological processes important in atherogenesis. BMC Cardiovasc Disord. 2007; 7:1.

26. Ambrose JA, Barua RS The pathophysiology of cigarette smoking and cardiovascular disease: an update. J Am Coll Cardiol. 2004; 43(10):1731-7

27. Bloomer RJ. Decreased blood antioxidant capacity and increased lipid peroxidation in young cigarette smokers compared to non-smokers: Impact of dietary intake. Nutr J. 2007; 6:39.

28. Heitzer T, Ylä-Herttuala S, Luoma J, et al. Cigarette smoking potentiates endothelial dysfunction of forearm resistance vessels in patients with hypercholesterolemia. Role of oxidized LDL. Circulation. 1996; 93(7):1346-53.

29. Panagiotakos D, Pitsavos C, Chrysohoou C, et al. Effect of exposure to secondhand smoke on markers of inflammation: the ATTICA study. Am J Med. 2004; 116:145-150

30. Chelland Campbell SC, Moffatt RJ, Stamford B. Smoking and smoking cessation-the relationship between cardiovascular disease and lipoprotein metabolism: a review. Atherosclerosis. 2008; 201(2):225-35

31. Benowitz NL. Pharmacological aspects of cigarette smoking and nicotine addiction. N Eng J Med. 1988; 319: 1318-30

32. Fitó M, Guxens M, Corella D, et al. Effect of a traditional Mediterranean diet on lipoprotein oxidation: a randomized controlled trial. Arch Intern Med. 2007; 167(11):1195-203.

33. Booker CS, Mann JI. Trans fatty acids and cardiovascular health: translation of the evidence base. Nutr Metab Cardiovasc Dis. 2008; 18(6):448-56.

34. Erkkilä A, de Mello VD, Risérus U, Laaksonen DE. Dietary fatty acids and cardiovascular disease: an epidemiological approach. Prog Lipid Res. 2008; 47(3):172-87

35. Kromhout D, Keys A, Aravanis C, et al. Food consumption patterns in the 1960's in seven countries. Am J Clin Nutr. 1989; 49:889-94

36. Renaud S, de Lorgeril M, Delaye J, et al. Cretan Mediterranean diet for prevention of coronary heart disease. Am J Clin Nutr. 1995; 61 (suppl.): 1360S-1367S

37. De Lorgeril M, Renaud S, Mamelle N, et al. Mediterranean alpha-linolenic acid-rich diet in the secondary prevention of coronary heart disease. Lancet. 1994; 343: 1454-1459

38. Serra-Majem L, Ngo de la Cruz J, Ribas L, Salleras L. Mediterranean Diet and Health: Is all the Secret in Olive Oil? Path Haem Thromb. 2003; 33(5-6): 461-5

39. Simopoulos A. Overview of evolutionary aspects of $\omega-3$ fatty acids in the diet. (1998). In Simopou$\operatorname{los} A(E d)$. The return of the $\omega-3$ fatty acids into the food supply: I land-based animal food products and their health effects. World Rev Nutr Diet. 83. 1-11

40. Sanders T, Oakley F, Miller G, Mitropoulos K, Crook D, Oliver M. Influence of $n-6$ versus n-3 Polyunsaturated Fatty Acids in Diets Low in Saturated Fatty Acids on Plasma Lipoproteins and Hemostatic Factors Arter, Thromb Vasc Biol. 1997; 17:3449-3460.

41. Riediger ND, Othman RA, Suh M, Moghadasian MH.A systemic review of the roles of $n-3$ fatty acids in health and disease J Am Diet Assoc. 2009; 109(4):668-79

42. Colussi G, Catena C, Baroselli S, Nadalini E, Lapenna R, Chiuch A, Sechi LA. Omega-3 fatty acids: from biochemistry to their clinical use in the prevention of cardiovascular disease. Recent Pat Cardiovasc Drug Discov. 2007; 2(1):13-21

43. Agostoni C, Riva E, Giovannini M, et al. Maternal smoking habits are associated with differences in infants' long-chain polyunsaturated fatty acids in whole blood: a case-control study. Arch Dis Child. 2008; 93(5):414-8.

44. Lopez-Garcia E, Schulze MB, Manson JE, et al. Consumption of ( $n-3)$ fatty acids is related to plasma biomarkers of inflammation and endothelial activation in women. $J$ Nutr. 2004; 134(7):1806-11. 
45. Vardavas C, Majchrzak D, Wagner K-H, Elmadfa I, Kafatos A. Lipid analysis of wild Cretan greens. Food Chem 2006; 99 (4): 822-834

46. Vardavas C, Majchrzak D, Wagner K-H, Elmadfa I, Kafatos A. The antioxidant and phylloquinone content of wildly grown greens in Crete. Food Chem. 2006; 99 (4): 835-843

47. Sarri KO, Linardakis MK, Bervanaki FN, Tzanakis NE, Kafatos AG. Greek Orthodox fasting rituals: a hidden characteristic of the Mediterranean diet of Crete. Br J Nutr 2004;92:277-284.

48. Akhilender Naidu. Vitamin $C$ in human health and disease is still a mystery. An overview. Nutr J, 2003; 2:7

49. Dwyer J.H, Navab M, Dwyer KM, et al. Oxygenated carotenoid lutein and progression of early atherosclerosis: The Los Angeles Atherosclerosis Study. Circulation. 2001; 103, 2922-2927

50. Tavani A, La Vecchia C. $\beta$-Carotene and risk of coronary heart disease. A review of observational and intervention studies. Biomed Pharmacother 1999; 53: 409-16

51. Alberg A. Samet J. Epidemiology of Lung Cancer. J Am Col Chest Phy. 2003; 123: 21s-49s.

52. Trimble $\mathrm{CL}$, Genkinger JM, Burke AE. et al. Active and passive cigarette smoking and the risk of cervical neoplasia. Obstet Gynecol. 2005; 105:174-181

53. Oxidative stress: adaptation, damage, repair and death, in Halliwell B, Gutteridge JMC, eds. Free radicals in Biology and Medicine. Oxford: oxford University press, 1999 pp 346-350

54. Sofi F, Cesari F, Abbate R, Gensini GF, Casini A. Adherence to Mediterranean diet and health status: meta-analysis. BMJ. 2008 Sep 11;337

55. De Lorgeril M, Salen P, Martin JL, Monjaud I, Boucher P, Mamelle N. Mediterranean dietary pattern in a randomized trial: prolonged survival and possible reduced cancer rate. Arch Intern Med. 1998; 158(11):1181-7.

56. Xia SH, Wang J, Kang JX. Decreased n-6/n-3 fatty acid ratio reduces the invasive potential of human lung cancer cells by down-regulation of cell adhesion/invasion-related genes. Carcinogenesis. 2005; 26(4):779-84.

57. Menendez JA, Ropero S, Lupu R, Colomer R. Omega-6 polyunsaturated fatty acid gamma-linolenic acid (18:3n-6) enhances docetaxel (Taxotere) cytotoxicity in human breast carcinoma cells: Relationship to lipid peroxidation and HER-2/neu expression. Oncology Reports. 2004; 11(6): 1241-52.

58. Bidoli E, Talamini R, Bosetti $C$, et al. Macronutrients, fatty acids, cholesterol and prostate cancer risk. Ann Oncol. 2005; 16(1): 152-7.

59. Agombar A, Cooper AJ, Johnson CD. An aqueous formulation of gamma-linolenic acid with antiproliferative action on human pancreatic cancer cell lines. Anticancer Drugs. 2004; 15 (2): 157-60

60. Hardman WE. N-3 fatty acids and cancer therapy. J Nutr. 2004; 134 (12 Suppl): 3427-3430

61. Dixon LB, Subar AF, Peters U, et al. Adherence to the USDA Food Guide, DASH Eating Plan, and Mediterranean dietary pattern reduces risk of colorectal adenoma. J Nutr. 2007; 137(11):2443-50.

62. Lam TK, Cross AJ, Consonni D, et al. Intakes of red meat, processed meat, and meat mutagens increase lung cancer risk. Cancer Res. 2009; 69(3):932-9.

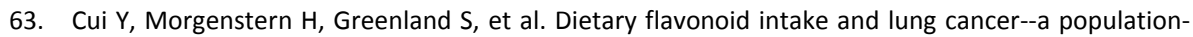
based case-control study. Cancer. 2008; 112(10):2241-8.

64. Menendez J, Papadimitropoulou A, Vellon L, Lupu R. A genomic explanation connecting "Mediterranean diet", olive oil and cancer: Oleic acid, the main monounsaturated fatty acid of olive oil induces formation of inhibitory "PEA3 transcription factod-PEA3 DNA binding site" complexes at the Her-2/neu (erb-2) oncogene promoter in breast, ovarian and stomach cancer cells. Eur J Cancer. 2006; 42: 2425-2432

65. Slamon DJ, Godolphin W, Jones LA, et al. Studies of the HER-2/neu proto-oncogene in human brest and ovarian cancer. Science 1989; 244:707-12

66. Hashim YZ, Eng M, Gill Cl, McGlynn H, Rowland IR. Components of olive oil and chemoprotection of colorectal cancer. Nutr Rev 2005; 63:374-386

67. Owen RW, Haubner R, Wurtele G, Hull E et al. Olives and olive oil in cancer prevention. Eur J Cancer Prev 2004; 13: 319-326 
68. Escrich E, Moral R, Grau L, Costa I, Solanas M. Molecular mechanisms of the effects of olive oil and other dietary lipids on cancer. Mol Nutr Food Res. 2007; 51: 1279-1292

69. Trichopoulou A, Benetou V, Lagiou P, Gnardellis Ch, Stacewicz-Sapunzakis M, Papas A. Plasma carotenoid levels in relation to the Mediterranean diet in Greece. Int J Vitam Nutr Res. 2003;73(3):221-5.

70. Yuan JM, Ross RK, Chu XD, Gao YT, Yu MC. Prediagnostic levels of serum beta-cryptoxanthin and retinol predict smoking-related lung cancer risk in Shanghai, China. Cancer Epidemiol Biomarkers Prev. 2001; 10(7):767-73.

71. Ito Y, Wakai K, Suzuki K, et al. Serum carotenoids and mortality from lung cancer: a case-control study nested in the Japan Collaborative Cohort (JACC) study. Cancer Sci. 2003; 94(1):57-63.

72. Lian F, Hu KQ, Russell RM, Wang XD. Beta-cryptoxanthin suppresses the growth of immortalized human bronchial epithelial cells and non-small-cell lung cancer cells and up-regulates retinoic acid receptor beta expression. Int J Cancer. 2006; 119(9):2084-9.

73. Cantin Am, North SL, Hubbard Rc, Crystal RG. Normal alveolar epithelial lining fluid contains high levels of glutathione. J Appl Physiol. 1987; 63: 152-7

74. Rahman I, McNee W. Oxidative stress and regulation of glutathione in lung inflammation. Eur Respir J. 2000; 16:534-54

75. Persinger RL, Poynter ME, Ckless K, Janssen-heininger YM. Molecular mechanisms of notroigec dioxide induced epithelial injury in the lung. Mol Cell Biochem. 2002; 234:71-80

76. Fitzpatrick A, Teague G, Holguin F, Yeh, M, Brown L for the sever asthma research program. Airway glutathione homeostasis is altered in children with severe asthma: Evidence for antioxidant stress. J Allergy Clin Immunol. 2009;123(1): 146-152

77. Riedl M, Nel A. Importance of oxidative stress in the pathogenesis and treatment of asthma. Curr Opin Allergy Clin Immunol. 2008; 8:49-56

78. Bowler Rp, Crapo JD. Oxidative stress in allergic respiratory disease. J Allergy Clin Immunol 2002; 110: 349-356

79. Oddy WH, De Klerk NH, Kendall GE, Mihrshahi S, Peat JK. Ratio of omega-6 to omega-3 fatty acids and childhood asthma. J Asthma; 2004; 41(3):319-26.

80. Vork KL, Broadwin RL, Blaisdell RJ. Developing asthma in childhood from exposure to secondhand tobacco smoke: insights from a meta-regression. Environ Health Perspect. 2007; 115(10):1394-400

81. de Batlle J, Garcia-Aymerich J, Barraza-Villarreal A, Antó JM, Romieu I. Mediterranean diet is associated with reduced asthma and rhinitis in Mexican children. Allergy. 2008; 63(10):1310-6.

82. Castro-Rodriguez JA, Garcia-Marcos L, Alfonseda Rojas JD, Valverde-Molina J, Sanchez-Solis M. Mediterranean diet as a protective factor for wheezing in preschool children. $J$ Pediatr. 2008; 152(6):823-8

83. Barros R, Moreira A, Fonseca J, et al. Adherence to the Mediterranean diet and fresh fruit intake are associated with improved asthma control. Allergy. 2008; 63(7):917-23.

84. Xu F, Yin X, Shen H, Xu Y, Ware RS, Owen N. Better understanding the influence of cigarette smoking and indoor air pollution on chronic obstructive pulmonary disease: a case-control study in Mainland China. Respirology. 2007; 12(6):891-7.

85. Rahman I. Antioxidant therapeutic advances in COPD. Ther Adv Respir Dis 2008; 2(6):351-74

86. Rahman I, Adcock IM. Oxidative stress and redox regulation of lung inflammation in COPD. Eur Respir J. 2006; 28:219-242

87. Postma DS, Renkeme TEJ, Noordhoek JA, Faber H, Sluiter HJ, Kauffman H. Association between non specific bronchial hyperactivity and superoxide anion production by polymorphonuclear leukocytes in chronic airflow obstruction. Am Rev Respir Dis. 1988; 137: 57-61

88. Boots AW, Haenen GR, Bast A. Oxidant metabolism in chronic obstructive pulmonary disease. Eur Respir J. 2003; 46:14s-27s.

89. Hu G, Cassano PA. Antioxidant nutrients and pulmonary function: the Third National Health and Nutrition Examination Survey (NHANES III). Am J Epidemiol 2000; 151: 975-981 
90. Tabak C, Smit HA, Heederick D, ocke MC, Kromhout D. Diet and chronic obstructive pulmonary disease: independent beneficial effects of fruit, whole grains and alcohol (the MORGEN study). Clin Exp Allergy 2001; 31:747-755

91. Walda IC, Tabak C, Smit HA, et al. Diet and 20 year chronic obstructive pulmonary disease mortality in middle aged men from three European Countries. Eur J Clin Nutr. 2002; 56: 638-643

92. Arts IC, Hollman PC. Polyphenols and disease risk in epidemiological studies. Am J Clin Nutr 2005; 81(suppl): 317s-325s

93. Culpitt SV, Rogers DF, Fenwick PS et al. Inhibition by red wine extract, resveratrol, of cytokine release by alveolar macrophages in COPD. Thorax 2003; 58: 942-946

94. Donnelly LE. Newton R, Kennedy GE, et al. Anti-inflammatory effects of resveratrol in lung epithelial cells. Molecular mechanisms. Am J Physiol Lung Cell Mol Physiol. 2004; 287: L774-783

95. Bardia A, Tleyjeh IM, Cerhan JR, et al. Efficacy of antioxidant supplementation in reducing primary cancer incidence and mortality: systematic review and meta-analysis. Mayo Clin Proc. 2008; 83(1):23-34.

96. Huang HY, Caballero B, Chang $S$, et al. Multivitamin/mineral supplements and prevention of chronic disease. Evid Rep Technol Assess. 2006; (139):1-117.

97. Riccioni G, Bucciarelli T, Mancini B, Di llio C, Capra V, D'Orazio N. The role of the antioxidant vitamin supplementation in the prevention of cardiovascular diseases. Expert Opin Investig Drugs. 2007; 16(1):25-32

98. Kaur B, Rowe BH, Arnold E. Vitamin C supplementation for asthma. Cochrane Database Syst Rev. 2009;(1):CD000993

99. Bernhard D, Wang XL. Smoking, oxidative stress and cardiovascular diseases--do anti-oxidative therapies fail? Curr Med Chem. 2007;14(16):1703-12. 



\title{
CHAPTER 6
}

\section{SMOKING STATUS IN RELATION TO SERUM FOLATE AND DIETARY VITAMIN INTAKE}

\author{
THE MESSARA STUDY
}

Constantine I Vardavas, Manolis K Linardakis, Christos M Hatzis, Niki Malliaraki, Wim H.M Saris, Anthony G Kafatos

Tobacco Induced Diseases 2008, 4:8 


\section{ABSTRACT}

Objective: Cigarette smoke itself is an abundant source of free radicals and a major cause of oxidative stress, to which plasma antioxidants function as a vital protective and counterbalancing mechanism. The objective of this study was to investigate into the relationship between smoking status and serum and dietary micronutrient concentrations.

Design: Cross-sectional study

Subjects - Setting: 502 farmers from the Valley of Messara in Crete were randomly selected and examined. Complete three-day and 24-hr recall questionnaires were collected along with anthropometrical, physical activity and clinical data from all participating subjects.

Results: After adjusting for age, gender and number of fasting days adhered to per year, current smokers were found to have a lower dietary intake of vitamin $C$ (112.1mg vs. $136.4 \mathrm{mg}, p=0.03)$, fibre (16.6g vs. $19.1 \mathrm{~g}, p=0.006)$ and fruits and vegetables (339g vs. $412 \mathrm{~g}, p=0.014$ ), while dietary vitamin $\mathrm{B}_{1}$ intake was found to be higher (1.7mg vs. $1.4 \mathrm{mg}, p=0.02$ ) in comparison to non/ex smokers. Dietary intake of meat, folate and vitamins $A, E, B_{2}, B_{6}$ and $B_{12}$ did not differ between the groups. Controlling age, gender, fasting days and dietary micronutrient intake, serum folate levels were found to be lower among smokers (geometric mean $15.3 \mathrm{nmol} / \mathrm{L}$ vs. $17.7 \mathrm{nmol} / \mathrm{L}, p=0.023$ ), while serum iron and vitamin $B_{12}$ levels were not affected by smoking status.

Conclusions: Current smoking status affects dietary nutrient intake as well as plasma folate levels. The above coherence between antioxidant depletion and reduced antioxidant intake may predispose smokers to the premature development of tobacco related mortality and morbidity. 


\section{INTRODUCTION}

Tobacco consumption is one of the worlds leading causes of preventable death. It had been estimated that in the year 2000 almost 5 million premature deaths globally were attributed to smoking, with cardiovascular disease, chronic obstructive pulmonary disease and lung cancer the leading causes of mortality and disability [1]. Both active and passive smoking have been related to the development of cancer and cardiovascular disease with tobacco's plethora of carcinogenic and volatile chemicals responsible for its negative effects on human health [2].

Cigarette smoke itself is an abundant source of free radicals that promote oxidative stress by both the direct delivery of radicals and their endogenous generation, via the activation of inflammatory cells [3]. It has been estimated that in one puff of a cigarette, the gas phase of the smoke exposes the smoker to greater than $10^{15}$ free radicals [4]. This oxidative stress acts as a significant risk factor for chronic disease development, such as atherosclerosis and carcinogenesis.

Vital lines of human defence against environmental and dietary oxidant intake are the endogenous radical scavengers and the serum antioxidants in the form of dietary micronutrients. Due to the fact that antioxidants are potential pro-oxidants, possible lower concentrations of antioxidants in smokers in comparison to nonsmokers may be a defensive adaptation to the pro-inflammatory environment in smoker's tissues [5]. As viewed in the literature, smokers have lower circulating concentrations of a number of micronutrients, such as ascorbic acid, a-carotene, bcarotene and cryptoxanthin. Although it is possible that differences in dietary intakes could potentially account for these disparities, few studies having controlled for differences in nutrient intake. In research study planning and design it is imperative that these differences are accounted for since smokers are generally known to adhere to a less healthy diet, consume fewer food items rich in fibre, antioxidants and phytochemicals and tend to prefer a meat/alcohol dietary pattern in comparison to non-smokers [6-10].

Taking the above into account, the purpose of this study was to investigate into the relationship between smoking status and a) dietary vitamin, folate, fibre, fruit and vegetable intake and $b$ ) serum folate, iron and vitamin $B_{12}$ concentrations.

\section{METHODS}

Participant sampling procedure

The questionnaire and biological sample database for this study used the framework of the existing MESSARA cross sectional study. The purpose of the MESSARA cross sectional study was to estimate the prevalence of cancer, cardiovascular and chronic disease and their risk factors among the farming population of the valley of 
Messara in Southern Crete, and for this purpose extensive questionnaire data and biological samples were stored.

Participants were randomly selected by using the six municipalities' voting lists using a random stratified sampling methodology, with the number of participants in each of the 24 villages selected according to the villages total farming population. A participant was regarded as a farmer if his main occupation was farming and/or sheep breeding, and was concurrently insured by the farmer's social insurance fund. Out of the 662 people randomly selected, 599 accepted to participate $(90,5 \%)$ out of which 504 (84\%) were finally examined with $44 \%(n=223)$ of the participants' male and $56 \%(n=281)$ of female gender respectively (age 18-79). The mean age $( \pm S D)$ of males was $49.1( \pm 12.7)$ in comparison to $49.2( \pm 12.4)$ for females.

All examinations were conducted during March-May of 2005, by a trained research group of medical doctors, nurses and dieticians, after the population was informed about the study and written consent was given. Approval to conduct the survey was obtained from the University of Crete Ethics committee, while funding was granted by the prefecture of Heraklion's governing authority.

\section{Dietary Survey}

Dietary intake was assessed using a three-day dietary record questionnaire that was handed to the study participants by the local council members of each village, prior to the examination day of the study $(n=251)$. Written and oral explanations were also provided. Where the three-day dietary record questionnaires were not returned, a trained dietician completed a 24-hour dietary recall questionnaire on the day of examination ( $n=249$ ). To re-ensure the representatives between the 35 compounds of the three-day dietary record questionnaires and the 24-hr dietary recall questionnaires, statistical methods were used. The differences were not significant, except for vitamin A intake. Detailed descriptions of all foods, beverages and supplements consumed during the three-day or 24-hour period before the interview, including the quantity, cooking method and brand names were recorded. Dietary records and fasting habits were available from 500 participants. Food quantities were assessed by the use of household measures and colour foodmodel photographs. Nutrient contents were analyzed according to the food database developed at the Department of Social Medicine of the University of Crete in 1998 and updated in 2000 [11]. The database includes about 500 foods, both single and composite. The macro- and micro-nutrient composition of about 20 foods has been chemically determined at Wageningen Agricultural University. The fatty acid content of 105 fat-containing foods was determined at the TNO Nutrition and Food Research Institute (The Netherlands) during 1997. For the remainder of fatcontaining foods, the fatty acid analyses were drawn from the analyses available within the European "trans fatty acid research project" database (TTDB, version 
1.2) developed at the TNO Nutrition and Food Research Institute between 1995 and 1997. For the foods whose composition was not chemically determined, values from the US Department of Agriculture database v11.1 were used. Recipe calculations were used for composite Greek foods with the ingredients being weighed prior to and also following cooking. For means of comparison with other studies the RDA for vitamins designated by a designated US food and Nutrition board was used [12]. Orthodox Christian church fasting days as a component of the Mediterranean diet of Crete play an important role in the dietary intake of the population and therefore were also taken into consideration during the dietary assessment [13].

\section{Laboratory measurements}

Early morning, venous blood samples were drawn from 457 participants, for biochemical screening tests, following a 12-hour overnight fast. The blood samples were transferred to the Nutritional Research Laboratory of the University of Crete in cases containing ice packs, so as to maintain a temperature of $3-4^{\circ} \mathrm{C}$. Quantitative determination of folate and vitamin B12 in serum was performed by competitive immunoassay using direct chemiluminescent technology. (Automated ADVIA Centaur system, BAYER). Serum iron levels were calculated for all 457 participants while funding for 265 randomly selected folate samples was available. 261 vitamin B12 serum levels were calculated, as 4 were lost during the lab analysis.

\section{Health assessment}

Smokers were classified as those who stated that they smoked more than one cigarette over the past three consecutive months. Ex-smokers were defined as those who had not been smoking for the last six consecutive months, and nonsmokers as those who did not fall in any of the two previous groups. During the analysis and due to the fact that the body's antioxidant capacity can replenish quickly during periods of high dietary antioxidant, folate and vitamin intake, both ex smokers and non-smokers were grouped together. Body mass Index (BMI) was calculated as body weight in kilograms $(\mathrm{kg})$ divided by the square of the body height in meters $\left(\mathrm{m}^{2}\right)$. Subjects were weighed without shoes, in their underwear or light clothing with an accuracy of $\pm 100 \mathrm{~g}$, while body height was measured without shoes to the nearest $0.1 \mathrm{~cm}$. Physical activity level was calculated using a weighted weekday and weekend physical activity questionnaire validated and used in a previous study in Crete [14]. Complete data on BMI and physical activity levels were available for 498 participants.

\section{Statistical analysis}

The statistical package SPSS 15.0 was used to perform the analysis. Student t-tests and chi-squared tests $\left(\chi^{2}\right)$ were used during comparisons. Log10 transformed values 
were used due to abnormality of serum folate, iron and vitamin 12 serum values while geometric means with $95 \%$ confidence intervals were presented. Analysis of covariance was performed to eliminate possible confounding factors such as age, gender and number of fasting days in relation to smoking status. Chi squared tests $\left(\chi^{2}\right)$ were also used to compare the frequency of inadequate food and nutrient intake between smokers and non/ex smokers. Statistical significance was noted as $p<0.05$.

\section{RESULTS}

Smoking prevalence was estimated at $29 \%$ with $48.2 \%$ of male participants and $13.3 \%$ of female participants daily smokers. Average years of smoking differed according to gender (male: $28 \pm 11$ vs. female: $14 \pm 7, p<0.001$ ) as also the number of cigarettes smoked daily (male: $31 \pm 16$ vs. female: $16 \pm 11 p<0.001$ ) (Table 1).

Regarding obesity indexes and physical activity, current smoking status vs. non/ex smoking was not found to effect BMI (29.6 vs. 30.2, $p=0.286$ ), daily energy intake (2121 vs. $2075, p=0.5$ ) and the level of physical activity performed (2.4 vs. 2.34, $p=0.399$ ) when gender, age and days of Orthodox church fasting per year were taken into account.

Table 1. Descriptive and nutritional related characteristics of the study sample in relation to smoking status.

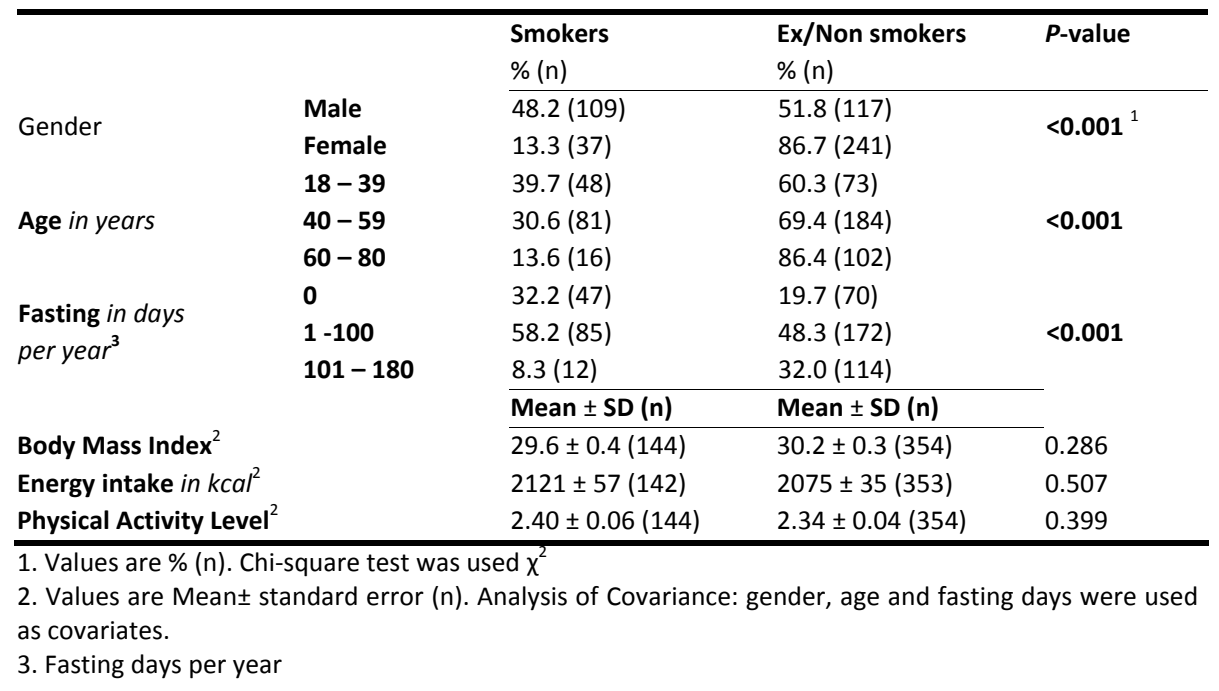


The relationship between smoking status and dietary nutrient, fruit and fibre intake as is shown in Table 2. Smokers were found to have a lower daily intake of Vitamin C (112.1mg vs $136.4 \mathrm{mg}, p=0.03)$, dietary fibre $(16.6 \mathrm{mg}$ vs. $19.1 \mathrm{mg}, p=0.006)$ and fruits and vegetables ( $339 \mathrm{~g}$ vs. $412 \mathrm{~g}, p=0.014$ ) in comparison to non-smokers, while dietary vitamin $B_{1}$ intake was found to be higher among smokers $(1.7 \mathrm{mg}$ vs. $1.4 \mathrm{mg}$, $p=0.02$ ). Daily dietary intake of vitamin $E$ although higher among non smokers did not reach statistical significance $(p=0.056)$ while no differences between smokers and non-smokers, were found regarding folate and vitamin $A, B_{2}, B_{6}$ and $B_{12}$ intake.

Table 2. Daily dietary nutrient, fruit and fibre intake in relation to current smoking status.

\begin{tabular}{|c|c|c|c|c|c|}
\hline & $\begin{array}{l}\text { Smokers } \\
{[n=142]}\end{array}$ & $\begin{array}{l}\text { Ex/Non smokers } \\
{[n=353]}\end{array}$ & & & \\
\hline & $\begin{array}{l}\text { Daily intake in } \\
\text { Weight }\end{array}$ & SD & $\begin{array}{l}\text { Daily intake in } \\
\text { Weight }\end{array}$ & SD & P-value \\
\hline Folate $(\mu \mathrm{g})$ & 210.1 & 10.8 & 230.1 & 6.6 & 0.130 \\
\hline Vitamin A $(\mu \mathrm{g})$ & 1067 & 109 & 1153 & 66 & 0.518 \\
\hline Vitamin E (mg) & 11.3 & 0.5 & 12.5 & 0.3 & 0.056 \\
\hline Vitamin C (mg) & 112.1 & 9.1 & 136.4 & 5.5 & 0.030 \\
\hline Vitamin $\mathbf{B}_{1}(\mathrm{mg})$ & 1.7 & 0.1 & 1.4 & 0.1 & 0.020 \\
\hline Vitamin $\mathbf{B}_{\mathbf{2}}(\mathrm{mg})$ & 1.7 & 0.1 & 1.8 & 0.1 & 0.745 \\
\hline Vitamin $\mathbf{B}_{6}(\mathrm{mg})$ & 1.6 & 0.1 & 1.6 & 0.1 & 0.709 \\
\hline Vitamin $\mathbf{B}_{12}(\mu \mathrm{g})$ & 4.3 & 0.7 & 4.6 & 0.5 & 0.728 \\
\hline Fibre (g) & 16.6 & 0.7 & 19.1 & 0.4 & 0.006 \\
\hline $\begin{array}{l}\text { Fruits } \\
\text { and Vegetables (g) }\end{array}$ & 339 & 24 & 412 & 15 & 0.014 \\
\hline Meat (g) & 88 & 9.0 & 90 & 6.0 & 0.915 \\
\hline
\end{tabular}

As for serum concentrations (Table 3 ), folate was found to be statistically significantly higher among non-smokers ( $17.7 \mathrm{nmol} / \mathrm{L}$ vs. $15.3 \mathrm{nmol} / \mathrm{L}, p=0.023)$, while iron and vitamin $\mathrm{B}_{12}$ serum concentrations did not differ according to smoking status when the participants' dietary intake, gender, age and number of fasting days per year were taken into account.

Table 3. Serum folate, iron and vitamin $\mathrm{B}_{12}$ concentrations in relation to smoking status

\begin{tabular}{|c|c|c|c|}
\hline & $\begin{array}{l}\text { Smokers }^{1} \\
\text { GM }(95 \% \mathrm{Cl})[\mathrm{N}]\end{array}$ & $\begin{array}{l}\text { Ex/Non smokers }{ }^{1} \\
\text { GM }(95 \% \mathrm{Cl})[\mathrm{N}]\end{array}$ & $P$-value \\
\hline Serum Folate $^{2}$ (nmol/L) & $15.3(13.8-16.9)[77]$ & $17.7(16.6-18.9)$ [188] & 0.023 \\
\hline Serum Iron2 $(\mu \mathrm{g} / \mathrm{dl})$ & $87(76-99)[131]$ & $80(73-86)[326]$ & 0.276 \\
\hline Serum $^{2}$ Vitamin $B_{12}(p g / m l)$ & $354(325-386)[77]$ & $341(324-360)[184]$ & 0.495 \\
\hline
\end{tabular}

1. Values are Geometric Mean (95\% Confidence Interval) [N]

2. Analysis of covariance (gender, age and the number of fasting days were used as covariates) 
Table 4 depicts the investigation into the relationship between smoking status and severely inadequate dietary nutrient intake (designated at less than $67 \%$ of the RDA). According to this cut-off, almost $80 \%$ of smokers were found to receive less than $2 / 3$ of the RDA for folate, while vitamin deficiencies were also noted in almost $40 \%$ of smokers for other micronutrients such as vitamin $A, E$ and $C$ to which almost $40 \%$ of smokers. On the other hand, the percentage of the population with $B_{1}, B_{6}$ and $B_{12}$ deficiencies was statistically significantly higher among non-smokers in comparison to active smokers $(p=0.013, p=0.032$ and $p<0.001$ respectively.) while non-smokers were found to have higher but non significant folate, vitamins A, E, C as well as fibre, fruit and vegetable intake.

Table 4. Severely inadequate food and nutrient intake in relation to current smoking status.

\begin{tabular}{|c|c|c|c|}
\hline & $\begin{array}{l}\text { Smokers } \\
\%(n)\end{array}$ & $\begin{array}{l}\text { Ex/Non smokers } \\
\% \text { (n) }\end{array}$ & $P$-value \\
\hline Folate $(<400 \mu \mathrm{g} /$ day $)$ & $94.4(133)$ & $92.1(327)$ & 0.371 \\
\hline Folate $(<268 \mu \mathrm{g} /$ day $)$ & $76.2(109)$ & $70.7(251)$ & 0.213 \\
\hline Vitamin A $(<67 \%$ of RDA) & $49.7(71)$ & $42.3(150)$ & 0.133 \\
\hline Vitamin E (<67\% of RDA) & $39.9(57)$ & $35.8(127)$ & 0.393 \\
\hline Vitamin C (<67\% of RDA) & $24.5(35)$ & $18.0(64)$ & 0.103 \\
\hline Vitamin $B_{1}(<67 \%$ of RDA) & $4.9(7)$ & $12.4(44)$ & 0.013 \\
\hline Vitamin $\mathbf{B}_{\mathbf{2}}(<67 \%$ of RDA) & $9.1(13)$ & $14.1(50)$ & 0.129 \\
\hline Vitamin $\mathbf{B}_{6}(<67 \%$ of RDA) & $11.2(16)$ & $19.2(68)$ & 0.032 \\
\hline Vitamin $B_{12}(<67 \%$ of RDA) & $21.1(30)$ & $42.5(148)$ & $<0.001$ \\
\hline Fibre (<15 g) & $39.2(56)$ & $36.3(129)$ & 0.555 \\
\hline Fruits and Vegetables (<67 \% of RDA) & $36.8(49)$ & $29.9(103)$ & 0.142 \\
\hline
\end{tabular}

1. Chi squared test $\left(\mathrm{X}^{2}\right)$

2. Severely inadequate food and nutrient intake was defined at $<67 \%$ of the RDA.

\section{DISCUSSION}

Current smoking status was strongly related to dietary patterns, with smokers found to have a lower dietary fibre, fruit and vegetable intake in comparison to non-smokers. Smoking status also affected serum folate concentrations when corrected for dietary intake, while serum iron and serum vitamin $B_{12}$ levels were not associated with current smoking status.

\section{Smoking among Cretan farmers}

As hypothesized, smoking prevalence among the farmers of Crete was elevated, especially among male participants. The $48.2 \%$ of male smokers is very similar to the $51 \%$ found in urban Athens, while the percentage of female smokers differs substantially according to place of residence with lower smoking rates found among female farmers (13.3\% vs. 39\%) [15]. This could be attributed to the fact 
that Greek women of higher socio-economic status are more likely to smoke than the less educated or those of lower income while women in rural areas most likely also smoke less, due to the existing traditional culture that regards female smoking taboo [16]. The elevated smoking prevalence as noted above, is a major risk factor for the development of cardiovascular disease and cancer, acting in coherence with the inadequate dietary intake of a number of vitamins, fibre, fruit and vegetables and concurrent depletion of available biological antioxidant deposits due to their smoking habits.

\section{Smoking status and vitamin deficiencies}

Folate and vitamins $B_{6}$ and $B_{12}$ are involved in the regulation of homocysteine, and elevation of homocysteine has been shown to be an independent risk factor for coronary heart disease [17]. Chemical components found in tobacco smoke interact with the above and transform them into inactive compounds reducing their active concentration in biological fluids and possibly alter the ability of the cell to store and metabolise folate [18]. The lower serum folate levels found in our study most likely follow the mentioned mechanism, and other studies have confirmed the finding [19-20].

Regarding $\mathrm{B}_{12}$ serum levels, we found that smokers had higher vitamin $\mathrm{B}_{12}$ levels in comparison to non-smokers even though the difference was not statistically significant. The existing literature is vague regarding the relationship between smoking and serum cobalamin levels (vitamin $\mathrm{B}_{12}$ ). Two studies investigating into smoking during pregnancy and vitamin status suggest that there may be a dose related relationship between smoking and the metabolism of vitamins $B_{6}$ and $B_{12}$ while a third study (among men only) found significantly higher $B_{12}$ levels among smokers (465 $\mathrm{pmol} / \mathrm{l}$ vs $314 \mathrm{pmol} / \mathrm{l}$ ) [21-24]. Although it has been stated, that elevated $\mathrm{B}_{12}$ levels among smokers might be attributed to higher meat consumption, (since smokers are more likely to choose meat instead of fruit and vegetables), both smokers and non smokers of our study population were found to have a similar dietary intake of $\mathrm{B}_{12}$ and meat.

Current smoking was not found to effect mean plasma concentrations of iron, a finding that is similar to previous researchers results, that state that although serum ferritin is related to smoking status iron levels are not, especially among men between 40-60 years old [25-26]. BMI, energy intake and level of physical activity were also not found to differ significantly according to smoking status, factors that could be influenced by the fact that the study population is in rural Crete.

\section{Vitamin deficiencies in smokers and non-smokers among farmers from Crete}

The traditional Mediterranean diet of Crete is renowned for its very high consumption of olive oil, vegetables, legumes, fruit, fish, whole-wheat cereals and a moderate consumption of dairy products and meat. Although it is possible that urban 
populations of Crete may not adhere that strongly to the traditional Mediterranean diet any more, those in rural areas and especially those middle aged or elderly are likely to adhere to the diet rich in antioxidants that historically granted them health and long life expectancy. An important source of the populations antioxidant intake are fruit, vegetables and wildly grown edible greens that are collected and eaten fresh or cooked in pies. Studies have shown that the wild Cretan greens are rich sources of vitamin C, K, E and carotenoids and are capable of significantly contributing to the antioxidant buffer and the RDA needs of the population [27-28].

Both smokers and non-smokers of our study population were found to have a lower folate intake than the recommended $400 \mu \mathrm{g} /$ day. A study performed in another Mediterranean cohort, in Spain, found that folate intakes of smokers was significantly lower than that of non smokers, as did the INTERMAP study [29-30]. We too found folate intake of smokers to be lower, although not significantly. The INTERMAP study also reported null differences in $B_{12}$ intake between smokers and non-smokers to which our data agree. A US population based study; the CSFII, showed that smokers had a significantly lower dietary intake of vitamins $C$ and $D$ in comparison to non-smokers, a finding that our study does not replicate [31]. It is possible though that the much higher vitamin intake of both smokers and nonsmokers in Crete may be due to some degree of adherence to the Mediterranean diet of Crete.

In general and irrespective of smoking status, a relative large proportion of the farming population of Messara has a number of alarming deficiencies in vitamin intake as well as daily fibre, fruit and vegetable consumption, a factor that would affect their predisposition to chronic disease and cancer [32-34]. The fact that almost $40 \%$ of the population consumes less than $67 \%$ of the RDA for fruit and vegetables might be due to the possibility that the population, or a subgroup of it, may not adhere to the traditional Mediterranean diet of Crete, further studies are needed to have a detailed analysis of this hypothesis. In line with the above, the farming population of the Messara valley could greatly benefit from an educational intervention programme that would stress the necessity of smoking prevention and cessation as also the benefits of adhering to a Mediterranean style diet towards the prevention of future disease development.

In total, the statistical data on the relationship between smoking status and dietary habits as well as plasma levels of folate provide strong evidence that cigarette smoking could be directly responsible for lowering plasma folate levels and may have a significant impact on smokers' dietary habits and nutrient intake. The above coherence between antioxidant depletion and reduced antioxidant intake has a further impact on the health status of smokers further predisposing them to the premature development of tobacco related death and disease. 


\section{Competing Interests}

The authors declare that they have no competing interests.

\section{Acknowledgements}

We would like to thank Sofia Flouri, Natalia Tsoumani, Magda Vatsina and Maria Paravoliasi as well as the personnel from the Health Centres of Haraka and Moires for their help in collecting the data. We are also grateful to the local authorities of Messara for their assistance and the governing body of the prefecture of Heraklion for their funding. 


\section{REFERENCES}

1. Ezzati M \& Lopez. Estimates of global mortality attributable to smoking in 2000. The Lancet 2003; 362: 847-52

2. International Agency for Research on Cancer. IARC. Monographs on the Evaluation of the carcinogenic risks to humans: Tobacco smoking. 1986 Vol 38 Lyon (France). International Agency for Research on Cancer

3. Burke A, FitzGerald G. Oxidative stress and smoking-induced vascular injury, Progress In Cardiovascular Diseases. 2003; 46(1):79-90.

4. Pryor \& Stone. Oxidants in cigarette smoke. Radicals, hydrogen peroxide, peroxynitrate and peroxynitrite. Annals of the New York Academy of Sciences 1993; 686: 12-27

5. Thurnham DI, Northrop-Clewes CA. Effects of infection on nutritional and immune status. In Hughes DA, Darlington LG, Bendich A, editors. Diet and human immune function. New Jersey: Humana Press; 2004. p35-63

6. Alberg A. The influence of cigarette smoking on circulating concentrations of antioxidant micronutrients. Toxicology 2002; 180: 121-137

7. Zondervan, K.T., Ocke, M.C., Smit, H.A., Seidell, J.C. Do dietary and supplementary intakes of antioxidants differ with smoking status? International Journal of Epidemiology 1996; 25: 70-79.

8. Margetts, B.M., Jackson, A.A. The determinants of plasma b-carotene: interaction between smoking and other lifestyle factors. European Journal of Clinical Nutrition 1996; 50: 236-238.

9. Touvier M, Niravong M, Volatier JL, Lafay L, Lioret S, Clavel-Chapelon F, Boutron-Ruault MC. Dietary patterns associated with vitamin/mineral supplement use and smoking among women of the E3N-EPIC cohort. European Journal of Clinical Nutrition 2009; 63(1):39-47

10. Padrao P, Lunet N, Santos AC, Barros H. Smoking, alcohol, and dietary choices: evidence from the Portuguese National Health Survey. BMC Public Health. 2007; 7:138.

11. Kafatos AG, Verhagen H, Moschandreas J, Apostolaki I, Van Westerop J. Mediterranean diet of Crete: foods and nutrient content. Journal of the American Dietetic Association 2000; 100:14871493.

12. Food and Nutrition Board loM: Dietary reference intakes for thiamin, riboflavin, niacin, vitamin b6, folate, vitamin b12, pantothenic acid, biotin, and choline. A report of the standing committee on the scientific evaluation of dietary reference intakes and its panel on folate, other B vitamins, and choline and subcommittee on upper reference levels of nutrients. Washington DC: National Academic Press 1998.

13. Sarri K, Linardakis M, Codrington C, Kafatos A. Does the periodic vegetarianism of Greek Orthodox Christians benefit blood pressure? Preventive Medicine. 2007; 44(4): 341-8

14. Sarri KO, Linardakis MK, Bervanaki FN, Tzanakis NE, Kafatos AG. Greek Orthodox fasting rituals: a hidden characteristic of the Mediterranean diet of Crete. British Journal of Nutrition 2004; 92(2):277-84

15. Pitsavos C, Panagiotakos D, Chrysohoou C, Stefanadis C. Epidemiology of cardiovascular risk factors in Greece: aims, design and baseline characteristics of the ATTICA study. BMC Public Health. 2003; 3(1): 32

16. Huisman M, Kunst $A E$, Mackenbach JP. Inequalities in the prevalence of smoking in the European Union: comparing education and income. Preventive Medicine. 2005; 40:756-764

17. Refsum H, Ueland PM, Nygard O, Vollset SE. Homocysteine and cardiovascular disease. Annual Review of Medicine. 1998; 49:31-62

18. Northrop-Clewes CA, Thurnham DI. Monitoring micronutrients in cigarette smokers. Clinica Chima Acta. 2000; 377:14-38

19. Ortega RM, Lopez-Sobaler AM, Gonzalez-Gross MM, Redondo RM, Marzana I, Zamora MJ, Andres P. Influence of smoking on folate intake and blood folate concentrations in a group of elderly Spanish men. Journal of the American College of Nutrition. 1994; 13:68-72. (a) 
20. Piyathilake CJ, Macaluso M, Hine RJ, Richards EW, Krumdieck CL. Local and systemic effects of cigarette smoking on folate and vitamin B-12. American Journal of Clinical Nutrition. 1994; 60:55966.

21. Pagan K, Hou J, Goldenberg RL, Cliver SP, Tamura T. Effect of smoking on serum concentrations of total homocysteine and B vitamins in midpregnancy. Clin Chim Acta. 2001; 306:103-9.

22. Relton $\mathrm{CL}$, Pearce MS, Parker L. The influence of erythrocyte folate and serum vitamin B12 status on birth weight. British Journal of Nutrition. 2005; 93:593-9.

23. Tungtrongchitr $R$, Pongpaew $P$, Soonthornruengyot $M$, Viroonudomphol $D$, Vudhivai $N$, Tungtrongchitr A, Phonrat B, Pooudong S, Schelp. Relationship of tobacco smoking with serum vitamin B12, folic acid and haematological indices in healthy adults. Public Health Nutrition. 2003; 6:675-81

24. Kim S, Kim J, Shin $\mathrm{H}$ and Keen C. Influence of smoking on markers of oxidative stress and serum mineral concentrations in teenage girls in Korea, Nutrition. 2003; 19:240-243

25. Milman M. and Kirchhoff $M$. Relationship between serum ferritin and risk factors for ischaemic heart disease in 2235 Danes aged 30-60 years, Journal of Internal Medicine. 1999; 245:423-433.

26. Hughes K, Choo M, Kuperan P, Ong C.N and Aw T.C. Cardiovascular risk factors in relation to cigarette smoking: a population-based survey among Asians in Singapore, Atherosclerosis. 1998; 137:253-258

27. Vardavas C.I, Majchrzak D, Wagner K-H, Elmadfa I, Kafatos A.The antioxidant and phylloquinone content of wildly grown greens in Crete. Food Chemistry.2006; 99(4): 813-821

28. Zeghini S, Kallithraka S, Simopoulos A, Kypryotakis Z (2003): Nutritional composition of selected wild plants in the diet of Crete. World review of nutrition and dietetics .2003; 91: 22-40

29. Dyer AR, Elliot P, Stamler J, Chan Q, Ueshima H, Zhou BF. Dietary intake in male and female smokers, ex-smokers and never smokers: the INTERMAP study. Journal of Human Hypertension 2003; 17:641-54.

30. Ortega RM, Requejo AM, Lopez-Sobaler AM, Navia B, Mena MC, Basabe B, Andres P. Smoking and passive smoking as conditioners of folate in young women. Journal of the American College of Nutrition. 2004; 23:365-71. (b)

31. Ma J, Hampl J, Betts N. Antioxidant intake and smoking status: data from the continuing survey of foods intakes by individuals 1994-1996. American Journal of Clinical Nutrition. 2000; 71: 774-80

32. Nomura AM, Hankin JH, Henderson BE, Wilkens LR, Murphy SP, Pike MC, Le Marchand L, Stram DO, Monroe KR, Kolonel LN. Dietary fiber and colorectal cancer risk: the multiethnic cohort study. Cancer Causes and Control. 2007; 18(7): 753-64.

33. Donaldson MS. Nutrition and cancer: a review of the evidence for an anti-cancer diet. Nutrition Journal. 2004; 3:19

34. Divisi D, Di Tommaso S, Salvemini S, Garramone M, Crisci R. Diet and cancer. Acta Biomedica. 2006; $77(2): 118-23$. 



\section{CHAPTER 7}

\section{THE ROLE OF PASSIVE SMOKING ON THE PREVALENCE OF TYPE II DIABETES MELLITUS AMONG ELDERLY MEN AND WOMEN LIVING IN MEDITERRANEAN ISLANDS: THE MEDIS STUDY}

\section{A Research Letter}

Constantine I. Vardavas, Christos Lionis, Evangelos Polychronopoulos,

Akis Zeimbekis, Vassiliki Bountziouka, Peter Stravopodis, George Metallinos, Demosthenes B. Panagiotakos.

Diabetic Medicine 2010; 27(2):242-243 
While research has indicated that active smoking is strongly related to the development of diabetes mellitus, limited evidence exists on the role of exposure to secondhand smoke (SHS) on the development of diabetes mellitus [1-2]. Subsequently the aim of this study was to evaluate the relationship between chronic exposure to SHS and the presence of diabetes mellitus, among elderly individuals living on Mediterranean islands.

During 2005-2007, 1190 elderly (aged 65 to 100 years) men and women (from the Republic of Cyprus, and the Greek islands of Mitilini, Samothraki, Cephalonia, Crete, Limnos, Corfu and Zakynthos) were enrolled after institutional review board approval (Harokopio University of Athens) and written informed consent. Clinical diagnosis of diabetes mellitus (type II) was determined by fasting plasma glucose tests greater than $125 \mathrm{mg} / \mathrm{dL}$ or the current use of anti-diabetic medication. Furthermore, adherence to the Mediterranean diet, and physical activity was also assessed. Current smokers were defined as those who smoked at least one cigarette per day or had stopped cigarette smoking during the past 12 months. Former smokers were defined as those who previously smoked, but have not done so in a year or more. Exposure to SHS was measured through a semi-quantitative questionnaire that documented information on daily SHS exposure (of at least 30 minutes) and the number of years of exposure. A high concordance between the responses of the investigated patients and their relatives or friends regarding the years of exposure to SHS was noted $(\tau=0.89, p=0.001)$.

Our findings indicate that after adjusting for possible confounding factors, chronic SHS exposure among non-smokers was associated with a $63 \%$ higher likelihood of having diabetes (OR=1.63, 95\%C.I: $1.04-2.58)$. Moreover, a positive association was observed between years of exposure to SHS and likelihood of having diabetes (OR per 1 year of exposure=1.02, 95\% Cl 1.00-1.04) after controlling for confounding factors. Former smoking (OR=1.49, 95\%C.I: $0.93-2.41)$, active smoking (OR=1.17, 95\%C.I: $1.64-2.23)$ or a combination of both active smoking and SHS exposure (OR=1.54, 95\%C.I: $0.69-3.58)$ showed less prominent results (Table). The latter effect was significant in males and females, and non-smokers.

Two previous cohorts that have studied the interaction between SHS exposure and glucose intolerance have presented similar results to ours. Houston et al., prospectively followed up 4572 participants over a 15 year period and concluded that active smoking and SHS exposure (verified by serum cotinine) was related to the development of glucose intolerance with an odds ratio of 1.65 and 1.35 respectively [1]. Hayashino et al., also investigated the role of self reported exposure to SHS on diabetes development and concluded that both active smoking and SHS exposure were related to the development of diabetes mellitus after 3 years of follow up, with and odds ratios of 1.99 and 1.81 respectively [2]. In comparison to the above studies, our analysis showed similar results regarding SHS exposure 
(odds ratio 1.63), but differed in regards to the role of active smoking. Our intriguing finding that exposure to SHS and not active smoking was related to the prevalence of diabetes could be partially attributed to the different toxic compounds between the tar phase and the gas phase of cigarette smoke, or to the fact that those who got diabetic stopped smoking [3].

This study shares some limitations mainly because of its cross-sectional design, which can indicate relationships but is limited in its ability to attribute cause and effect. Additionally, while it is possible that these people exposed to SHS might share other confounding factors; we did control for possible dietary or lifestyle differences in the regression analysis.

Conclusively, our findings indicate that chronic exposure to SHS could be related to the prevalence of diabetes mellitus among elderly individuals, after controlling for lifestyle, dietary habits and various cardiovascular disease risk factors. Nevertheless, further research with the use of longitudinal studies with concurrent biomarker evaluation is needed.

Table 1. Results from the logistic regression analysis that evaluated the effect of SHS on the presence of diabetes.

\begin{tabular}{llll}
\hline & Odds Ratio & $\mathbf{9 5 \%} \mathbf{~ C l}$ \\
\cline { 2 - 4 } Passive smoking categories & \multicolumn{3}{l}{} \\
No active or SHS & 1.00 & - & - \\
Active smoking - no SHS & 1.17 & 0.64 & 2.23 \\
No smoking -SHS & 1.60 & 1.05 & 2.51 \\
Both active and SHS & 1.54 & 0.69 & 3.48 \\
Age (per 1 year) & 1.02 & 0.99 & 1.03 \\
Males vs. females & 1.08 & 0.69 & 1.69 \\
Hypertension (yes vs. no) & 2.07 & 1.35 & 3.16 \\
Hypercholesterolemia (yes vs. no) & 1.28 & 0.88 & 1.86 \\
Family history of diabetes (yes vs. no) & 4.46 & 2.69 & 7.41 \\
Physical activity status (High vs. inactive) & 0.57 & 0.42 & 0.78 \\
Body mass index (per 1 kg/m ${ }^{2}$ ) & 1.05 & 1.01 & 1.08 \\
Years of school (per 1 yr) & 0.98 & 0.93 & 1.04 \\
MedDietScore (per $1 / 55$ units) & 0.97 & 0.91 & 1.03 \\
\hline
\end{tabular}

Declaration of competing interests: Nothing to declare.

Funding: The MEDIS study was funded by Research grants from the Hellenic Heart Foundation. Author CIV is currently supported by a Flight Attendant Medical Research Institute (FAMRI) award. 


\section{REFERENCES}

1. Houston T, Person S, Pletcher M, Liu K, iribarren C, Kiefe C. Active and passive smoking and development of glucose intolerance among young adults in a prospective cohort: CARDIA study. BMJ. 2006; 332; 1064-1069

2. Hayashino $\mathrm{Y}$, Fukuhara S, Okamura T, Yamato H, Tanaka H, Tanaka T, Kadowaki T, Ueshima H; HIPOP-OHP Research Group. A prospective study of passive smoking and risk of diabetes in a cohort of workers: the High-Risk and Population Strategy for Occupational Health Promotion (HIPOPOHP) study. Diabetes Care. 2008; 31(4):732-4.

3. Schick S, Glantz S. Philip Morris toxicological experiments with fresh sidestream smoke: more toxic than mainstream smoke. Tob Control. 2005; 14:396-404 
CHAPTER 8

\section{GENERAL DISCUSSION}




\subsection{Cardiovascular disease risk factors among farmers in Crete}

Currently cardiovascular disease (CVD) is one of the leading causes of global mortality. Through this thesis we were able to investigate into the changes in a number of traditional risk factors for the development of cardiovascular disease (CVD) within a farming population in the valley of MESSARA in Crete, very similar to the farming population first studied within the context of the Seven Countries Study 45 years ago. Greece has witnessed a continuous increase in CVD mortality over the past few decades [1]. In comparison to 45 years ago when the Mediterranean diet was first scientifically described, the risk factors for the development of CVD in rural Crete have significantly changed. Two key factors that we attribute this change to, are the adoption of a more "western European" lifestyle that effects health related behaviours and specifically dietary habits [2-3].

The changes in the prevalence of the risk factors for the development of CVD come to reflect the cultural social differences between rural Crete of the 1960's and today, changes mainly influenced by the boom in the tourist industry during the 1970's-1980's, that introduced the island of Crete -and Greece in general- as a major tourist destination.

As noted in Chapter 2, based on the significantly modification by the population's non adherence to the traditional Mediterranean diet, we identified a decrease in systolic blood pressure over the years but an increase in obesity indexes, physical inactivity, serum glucose and lipids [3] The decrease in the mean SBP (-8\%) and in the percentage of the population with SBP>130 (-26\%) is likely to be due to the improvement in hypertensive treatment and primary care prevention as part of the global effort to reduce the burden of hypertension [4-5]. On the other hand, the $16 \%$ increase in the populations total cholesterol level is a strong indicator of the increased excess risk for the development of CVD [6, 7-8]. Prospective follow up cohorts, as the 20, 25 and 40 year follow-ups on the survivors of the initial SCS cohort have demonstrated at a population based level the significance of cholesterol levels on CVD, cancer and general mortality [6, 9-11]. This noted difference in mean cholesterol levels between the initial SCS cohort from Crete and the MESSARA study participants is stressed by the fact that even among the initial participants and subsequent 25 year follow up survivors of the SCS, the highest coefficient for mortality found in the multivariate analysis in Greece was for total blood cholesterol [6].

Affecting insulin resistance, lipid metabolism and promoting systemic inflammation, obesity predisposes to a number of non-communicable diseases such as hypertension, dyslipideimia and type II diabetes [12-13]. The association between bodyweight and both total and cardiovascular disease mortality is well documented [8]. Population based follow up studies with cohorts from the Mediterra- 
nean have clearly demonstrated the relationship between increased obesity indexes and both acute and chronic cardiovascular disease [6, 14-15] As depicted in chapter 3, a sex-specific association with overweight and obesity was also detected among participants in the MESSARA study. Females had a higher BMI, WC, W/Hip ratio, W/Height ratio and percentage of body fat when compared to male participants. It is of significant interest to compare our results with the results of the Seven Countries Study, which took place in Crete in the 1960s with a cohort of men from several villages, 75\% of which were farmers born between 1900 to 1919 and followed up over 40 years [16]. The mean age of the participants then was 49 years (range 40-59) and their mean BMI was $22.9 \mathrm{~kg} / \mathrm{m}^{2}$. For the same age group in our study population the mean BMI was $29.8 \mathrm{~kg} / \mathrm{m}^{2}$, almost $7 \mathrm{~kg} / \mathrm{m}^{2}$ higher than the $\mathrm{BMI}$ of farmers in Crete forty years ago. The average body weight of farmers was $63 \mathrm{~kg}$ in the 60 's during the baseline measurements of the seven countries study, while male participants in Messara currently have an average weight of $83 \mathrm{~kg}$, thus noting an alarming $32 \%$ increase, a fact that can't certainly not be explained by the noted but not significant decrease in energy intake (2820kcal in the 1960's to $2412 \mathrm{Kcal}$ in the Messara study) [17-18]. Subsequently, as the energy input has not differed significantly over the past 45 years among the farming population of Crete we hypothesise that this noted difference in obesity indexes are attributable in the first place to much lower levels of physical activity. But also possibly a difference in the macronutrient content through which the calories are obtained.

A sedentary lifestyle is considered to be one of the most important modifiable risk factors for cardiovascular morbidity and mortality [19]. Among the participants of the MESSARA study, women of all ages were found to have a more sedentary lifestyle and noted lower levels of Moderate to Vigorous Physical Activitiy (MVPhA) and higher levels of Light Physical Activity (LPhA) thus affecting their daily energy expenditure and subsequently also their obesity indexes and most likely their risk for both CVD and cancer [20]. Fortunately, a moderate level of occupational or recreational activity appears to confer a significant protective effect, while systematic reviews have shown that there is a dose-dependent reduction in CVD risk with higher walking duration, distance, energy expenditure and pace [21].

A large amount of evidence suggests that regular moderate exercise prevents the development and progression of atherosclerosis and benefits dyslipidemia and reduces vascular symptoms in patients with documented CVD. The mechanism of benefits is derived from maintenance of body weight, blood pressure control, insulin resistance, and dyslipidemia management, all of which promote endothelial stabilization and vascular health $[22,23]$.

Currently, the American College of Sports Medicine (ACSM) and the American Heart Association (AHA) recommend for the healthy population (ages 18-64 years 
old) a minimum of 30 minutes of moderate physical activity at least 5 days weekly but, preferably everyday or 20 minutes of vigorous exercise [24]. Moreover, as research has indicated that in patients with established vascular disease, regular physical activity decreases the rate of CV events we stress the fact that the farming population of Crete would benefit from an increase in both the level and frequency of weekly physical activity [25].

Based on job related physical activity, over $60 \%$ of the men in the Seven Countries Study habitually engaged in hard physical work for which their mean energy expenditure was estimated at more than $3000 \mathrm{kcal}$ per day, while only $7 \%$ of the population in the 1960s; were classified as having sedentary levels of physical activity [26], Notably, the level of physical activity among the Messara Study participants is considerable lower, a factor further increasing the populations mortality risk [27]. This reduction in physical activity among the farming population of Crete could be attributed to the mechanization of farming techniques, the use of vehicles and motorcycles in sheep herding and the purchase of food produce from the supermarkets, which 45 years ago would have been, at least up to a point, self cultivated.

Among populations with a number of other cardiovascular risk factors, such as diabetes mellitus, physical activity has been associated with a reduced risk of cardiovascular death, and total mortality in men [28].

Over the past decades type 2 diabetes has changed from a chronic metabolic disease in elderly into a major health problem affecting an increasing number of people worldwide [29]. Diabetes related complications are considerable and prevention and treatment of diabetes are of utmost importance to increase quality of life and reduce the increasing health care costs. The analysis of the data of the MEDIS study, (Chapter 7) showed that a considerable proportion of the participants had diabetes, a condition that could have possibly been partially promoted by chronic exposure to SHS and/or non adherence to the Mediterranean diet. Thus, the presented findings have substantial importance for public health and diabetes management, and thus extend the current scientific knowledge on the detrimental effects of exposure to SHS. In line with these studies findings, exposure to SHS was independently related to the development of diabetes mellitus, along with other more "classical" predisposing factors such as the family history, a lack of physical activity, hypertension and hypercholesterolemia. [30]

Research has indicated that adherence to the Mediterranean diet can influence endothelium function among people with abdominal obesity which in turn is associated with an increased risk of cardiovascular disease and type 2 diabetes [31] Similarly to previous findings, adherence to the Mediterranean diet (as assessed through the 55 point scale), was independently found to reduce the likelihood of 
the development of diabetes mellitus, although the results were not as prominent as for the aforementioned predisposing factors. This discrepancy we attribute to the fact that the participants in the MEDIS study were elderly (aged 65-100), and most probably their dietary habits may have changed over the years.

\subsection{Dietary habits of farmers from Crete: A disappearing Mediterranean diet}

Since antiquity the Greek population followed to consume a traditional dietary pattern, known as the Mediterranean diet of Crete. This diet is low in saturated fat and red meat consumption but high in monounsaturated fat (obtained mainly through the elevated intake of olive oil), antioxidants and vitamins (from fresh fruit, wild greens, vegetables, nuts and legumes) [32-33].

In general and irrespective of smoking status, a relative large proportion of the farming population of Messara was found to have a number of alarming deficiencies in vitamin intake as well as daily fibre, fruit and vegetable consumption, a factor that would effect their predisposition to chronic disease and cancer [34-36]. As seen in Chapters $2 \&$, the fact that almost $40 \%$ of the population consumes less than $67 \%$ of the RDA for fruit and vegetables might be due to the possibility that the population, or a subgroup of it, may not adhere to the traditional Mediterranean diet of Crete, further studies are needed to have a detailed analysis of this hypothesis. Indeed in comparison to 45 years ago, current $40-60$ year old farmers consume $40 \%$ less fruit and vegetables while a remarkable $254 \%$ more meat per day, a very strong indicator of their non adherence to the Mediterranean diet.

As described in Chapter 2, the mean daily dietary intake of saturated, polyunsaturated and monounsaturated fat has altered over the past 45 years (by $+9 \%,+10 \%$ and $-10 \%$ respectively). These results also indicate a lower adherence to the Mediterranean diet and a decrease most likely in olive oil consumption as verified by the decrease in daily monounsaturated fat intake, a fact that in correlation with the increased protein intake could explain the difference in calorie intake over the past 45 years. It has been speculated that modern lifestyles, less time in preparing the meals at home; and the increased cost of olive oil, fish, cereals, fruits and vegetables, instead of other fats and animal products, may have lead southern Mediterranean populations away from this healthy dietary patter, a hypothesis with which we agree to [37]. These above findings, although previously noticed among some urban populations in Greece, have never been found among the rural population, especially that of Crete [38]. As adherence to the Mediterranean diet and activity levels has a protective effect on obesity, acute CVD episodes, the metabolic syndrome and lowers overall mortality, the gradual trend of the populations move towards a more northern European diet, (replacing saturated with monounsaturated fat) as well as lower levels of activity, would also have a significant effect on the health status of the population [39-42]. 


\section{2a Adipose tissue fatty acid composition: the changing dietary fingerprint of farmers in Crete}

The extent to which epidemiological research methods can be exploited to elucidate and substantiate the relation between dietary fat and the risk of chronic diseases such as heart disease and cancer is dependent heavily on the accurate and precise measurement of usual intake of dietary fats. Respondents often underreport consumption, a practice more common amongst those who are overweight than lean, while incorrect portion size estimations, coding and computational errors, and errors associated with the use of food composition databases are also known problems when evaluating dietary profiles [43] The fatty acid composition of adipose tissue has been considered a gold standard for the representation of dietary fatty acids, due to the slow turnover time in weight stable individuals. In the 1960s it was estimated that the $t_{1 / 2}$ of adipose tissue TAG was between 1 and 2 years. Recent work by Strawford et al. using stable isotope methodology estimated that the $t_{1 / 2}$ of adipose tissue lipids is between 6 and 9 months [44-46].

Taking the above into account, in addition to the use of dietary food frequency questionnaires (Chapter 6), in the context of the MESSARA study (Chapter 2), gluteal adipose tissue was collected from the study participants as a method of evaluating long term, chronic dietary intakes.

The noted increase in the SFA and the decrease in the MUFA of adipose tissue among farmers from Crete over the past 45 years gave a clear insight into the abandoning of the traditional Mediterranean diet of Crete and the adoption of a more westernised "modern" diet. Furthermore, the qualitative changes in adipose tissue content between the MESSARA study, the Seven Countries Study and the 1960's study by Christakis et al are indicative of the increase in cardiovascular risk, as the ratio of adipose tissue fatty acids is a clear marker of CVD and related to mortality [47-48]. In coherence with the reported dietary intake, adipose tissue fatty acid composition was found to differ between the population of Crete in the 1960's and the population of Messara in 2005 with the latter found to have a higher percentage of saturated fats, and a lower percentage of monounsaturated fats. These results are indicative of the abandoning of the Mediterranean diet and its consequences both on a personal and public health level among farmers in Crete. Indeed Case-control or prospective cohort data sets examining the risk for CHD endpoints as a function of tissue fatty acid composition have indicated that the long-chain n-3 fatty acids, are consistently and significantly reduced in patients experiencing CHD events [47]

As seen in Chapter 3 the FA profile of the survivors of the SCS (taken in 2000) is different to the FA profile of the Messara study participants (taken in 2005), something which we expected due to the fact that that the participants of the SCS in 
2000 were between $80-100$ years old, in comparison to the participants of the MESSARA study who were 40-60. It is further possible that the differences in dietary habits between the 80-100 year old survivors of the SCS and the current MESSARA study participants could not be attributable to age but to long term dietary habits since research has indicated that the majority of changes in the fatty acid composition of tissue and blood lipids that have been reported to occur with age can in part be explained by differences in dietary fatty acid intakes rather than agerelated perturbations in fatty acid metabolism. [43]

\section{2b Fasting and its role in the Mediterranean diet}

In recent years, much interest has focused on this special practice that is retained and is characteristic of the Mediterranean diet of Crete, and in regards to its beneficial effect on dietary habits and health [44]. Our results agree with an earlier study investigating the eating habits of people living in monasteries and free-living individuals who fast, in comparison with matched controls who never fast [50]. Fasters were generally reported to have lower intakes of dietary cholesterol, total and saturated fat, protein and calcium and higher intakes of dietary fiber, folate, iron and carbohydrates, during fasting, as compared to non-fasting periods [50]. A model of the Greek Orthodox fasting rituals was also established in another study, which assessed the nutrient composition of this eating pattern by chemically analyzing the weekly food and nutrient intake of a strict adherent to the Church's recommendations [51]. Similar to our findings, this study demonstrated higher intakes of dietary fibre and antioxidant vitamins and lower intakes of saturated fat and dietary cholesterol compared to adults and adolescents of the same region. A further indication of the healthy dietary habits associated with the Greek Orthodox Church's fasting rituals is the increased mean daily fruit and vegetable intake observed during the fasting weeks, which would further act protectively against the development of chronic diseases such as cancer and CVD, which would thus have an impact on mortality and public health.

\subsection{Smoking, oxidative stress and antioxidant intake}

Observing the strong role of the Mediterranean diet as studied through the context both of the historical Seven Countries Study as also through the current MESSARA study we were led to hypothesise that adherence to the Mediterranean diet could partially ameliorate some of the negative health affects of active and passive smoking [52].

In our study of randomly selected farmers in Crete (Chapter 6) current smoking status was strongly related to dietary patterns, with smokers found to have a lower dietary fibre, fruit and vegetable intake in comparison to non-smokers. After adjusting for age, gender and number of fasting days adhered to per year, current 
smokers were found to have a lower dietary intake of vitamin $\mathrm{C}$, fibre and fruits and vegetables, while dietary vitamin $B_{1}$ intake was found to be higher in comparison to non/ex smokers. Smoking status also effected serum folate concentrations when corrected for dietary intake, while serum iron and serum vitamin $B_{12}$ levels were not associated with current smoking status. Folate and vitamins $B_{6}$ and $B_{12}$ are involved in the regulation of homocysteine, and elevation of homocysteine has been shown to be an independent risk factor for coronary heart disease [53].

Cigarette smoke can promote atherosclerosis, in part, by its effects on the lipid profile of the active and passive smoker. Smoking decreases plasma high lipoprotein levels (HDL) and alters the ratios between HDL and low density lipoproteins (LDL), HDL and triglycerides (TG) and HDL and total cholesterol levels, both in animal models and humans [54-56]. It is interesting to note that lipid peroxidation among young smokers is noted, even after controlling for dietary intake, as a reliable indicator of the level of smoking. In contrast to the above it has been shown in randomized controlled trials that adherence to the Mediterranean diet had a beneficial effect on circulating oxidised LDL levels, a factor that could possibly counter balance the increase in oxidised LDL molecules induced by exposure to tobacco smoke [57]

The differences in dietary fat intake are clearly apparent when comparing the Mediterranean diet, with a more westernised diet. Although the fat percentage is similar in quantity in both, it differs dramatically in quality as the Mediterranean diet is rich in monounsaturated fatty acids, such as oleic acid, but very low in saturated fat. Furthermore, the high fruit and vegetable intake of the Mediterranean diet also leads to an increase in vitamin and antioxidant intake with additional protective properties. These essential antioxidants are abundant in the traditional Mediterranean diet, and as depicted in Chapter 4, are found to be even higher during fasting weeks of the traditional diet of Crete. Vitamins A, E and C. Human health benefits from these high levels of antioxidant vitamins such as vitamin $C$, beta-Carotene as well as lutein that inhibit the oxidative process of LDL cholesterol into its atherogenic forms and therefore preserve endothelial function and prevent the development of atherosclerosis and coronary heart disease [58-60].

\subsection{Smoking, inflammation and serum antioxidants}

Atherosclerotic lesions in coronary heart disease have been found to accumulate CD4+ $\mathrm{T}$ lymphocytes, and can contribute to lesion progression and remodelling [61]. The rupture of these lesions and the subsequent thrombus formation is the dominant mechanism for acute coronary events [62]. Additional research among mice exposed to side stream second hand smoke has also provided evidence that long term exposure to second hand smoke can cause a state of permanent inflam- 
mation, influencing pro-inflammatory and cell mediated responses and produce cytokines that further activate antibody producing T-cells and so activating a cascade of reactions in response to the oxidative stress of SHS [63]. As SHS is a potent source of oxidative stress, we had hypothesized that it is plausible that a higher serum antioxidant status could act protectively and act as a buffer against the increased free radical production, antioxidant depletion and oxidative stress caused by exposure to SHS [64].

\subsection{Future research avenues}

While the evidence on the role of antioxidants and dietary intakes on cancer, cardiovascular, respiratory and other chronic diseases is extensive, our knowledge of the role of antioxidant or micronutrient supplementation on these outcomes is incomplete and contradictive as the evidence is insufficient to conclude that micronutrient supplementation has a definite protective effect [65-69]. To date, the existing scientific literature has indicated that the dietary intake of beneficial antioxidants, lipids and other micronutrients, through adherence to the Mediterranean diet, can have a protective effect on cancer, cardiovascular and respiratory diseases and it is possible that this diet can act as an positive effect modifier of the role active and passive smoking on health. Acknowledging the fact that it has been estimated that at least 1000 million adults are smokers worldwide and that at least 700 million children breathe air polluted by tobacco smoke at home the public health implications of adherence to such a diet are significant [70].

We must state that further research is needed so as to investigate into this current hypothesis. Within Crete, it would be possible to conduct either a cohort study and follow up farmers from Crete and investigate prospectively in the interaction between smoking and dietary intakes on the development of acute or chronic disease. Such a study though would need a substantial number of years and a large sample size so as to detect differences. On the other hand it would be interesting to perform a controlled study, in which participants would be allocated to either a Mediterranean style diet, or a more western European diet and then followed up for a number of months after which measures of oxidative stress, DNA damage, molecular markers of inflammation, genetic profiles and long term exposure to secondhand smoke would be measured. This controlled study would be of significant interest and might not have to be located alone in Crete. It could be possible to perform such a study using cohorts from different countries and thus populations that adhere to different dietary habits, however exposure to second hand smoke varies greatly by population and thus participants would have to be carefully selected by both dietary habits and level of second hand smoke they are exposed to. As the European Union continues to support multidisciplinary and multinational research within the borders of the EU, such a study could be the base of a future EU Framework Package grant submission. 
Conclusively, although the best ways to avoid the negative health ramifications of active and passive smoking are to stop smoking, avoid exposure to SHS and promote cessation and the adoption of smoke free environments, adherence to the Mediterranean diet could provide an additional supportive effect to the above and thus have significant implications on clinical outcomes and public health. 


\section{REFERENCES}

1. Sans S, Kesteloot H, Kromhout D on behalf of the Task Force. The burden of cardiovascular diseases mortality in Europe. Task force of the European Society of Cardiology on Cardiovascular Mortality and Morbidity Statistics in Europe. European Heart Journal. 1997; 18: 1231-48

2. Trichopoulos D, Lagiou P. Mediterranean diet and overall mortality differences in the European Union. Public Health Nutr. 2004; 7(7):949-51.

3. Panagiotakos DB, Pitsavos C, Chrysohoou C, Skoumas J, Tousoulis D, Toutouza M, et al. Impact of lifestyle habits on the prevalence of the metabolic syndrome among Greek adults from the ATTICA study. Am Heart J. 2004; 147(1):106-12

4. Danon-Hersch N, Marques-Vidal P, Bovet P, Chiolero A, Paccaud F, Pécoud A, et al. Prevalence, awareness, treatment and control of high blood pressure in a Swiss city general population: the CoLaus study. Eur J Cardiovasc Prev Rehabil. 2009; 16(1):66-72.

5. Levi F, Chatenoud L, Bertuccio P, Lucchini F, Negri E, Vecchia CL. Mortality from cardiovascular and cerebrovascular diseases in Europe and other areas of the world: an update. Eur J Cardiovasc Prev Rehabil. 2009; 16(3):333-350

6. Menotti A, Blackburn H, Kromhout D, Nissinen A, Adachi H, Lanti M. Cardiovascular risk factors as determinants of 25-year all-cause mortality in the Seven Countries Study. Eur J Epidem. 2001; 17;337-346.

7. Moschandreas J, Kafatos A, Aravanis C, Dontas A, Menotti A, Kromhout D. Long-term predictors of survival for the Seven Countries Study cohort from Crete: from 1960 to 2000. Int J Cardiol. 2005; 100(1):85-91.

8. Romero-Corral A, Montori V, Somers V, Korinek J, Thomas RJ, Allison TG et al. Association of bodyweight with total mortality and with cardiovascular events in coronary heart disease: a systematic review of cohort studies. Lancet. 2006; 368:666-78

9. Pitsavos C, Panagiotakos DB, Menotti A, Chrysohoou C, Skoumas J, Stefanadis C, et al. Forty-year follow-up of coronary heart disease mortality and its predictors: the Corfu cohort of the seven countries study. Prev Cardiol. 2003;6(3):155-60

10. Menotti A, Lanti M, Nedeljkovic S, Nissinen A, Kafatos A, Kromhout D. The relationship of age, blood pressure, serum cholesterol and smoking habits with the risk of typical and atypical coronary heart disease death in the European cohorts of the Seven Countries Study. Int J Cardiol. 2006; 106(2):157-63.

11. Menotti A, Lanti M, Kromhout D, Blackburn H, Nissinen A, Dontas A, et al. Forty-year coronary mortality trends and changes in major risk factors in the first 10 years of follow-up in the seven countries study. Eur J Epidemiol. 2007; 22(11): 747-54.

12. Pi-Sunyer FX. The obesity epidemic:pathophysiology and consequences on obesity. Obes Res. 2002. 10 (Suppl 2):97-104

13. Kraus RM, Winston M, Fletcher BJ, Grundy SM (1998) Obesity: impact on cardiovascular disease. Circulation. 98:1472-76

14. Panagiotakos DB, Pitsavos C, Chrysohoou C, Skoumas I, Stefanadis C. Five year incidence of cardiovascular disease and its predictors in Greece: the Attica Study. Vasc Med. 2008. 13(2):113-21

15. Panagiotakos DB, Pitsavos C, Chrysohoou C, Stefanadis C, Toutouza P. Risk stratification of coronary heart disease through established and emerging lifestyle factors in a Mediterranean population; Cardio2000 epidemiological study. J Cardiovasc Risk. 2001. 8:329-335

16. Keys A (editor). Coronary heart disease in seven countries. Circulation. 1970; 41(suppl 1): 1-211.

17. Vardavas C.I, Linardakis M, Hatzis C, Malliaraki N, Saris W, Kafatos A. Smoking Status in Relation to Serum and Dietary Vitamin and Micronutrient Concentrations. Tobacco Induced Diseases 2008, 4:8

18. Kromhout D, Keys A, Aravanis C, et al. Food consumption patterns in the 1960's in seven countries. Am J Clin Nutr; 49:889-94

19. Prasad DS, Das BC. Physical inactivity: a cardiovascular risk factor. Indian J Med Sci. 2009;63(1):3342 
20. Kruk J, Aboul-Enein HY. Physical activity in the prevention of cancer. Asian Pac J Cancer Prev 2006. 7(1):11-21

21. Boone-Heinonen J, Evenson KR, Taber DR, Gordon-Larsen P. Walking for prevention of cardiovascular disease in men and women: a systematic review of observational studies. Obes Rev. 2009; 10(2):204-17.

22. Maron B.J., Chaitman B.R. and Ackerman M.J. Bayés de Luna A, Corrado D, Crosson JE, Deal BJ, Driscoll DJ, Estes NA 3rd, Araújo CG, Liang DH, Mitten MJ, Myerburg RJ, Pelliccia A, Thompson PD, Towbin JA, Van Camp SP; Working Groups of the American Heart Association Committee on Exercise, Cardiac Rehabilitation, and Prevention; Councils on Clinical Cardiology and Cardiovascular Disease in the Young. Recommendations for physical activity and recreational sports participation for young patients with genetic cardiovascular diseases, Circulation. 2004; 109 pp. 2807-2816.

23. Di Francescomarino S, Sciartilli A, Di Valerio V, Di Baldassarre A, Gallina S. The effect of physical exercise on endothelial function. Sports Med. 2009;39(10):797-812.

24. Jolliffe JA, Rees K and Taylor R.S. Thompson D, Oldridge N, Ebrahim S. Exercise-based rehabilitation for coronary heart disease, Cochrane Database Syst Rev. 2001, p. CD001800

25. Haskell W.L., Lee I.M. and Pate R.R. Powell KE, Blair SN, Franklin BA, Macera CA, Heath GW, Thompson PD, Bauman A; American College of Sports Medicine; American Heart Association. Physical activity and public health: updated recommendation for adults from the American College of Sports Medicine and the American Heart Association, Circulation 2007; 116, pp. 1081-1093.

26. Trichopoulos D, Lagiou P. Mediterranean diet and overall mortality differences in the European Union. Public Health Nutr. 2004; 7(7):949-51.

27. Wei M, Kampert JB, Barlow CE, Nichaman MZ, Paffenbarger Jr RS, Blair SN. Relationship between low cardiorespiratory fitness and mortality in normal-weight, overweight and obese men. JAMA. 1999; 282:1547-53

28. Tanasescu M, Leitzmann MF, Rimm EB, Hu FB. Physical activity in relation to cardiovascular disease and total mortality among men with type 2 diabetes. Circulation. 2003;107(19):2435-9.

29. Wild S, Roglic G, Green A, Sicree R, King H: Global prevalence of diabetes: estimates for the year 2000 and projections for 2030. Diabetes Care 27:1047-1053, 2004

30. Vardavas $\mathrm{Cl}$, Lionis C, Polychronopoulos E, Zeimbekis A, Bountziouka V, Stravopodis S, Metallinos G, Panagiotakos DB. The role of passive smoking on the prevalence of type II diabetes mellitus among elderly men and women living in Mediterranean islands: the MEDIS study. Diabetic Medicine 2010; 27(2):242-243

31. Rallidis LS, Lekakis J, Kolomvotsou A, Zampelas A, Vamvakou G, Efstathiou S, Dimitriadis G, Raptis SA, Kremastinos DT. Close adherence to a Mediterranean diet improves endothelial function in subjects with abdominal obesity. Am J Clin Nutr. 2009; 90(2):263-8.

32. Simopoulos A. Overview of evolutionary aspects of $\omega-3$ fatty acids in the diet. In Simopoulos A (Ed). The return of the $\omega-3$ fatty acids into the food supply: I land-based animal food products and their health effects. World Review of Nutrition Diet. 1998; 83. 1-11

33. Ferro-Luzzi A, James W, Kafatos A. The high fat Greek diet: A recipe for all? Eur J Clin Nutr 2002, 56:796-809

34. Nomura AM, Hankin JH, Henderson BE, Wilkens LR, Murphy SP, Pike MC, Le Marchand L, Stram DO, Monroe KR, Kolonel LN. Dietary fiber and colorectal cancer risk: the multiethnic cohort study. Cancer Causes Control. 2007; 18(7): 753-64.

35. Donaldson MS. Nutrition and cancer: a review of the evidence for an anti-cancer diet. Nutrition Journal. 2004; 3:19

36. Divisi D, Di Tommaso S, Salvemini S, Garramone M, Crisci R. Diet and cancer. Acta Biomedica. 2006; 77(2):118-23.

37. Panagiotakos DB, Matalas AL. Back to the ancient diet: A matter of urgency for southern European countries. Nutr Metab Cardiovasc Dis. 2009; 19:153-155 
38. Panagiotakos DB, Tzima N, Pitsavos C, Chrysohoou C, Zampelas A, Toussoulis D, et al. The association between adherence to the Mediterranean diet and fasting indices of glucose homoeostasis: the ATTICA Study. J Am Coll Nutr. 2007; 26(1):32-8.

39. Trichopoulou A, Costacou T, Bamia C, Trichopoulos D. Adherence to a Mediterranean diet and survival in a Greek population. N Engl J Med. 2003; 348(26):2599-608.

40. Mendez MA, Popkin BM, Jakszyn P, Berenguer A, Tormo MJ, Sanchéz MJ, et al. Adherence to a Mediterranean diet is associated with reduced 3-year incidence of obesity. J Nutr. 2006; 136: 2934-8.

41. Babio N, Bullo' M, Basora J, Martı́nez-Gonza'lez MA, Ferna'ndez- Ballart J, Ma'rquez-Sandoval F, , et alon behalf of the Nureta- PREDIMED investigators. Adherence to the Mediterranean diet and risk of metabolic syndrome and its components. Nutr Metab Cardiovasc Dis 2009; 19(8):563-70

42. Verschuren WM, Jacobs DR, Bloemberg BP, Kromhout D, Menotti A, Aravanis C, et al. Serum total cholesterol and long-term coronary heart disease mortality in different cultures. Twenty-five-year follow-up of the seven countries study. JAMA. 1995; 274(2):131-6.

43. Hodson L, Skeaff CM, Fielding BA. Fatty acid composition of adipose tissue and blood in humans and its use as a biomarker of dietary intake. Prog Lipid Res. 2008; 47(5):348-80.

44. Hirsch, J.W. Farquhar, E.H. Ahrens Jr., M.L. Peterson and W. Stoffel, Studies of adipose tissue in man. A microtechnic for sampling and analysis, Am J Clin Nutr 1960. 8: pp. 499-511.

45. A.C. Beynen, R.J. Hermus and J.G. Hautvast, A mathematical relationship between the fatty acid composition of the diet and that of the adipose tissue in man, Am J Clin Nutr. 1980; 33, pp. 81-85.

46. Strawford, F. Antelo, M. Christiansen and M.K. Hellerstein, Adipose tissue triglyceride turnover, de novo lipogenesis, and cell proliferation in humans measured with $2 \mathrm{H}_{2} \mathrm{O}, A m \mathrm{~J}$ Physiol Endocrinol Metab 2004; 286: pp. E577-E588.

47. Harris W, Poston W, Haddock K. Tissue n-3 and n-6 fatty acids and risk for coronary heart disease events. Atherosclerosis. 2007; 193: 1-10

48. Christakis G, Severinghaus EL, Maldonado Z, Kafatos F, Hashim S. Crete: a study in the metabolic epidemiology of coronary heart disease. Am J Cardiology. 1965; 15(3): 320-332

49. Chliaoutakis JE, Drakou I, Gnardellis C, Galariotou S, Carra H, Chliaoutaki M. Greek Christian Orthodox Ecclesiastical Lifestyle: Could it become a pattern of health-related behavior? Preventive Medicine 2002; 34: 428-435.

50. Sarri KO, Linardakis MK, Bervanaki FN, Tzanakis NE, Kafatos AG. Greek Orthodox fasting rituals: a hidden characteristic of the Mediterranean diet of Crete. British Journal of Nutrition 2004; 92: 277284.

51. Kafatos AG, Verhagen $\mathrm{H}$, Moschandreas J, Apostolaki I, Van Westerop J. Mediterranean diet of Crete: foods and nutrient content. J Am Diet Assoc; 2000; 100:1487-1493

52. Vardavas C.I, Papadaki A, Saris W, Kafatos A. Is Adherence To The Mediterranean Diet An Effect Modifier Of The Impact Smoking Has On Health? Public Health. 2009; 123(6):459-460

53. Refsum H, Ueland PM, Nygard O, Vollset SE. Homocysteine and cardiovascular disease. Annual Review of Medicine. 1998; 49:31-62

54. Chelland Campbell SC, Moffatt RJ, Stamford B. Smoking and smoking cessation-the relationship between cardiovascular disease and lipoprotein metabolism: a review. Atherosclerosis. 2008; 201(2):225-35

55. Ambrose JA, Barua RS The pathophysiology of cigarette smoking and cardiovascular disease: an update. J Am Coll Cardiol. 2004; 43(10):1731-7

56. Bloomer RJ. Decreased blood antioxidant capacity and increased lipid peroxidation in young cigarette smokers compared to non-smokers: Impact of dietary intake. Nutr J. 2007; 6:39.

57. Fitó $M$, Guxens $M$, Corella $D$, et al. Effect of a traditional Mediterranean diet on lipoprotein oxidation: a randomized controlled trial. Arch Intern Med. 2007; 167(11):1195-203.

58. Akhilender Naidu. Vitamin C in human health and disease is still a mystery. An overview. Nutr J, 2003; 2:7 
59. Dwyer J.H, Navab M, Dwyer KM, et al. Oxygenated carotenoid lutein and progression of early atherosclerosis: The Los Angeles Atherosclerosis Study. Circulation. 2001; 103, 2922-2927

60. Tavani A, La Vecchia C. $\beta$-Carotene and risk of coronary heart disease. A review of observational and intervention studies. Biomed Pharmacother 1999; 53: 409-16

61. Zhou, X. CD4+ T cells in atherosclerosis. Biomed Pharmacother; 2003; 57:287-291

62. Halvorsen B, Otterdal K, Dahl TB, Skjelland M, Gullestad I, Oie E, Aukrust P. Atherosclerotic plaque stability-what determines the fate of a plaque? Prog Cardiovasc Dis. 2008; 51(3): 183-194

63. Yuan $\mathrm{H}$, Wong LS, Bhattacharya $\mathrm{M}$, et al. The effects of second-hand smoke on biological processes important in atherogenesis. BMC Cardiovasc Disord. 2007; 7:1.

64. Rubin RN, Navon L, Cassano PA. Relationship of serum antioxidants to asthma prevalence in youth. Am J Respir Crit Care Med. 2004; 169(3):393-8.

65. Bardia A, Tleyjeh IM, Cerhan JR, et al. Efficacy of antioxidant supplementation in reducing primary cancer incidence and mortality: systematic review and meta-analysis. Mayo Clin Proc. 2008; 83(1):23-34.

66. Huang HY, Caballero B, Chang S, et al. Multivitamin/mineral supplements and prevention of chronic disease. Evid Rep Technol Assess. 2006; (139):1-117.

67. Riccioni G, Bucciarelli T, Mancini B, Di Ilio C, Capra V, D'Orazio N. The role of the antioxidant vitamin supplementation in the prevention of cardiovascular diseases. Expert Opin Investig Drugs. 2007; $16(1): 25-32$

68. Kaur B, Rowe BH, Arnold E. Vitamin C supplementation for asthma. Cochrane Database Syst Rev. 2009;(1):CD000993

69. Bernhard D, Wang XL. Smoking, oxidative stress and cardiovascular diseases--do anti-oxidative therapies fail? Curr Med Chem. 2007;14(16):1703-12.

70. World Health Organization Division of Noncommunicable Disease, Tobacco Free Initiative. International Consultation on Environmental Tobacco Smoke (ETS) and Child Health. Consultation Report, Geneva 1999. http://www.who.int/tobacco/research/en/ets_report (viewed 04 / 07 / 05) 


\section{Summary}

This thesis describes the public health implications of adherence to the Mediterranean diet among farmers from the island of Crete, Greece and secondly indicates how adherence to the Mediterranean diet could have a protective role against the ramifications of active and passive smoking.

The main core of research was provided through the context of the MESSARA study, which was a cross sectional study of 500 farmers randomly selected from villages of the Valley of Messara, not far from the villages from which participants of the historical Seven Countries Study (SCS) were recruited from almost 50 years ago. In addition to the MESSARA study, data from the cross sectional MEDIS study (data courteously provided by Prof Panagiotakos of the Harokopio University of Athens), was analysed so as to investigate the interaction between diabetes, secondhand smoke and adherence to the Mediterranean diet among a cohort of 1190 elderly (aged 65 to 100 years) men and women from the Republic of Cyprus, and the Greek islands of Mitilini, Samothrace, Cephalonia, Crete, Limnos, Corfu and Zakynthos.

As described in chapter 2, we compared the risk factors for the development of CVD between farmers from Crete in the 1960's and farmers from Crete in 2005. Our results were compared with both findings from the initial SCS, led by Prof Ancel Keys in 1960 and from a regional study led by Prof Christakis a few years later. According to these findings, although smoking status and diastolic blood pressure was not found to differ between the two cohorts, the majority of other indexes were found to be significantly different. Total serum cholesterol was found to have increased by $16 \%$ from $206.9 \pm 41.4 \mathrm{mg} / \mathrm{dl}$ to $239.6 \pm 45.8 \mathrm{mg} / \mathrm{dl}$ and this difference was statistically significant $(p<0.001)$, while the percentage of the population with total serum cholesterol>200 rose by $22 \%$, from $51.5 \%$ in the SCS to $73.6 \%$ in 2005 . From a public health perspective this increase in serum cholesterol levels would have a significant impact on the development of CVD. One consoling finding was that systolic blood pressure was found to have dropped by $8 \%$, as also the percentage of the population with high blood pressure (by - $26 \%$ ) a fact which we attribute to the improvement in hypertensive treatment and primary care prevention of hypertension.

Although the energy intake among participants of the SCS was higher than those of the MESSARA study a significant increase in the daily intake of PUFA and SFA from $13.4 \mathrm{~g}$ to $14.7 \mathrm{~g}$ and from $28 \mathrm{~g}$ to $30.4 \mathrm{~g}$ was noted, and these differences were statistically significant ( $p=0.035$ and $p=0.031$ respectively). The daily intake of MUFA has 
on the other hand decreased over the past 45 years from $84.1 \mathrm{~g}$ to $63.4 \mathrm{~g}$ $(p<0.001)$. The above dietary fat and energy intake have also affected the BMI among farmers in Crete and the mean BMI was found to have increased by almost $7 \mathrm{~kg} / \mathrm{m}^{2}$ over the past 45 years from $23 \mathrm{~kg} / \mathrm{m}^{2}$ to almost $30 \mathrm{~kg} / \mathrm{m}^{2}(p<0.001)$. This surprisingly large increase in $\mathrm{BMI}$ among farmers of Crete is a direct indicator of their increased risk for the development of CVD. Puzzled by these scientific findings we investigated into the possible dietary intakes of farmers from Crete then and now by comparing food groups initially and secondly by comparing the fatty acid composition of gluteal adipose tissue. Indeed the daily intake of fruit alone in the 1960's SCS cohort was 464gr in comparison to today's $118 \mathrm{gr}(-75 \%, \mathrm{p}<0.001)$ of the MESSARA cohort, while combined consumption of fruit and vegetables dropped $39 \%$ (655 to 401gr, $\mathrm{p}<0.001$ ).

Moreover farmers of the MESSARA study were found to consume $254 \%$ more meat per day, a very strong indicator of their non adherence to the Mediterranean diet. These dietary preferences were also corroborated by the adipose tissue composition which indicated an increase in the percentage of saturated fats and a decrease in the percentage of monounsaturated fats located within gluteal adipose tissue. In summary it has become clear that from the world famous meditarenian diet originated in Crete, little is left nowadays which certainly will have its public health implication in the near and far future for the population in Crete.

In chapter 3, we investigated into the obesity indexes of both men and women of the MESSARA study and found that $86 \%$ of the population was either overweight or obese. Specifically $42.9 \%$ had a BMI of $25.1-30 \mathrm{~kg} / \mathrm{m}^{2}$ and were overweight and $43.2 \%$ were obese with a $\mathrm{BMI}>30 \mathrm{~kg} / \mathrm{m}^{2}$. The percentage of body fat was estimated at $27.3 \%$ of total body weight among males and $39.3 \%$ among females. Moreover for all indexes, women were found to be of a higher risk for the development of chronic disease as both BMI and waist circumference were statistically related to gender with a $\mathrm{p}$-value of 0.007 and $<0.001$ respectively. Similar findings were also found regarding WC (males $100.4 \mathrm{~cm}$, females $102.7 \mathrm{~cm}, \mathrm{p}=0.037$ ), $\mathrm{W} /$ Hip ratio (males 0.99 , females $0.96, \mathrm{p}=0.001$ ) and $\mathrm{W} /$ Height ratio (males 0.60 , females $0.66, p<0.001)$. Additionally the participants conicity index was found to be affected by gender $(p<0.001)$, daily energy intake $(p=0,019)$ and fasting days that the participant adheres to per year $(p=0.010)$, leading us to investigate into the role of the fasting rituals of the Mediterranean diet, and we did so in the study presented in chapter 4.

In chapter $\mathbf{4}$ we showed that nutrient and food intake profiles of Greek Orthodox monks were favourable in the fasting weeks in comparison to non fasting weeks. Lower intakes of total, saturated and trans fatty acids were noted, while on the contrary the participants were noted to have a higher intake of dietary fibre, folate 
legumes and seafood. This important compound of the Mediterranean diet should be widely recognised for its ability to lower serum cholesterol lipid levels, as noted within the context of this study. Furthermore, the ratio of total:HDL-cholesterol, a better predictor of coronary heart disease risk status than total cholesterol levels, was also significantly lower during the fasting week, suggesting the potential contribution of the Greek Orthodox fasting rituals in favourable blood lipid profiles. It is possible at a population based level that public health could be effectively influenced by such a lipid profile. A further indication of the healthy dietary habits associated with the Greek Orthodox Church's fasting rituals is the increased mean daily fruit and vegetable intake observed during the fasting weeks, which would act protectively against the development of chronic diseases such as cancer and CVD, which could thus have an impact on mortality and public health.

In chapter 5, an overview is given about the possible role of the Mediterranean diet as an effect modificator of the role active and passive smoking can have on ones health and number of mechanisms and possible role of micronutrients and antioxidants is discussed. One important point raised by this review is that smokers often have a different dietary profile when compared to non smokers and thus the epidemiological noted differences could be attributed to a "smoker diet" and not solely to cigarette smokes role on circulating lipids, antioxidants and atherosclerotic mechanisms in the human body.

Taking the above into account we deemed it of interest to investigate into the dietary intakes of both smokers and non-smokers and how they have an effect on selected serum micronutrients. Thus we investigated into this hypothesis through the MESSARA study participants for whom analytical dietary data was available and the results of this investigation are presented in chapter 6 . According to the collected information and after controlling for possible confounding factors such as age, gender and Christian Orthodox fasting rituals current smokers were found to have a lower dietary intake of vitamin C (112.1mg vs. $136.4 \mathrm{mg}, p=0.03)$, fibre (16.6g vs. $19.1 \mathrm{~g}, p=0.006$ ) and fruits and vegetables ( $339 \mathrm{~g}$ vs. $412 \mathrm{~g}, p=0.014$ ), while dietary vitamin $B_{1}$ intake was found to be higher ( $1.7 \mathrm{mg}$ vs. $1.4 \mathrm{mg}, p=0.02$ ) in comparison to non/ex smokers. This different dietary pattern has an impact on their intake of essential micronutrients and antioxidants. This in coherence with their increased oxidative stress that they are exposed to could further predispose smokers to chronic disease development.

Moreover, almost $40 \%$ of the participants of the MESSARA study were found to consume less than $67 \%$ of the RDA for fruit and vegetables. A fact that is indicative that the population of the Messara valley, or a subgroup of it, may not adhere to the traditional Mediterranean diet of Crete. 
In Chapter 7, we investigated into the factors that influence the development of diabetes mellitus among the elderly and found that hypertension (OR 2.07), family history of diabetes (OR 4.46) and body mass increase (OR 1.05 per $1 \mathrm{~kg} / \mathrm{m}^{2}$ increase) were risk factors for the development of diabetes mellitus. Taking these factors into account we must stress that adherence to the Mediterranean diet has been shown to effectively reduce these factors independently and thus subsequently could reduce the prevalence of diabetes mellitus and thus have an additional role in public health measures. Furthermore, chronic exposure to second hand smoke was independently related to the development of type II diabetes mellitus (OR 1.60), while on the other hand adherence to the Mediterranean diet (assessed with a 55 point dietary scale) was independently found to act protectively against the development of type II diabetes mellitus (OR 0.97 per 1/55 units).

In summary, from the series of studies described in this thesis the main conclusions are that:

- The potential risk for the development of CVD among farmers from Crete has significantly changed over the past 45 years with current farmers found to have a by $7 \mathrm{~kg} / \mathrm{m}^{3}$ higher BMI, higher cholesterol levels and lower levels of physical activity albeit lower mean systolic blood pressure in comparison to the initial participants of the SCS.

- The above changes in the prevalence of the above CVD risk factors are attributable to the population's non adherence to the Mediterranean diet as indicated through both the decrease in consumption of fruit and vegetables and the increase in consumption of meat. These above dietary differences have lead to an alteration of the fatty acid composition of gluteal adipose tissue over the past 45 years with a noted increase in the percentage of saturated fats and a decrease with the percentage of monounsaturated fats within gluteal adipose tissue.

- The majority of farmers from Messara in Crete were overweight and obese while their farmers' conicity index was found to be related to energy intake and the number of fasting days per week.

- Adherence to the Mediterranean diet and specifically to the fasting rituals of the Mediterranean diet can increase the intake of fibre, folate, antioxidants vitamins and reduce fat intake. The latter has an impact on total serum cholesterol levels.

- Smoking status has a significant impact on dietary preferences as smokers were found to have a lower dietary intake of antioxidants, fruit and vegetables while a higher intake of meat. These dietary preferences of smokers increase the percentage of the population that receives less than the recommended daily allowance in essential micronutrients and vitamins. 
- Chronic exposure to second hand smoke is related to the development of type II diabetes mellitus, while adherence to the Mediterranean diet is independently found to act protectively against the development of type II diabetes mellitus at a population based level.

Further research is necessary to investigate into the public health implications of the interaction between active/passive smoking and adherence to the Mediterranean diet through prospective cohort studies or dietary/exposure control trials.

The farming population of Crete would benefit from population based and school based educational interventions. Having identified the problem within the context of the MESSARA study, a campaign aimed on educating the young population of the Messara valley in regards to the beneficial effects of a healthy lifestyle, that would include smoking prevention, physical activity and adherence to the traditional Mediterranean diet, is essential.

Smoking and exposure to secondhand smoke must be recognised as two significant factors that may play a role in the development of chronic disease among populations that adhere to the Mediterranean diet, and efforts should be made so as to both "denormalise" smoking and eliminate exposure to secondhand smoke in public places, such as the traditional "kafenia".

Health practicioners, school teachers and the local authorities should unify their efforts so as to promote good health and protect public health in both rural areas as also urban areas of Crete. 



\section{Acknowledgements}

It is with great pleasure that I express my sincere gratitude to Prof Wim Saris, of the University of Maastricht. I am very grateful to have had him as the UM promoter of $\mathrm{my} \mathrm{PhD}$ and it is an honor to have received his support, guidance, comments and critique during the process of my PhD studies.

I am also very privileged to have worked with Prof Anthony Kafatos on both my $\mathrm{PhD}$ and on numerous other topics of interest to nutrition, obesity, smoking and prevention. His guidance over the past 6 years at the University of Crete has been influential on my career path and my understanding of the importance of prevention as the corner stone of personal and population based health.

I gratefully thank both promoters for their mentoring, support and guidance that allowed me to make my first successful steps into the world of scientific research.

I would like to thank Prof Christos Lionis for his support and mentoring and also for his trust in the capabilities of young researchers who he so passionately supports.

I would also like to thank Prof Anastasios Philalithis of the University of Crete, and chairman of the M.Sc course in Public Health, as it was through this degree that I was able to pursue a PhD at the University of Maastricht and through which I was provided with the tools necessary to be able to perform community based research.

I would also like to thank Prof Manolis Kogevinas of CREAL, senior Principal Investigator of the FETAL study, funded by the Flight Attendant Medical Research Institute (FAMRI) for his understanding and support. I am also thankful to have received FAMRI funding that enabled me to embark on my research endeavors.

As a substantial amount of my PhD work was based on the MESSARA study, I am grateful to the local authorities of Messara for their assistance and the governing body of the prefecture of Heraklion for their funding. I would like to thank my colleagues who participated with me in the field study throughout the villages of the Messara Valley. Notably Sofia Flouri, Natalia Tsoumani, Magda Vatsina and Maria Paravoliasi as well as the personnel from the Health Centers of Haraka and Moires for their help in collecting the data. Also Manolis Linardakis for his tireless efforts in setting up the sampling frame and in providing advice, at any time, on the statistical analyses performed and also to Dr Christos Hatzis, together with whom we 
performed the medical assessment, blood aspiration and adipose tissue sampling. Special thanks to Alina Papadaki for her close collaboration in the "Monks" study.

Part of this thesis was based on research performed through the MEDIS study and therefore I would like to thank the field investigators of the MEDIS study and also Prof Demosthenes Panagiotakos and Prof Evangelos Polychronopoulos for allowing me access to their intriguing data.

Finally, I would like to express my deep appreciation to my family for all their inspiration and moral support. 


\section{About the author}

Constantine Ilias Vardavas was born in Canberra Australia on the $10^{\text {th }}$ May 1980 . He completed secondary education at the Lyceum of Archanes in Crete, Greece in 2000. In the same year he started studies at the department of Nursing of the Educational Institute of Crete, with a focus on cardiovascular nursing, where he graduated with a distinction (89\%) in 2005. During the next year he started his Masters Degree in Public Health, at the Department of Social Medicine, of the University of Crete, Greece and graduated with high distinction (93\%). During the his postgraduate studies, Constantine Vardavas was actively involved in a number of local and international projects, including the MESSARA study and a number of EU FP6 projects, one of which was the DIOGENES "Diet Obesity and Genes" project. Through his active participation in the field work of the DIOGENES project, Constantine met Prof. dr. Wim Saris (Principal Investigator of the DIOGENES project) and subsequently started his PhD in 2007, in the Department of Human Biology (NUTRIM), Maastricht University under the supervision of Prof. dr. Wim Saris and Prof. dr. Anthony Kafatos (of the University of Crete), investigating the public health implications of the Mediterranean diet, with a secondary focus on its interaction with active and passive smoking.

Constantine has a strong interest in public health, its policy implications and its determinants with a focus on nutrition and tobacco use. 


\section{List of publications}

\section{Full papers}

- $\quad$ Vardavas C.I, Majchrzak D, Wagner K-H, Elmadfa I, Kafatos A. The antioxidant and phylloquinone content of wildly grown greens in Crete. Food Chemistry 2006; 99 (4): 813-821

- Vardavas C.I, Majchrzak D, Wagner K-H, Elmadfa I, Kafatos A. Lipid analysis of wild Cretan greens. Food Chemistry 2006; 99 (4): 822-834

- Vardavas C.I, Tzatzarakis M, Tsatsakis A, Athanasopoulos D, Balomenaki E, Linardakis M, Kafatos A. Biomarkers of Passive Smoking among Greek Preschool Children. European Journal of Pediatrics 2006; 165(12): 891-6

- Vardavas C.I, Linardakis M, Kafatos A. Environmental Tobacco Smoke exposure in motor vehicles. Tobacco control. 2006; 15:415

- Vardavas C.I, Giannopoulos S, Kiriakakis M, Poulli K, Kafatos A. Fatty acid and salt content of snacks in the Cypriot market: A children's and adolescents dietary hazard. Food Chemistry 2007; 101:924-931

- Vardavas C.I, Kafatos A. Tobacco policy and smoking prevalence in Greece. European Journal of Public Health 2006 17; (2): 211-213

- Vardavas C.I, Athanasopoulos D, Balomenaki E, Linardakis M, Kafatos A. Smoking habits of Greek preschool children's parents. BMC Public Health 2007, 7:112

- Vardavas C.I, Kondili B, Petsetaki E, Tountas Y, Kafatos A.G. Environmental Tobacco Smoke in hospitality venues in Greece. BMC Public Health 2007; 7(1):302

- $\quad$ Papadaki A, Vardavas C.I, Hatzis C, Kafatos A. Nutrient and food intake during a Greek Orthodox Fasting and non fasting week. Public Health Nutrition 2007 Dec 20;1-8

- $\quad$ Vardavas C.I, Linardakis M, Hatzis C, Malliaraki N, Saris W, Kafatos A. Smoking Status in Relation to Serum and Dietary Vitamin and Micronutrient Concentrations. Tobacco Induced Diseases 2008, 4:8 
- Vardavas C.I, Bouloukaki I, Linardakis M.K, Ntzilepi P, Tzanakis N, Kafatos A. Excess Lung Cancer Mortality Risk Due To Non-Compliance To Hospital Smoking Regulations. International Journal of Environmental Research and Public Health. 2008; 5:3

- Vardavas C.I, Linardakis M, Hatzis C, Saris W, Kafatos A. Prevalence of Obesity and Physical Inactivity among Farmers from Crete (Greece), Four Decades after the Seven Countries Study. Nutrition Metabolism and Cardiovascular Disease 2009; 19: 156-162

- $\quad$ Mantziou V, Vardavas C.I, Kletsiou E, Zaxos I, Priftis K. Predictors of childhood exposure to parental secondhand smoke in the house and family car. International Journal of Environmental Research and Public Health. 2009; 6, 433-444

- Vardavas C.I, Kondilis B, Patelarou E, Akrivos D, Falagas M. Health Literacy And Sources Of Health Education Among Adolescents In Greece. International Journal of Adolescent Medicine and Health 2009; 2:7

- Vardavas C.I, Connolly G, Karamanolis K, Kafatos A. Preventing Adolescent Smoking via Graphic Cigarette Warning Labels. European Journal of Public Health. 2009 19(2):212-7.

- Vardavas C.I, Connolly G, Kafatos A. Geographical Information Systems as a Tool for Monitoring Tobacco Industry Advertising. Tobacco Control. 2009; 18: 3

- Vardavas C.I, Bouloukaki I, Linardakis M.K, Tzilepi P, Tzanakis N, Kafatos A. Smoke free hospitals in Greece: Personnel perceptions, compliance and smoking habits. Tobacco Induced Diseases. 2009. 31;5(1):8

- Vardavas C.I, Linardakis M, Kafatos A. Prolonged bottle-feeding and the risk of obesity among preschool children. International Public Health Journal. $2009 ; 1(2)$

- Patelarou E, Vardavas C.I, Fioraki I, Alegakis T, Dafermou, M, Tzilepi P. Euthanasia in Greece: Greek Nurses involvement and attitudes. International Journal of Palliative Nursing. 2009 15(5):242-8.

- $\quad$ Patelarou E, Vardavas C.I, Ntzilepi P, Sourtzi P. Nursing education and practice in a changing environment: the case of Greece. Nurse Education Today. 2009. [Epub ahead of print] 
- Vardavas C.I, Papadaki A, Saris W, Kafatos A. Is Adherence To The Mediterranean Diet An Effect Modifier Of The Impact Smoking Has On Health? Public Health. 2009; 123(6):459-460

- Lionis C, Symvoulakis EK, Markaki A, Vardavas C, Papadakaki M, Daniilidou N, Souliotis K, Kyriopoulos I. Integrated primary health care in Greece, a missing issue in the current health policy agenda: a systematic review. International Journal of Integrated Care. 2009; 9:e88

- Bouloukaki I, Tsoumakidou M, Vardavas Cl, Mitrouska I, Koutala E, Siafakas N, Tzanakis N. Alteration in sputum inflammatory cells after smoking cessation. Mediators of Inflammation 2009; 8:12102

- Vardavas C.I, Panagiotakos D. The causal relationship between passive smoking and inflammation on the development of cardiovascular disease: a review of the evidence. Inflammation and Allergy-Drug Targets 2009; 8(5):328-33.

- Vardavas $\mathrm{Cl}$, Lionis C, Polychronopoulos E, Zeimbekis A, Bountziouka V, Stravopodis $S$, Metallinos $G$, Panagiotakos DB. The role of passive smoking on the prevalence of type II diabetes mellitus among elderly men and women living in Mediterranean islands: the MEDIS study. Diabetic Medicine 2010; 27(2):242-243

- $\quad$ Flouris AD, Vardavas Cl, Metsios G, Tsatsakis A, Koutedaki Y. Molecular evidence for the acute health effects of secondhand smoke exposure. American Journal of Physiology: Lung, Cellular and Molecular Physiology. 2010; 298(1):3-12

- Vardavas C.I, Symvoulakis K, Connolly G, Patelarou E, Lionis C. What are the characteristics of an effective anti-tobacco advertisement: A pilot study among Greek Adolescents? International Journal of Environmental Research and Public Health 2010; 7(1):78-88

- $\quad$ Lionis C, Symvoulakis M, Vardavas Cl. Implementing family practice research in countries with limited resources and capacity: A stepwise model experienced in Crete, Greece. Family Practice. 2010; 27(1):48-54

- Vardavas Cl, Chatzi L, Patelarou E, Plana E, Sarri K, Kafatos A, Koutis A, Kogevinas $M$. Smoking and smoking cessation during early pregnancy and its effect on adverse pregnancy outcomes and fetal growth. European Journal of Pediatrics 2009 Epub ahead of print

- Vardavas C.I, Tzatzarakis MN, Plada M, Tsatsakis A, Papadaki A, Saris WH, Moreno L, Kafatos AG, on behalf of the HELENA Heraklion Study Group. Bio- 
marker evaluation of Greek adolescents' exposure to second-hand smoke. Human and Experimental Toxicology. 2009, Epub ahead of print

- Vardavas Cl, Mancariama G, Behrakis P. "Environmentally friendly" brand promotion activities: Cigarette butt clean up campaigns. Tobacco Control 2010 (In press)

- Vardavas C.I, Plada M, Tzatzarakis M.N, Marcos A, Warnberg J, GomezMartinez S, Breidenassel C, Tsatsakis A.M, Saris W.H, Moreno L.A, Kafatos A.G, On Behalf Of The Helena Heraklion Study Group. Exposure to Second Hand Smoke is Associated with a Dose-Response Systemic Alteration of the Naïve and Memory CD3+ and CD4+ T-Cell Subpopulations in Healthy Adolescents. Pediatric Allergy and Immunology. 2010 (In press)

- $\quad$ Vardavas Cl, Patelarou E, Chatzi L, Roumeliotaki T, Sarri K, Murphy S, Koutis A, Kafatos $A$, Kogevinas $M$. Factors associated with active smoking, quitting and second-hand smoke exposure among pregnant women in Greece. Journal of Epidemiology. 2010 (In press)

- Vardavas C.I, Linardakis M, Hatzis C, Saris W, Kafatos A. Cardiovascular Disease Risk Factors among Farmers from Crete 45 Years after the Seven Countries Study. Eur J Card Disease 2010 (In press)

- $\quad$ Papadaki A, Valsta LM, Lampi AM, Penalvo J, Adlercreutz H, Vardavas Cl, Kafatos A. Validation of a nutrient database using chemical analyses of food samples during a Greek Orthodox Christian fasting and non-fasting week. Journal of Food Composition and Analysis 2010 (In press)

\section{Letters and editorials}

- Vardavas C.I, Kafatos A. Greece's tobacco policy: Another myth? The Lancet 2006; 367 (9521): 1485-1486 (letter)

- Vardavas C.I, Kafatos A. Bans on smoking in public places: Policy enforcement needed. The Lancet 2007; 370(9582): 133-134 (letter)

- $\quad$ Symvoulakis E, Vardavas $\mathrm{Cl}$, Fountouli P. Policy Implications of Blood Donation in Adolescence. JAMA. 2008; 300 (15):1759-1760 (letter)

- Vardavas $\mathbf{C l}$. How to prevent tobacco use among adolescents. Tobacco Induced Diseases 2010; 8 (Editorial)

- Vardavas C.I, Behrakis P. Greece: Action at last. Tobacco Control. 2009; 18: 78-81 (News analysis commentary) 